NBER WORKING PAPER SERIES

\title{
VACANCY DURATIONS AND ENTRY WAGES: \\ EVIDENCE FROM LINKED VACANCY-EMPLOYER-EMPLOYEE DATA
}

\author{
Andreas I. Mueller \\ Damian Osterwalder \\ Josef Zweimüller \\ Andreas Kettemann \\ Working Paper 25118 \\ http://www.nber.org/papers/w25118
NATIONAL BUREAU OF ECONOMIC RESEARCH
1050 Massachusetts Avenue
Cambridge, MA 02138
October 2018, Revised July 2020

\begin{abstract}
A previous version of this paper circulated under the title "Wages, Workers and Vacancy Durations: Evidence from Linked Data". We thank Jake Bradley, Carlos Carrillo-Tudela, Leland Crane, Steven Davis, Jan Eeckhout, Jason Faberman, Leo Kaas, Philipp Kircher, Simon Mongey, Chris Moser, Robert Shimer, Gianluca Violante, David Wiczer and participants at seminars or presentations at Aarhus University, the Board of Governors, CEMFI Madrid, CESifo Munich, Columbia Business School, ETH Zurich, the Federal Reserve Bank of Chicago, the Federal Reserve Bank of New York, the Federal Reserve Bank of Philadelphia, Goethe University Frankfurt, the NBER Summer Institute, Sciences Po, UC Berkeley, the University at Buffalo, the University of Essex, and IAB Nürnberg for useful comments and suggestions. We are grateful to Dominik Egloff for excellent research assistance. The views expressed herein are those of the authors and do not necessarily reflect the views of the National Bureau of Economic Research.
\end{abstract}

At least one co-author has disclosed a financial relationship of potential relevance for this research. Further information is available online at http://www.nber.org/papers/w25118.ack

NBER working papers are circulated for discussion and comment purposes. They have not been peer-reviewed or been subject to the review by the NBER Board of Directors that accompanies official NBER publications.

(C) 2018 by Andreas I. Mueller, Damian Osterwalder, Josef Zweimüller, and Andreas Kettemann. All rights reserved. Short sections of text, not to exceed two paragraphs, may be quoted without explicit permission provided that full credit, including $\odot$ notice, is given to the source. 
Vacancy Durations and Entry Wages: Evidence from Linked Vacancy-Employer-Employee

Data

Andreas I. Mueller, Damian Osterwalder, Josef Zweimüller, and Andreas Kettemann

NBER Working Paper No. 25118

October 2018, Revised July 2020

JEL No. E24,J31,J63

\section{ABSTRACT}

This paper explores the relationship between the duration of a vacancy and the starting wage of a new job, using linked data on vacancies, the posting establishments and the workers eventually filling the vacancies. The unique combination of large-scale, administrative worker-, establishment- and vacancy-data is critical for separating establishment- and job-level determinants of vacancy duration from worker-level heterogeneity. Conditional on worker observables, we find that vacancy duration is negatively correlated with the starting wage and its establishment component, with precisely estimated elasticities of -0.04 and -0.10 , respectively. While the negative relationship is qualitatively consistent with models of wage posting, these elasticities are small, suggesting that firms' wage policies can account only for a small fraction of the variation in vacancy filling across establishments.

Andreas I. Mueller

The University of Texas at Austin

Department of Economics

2225 Speedway

Austin, TX 78712

and NBER

andimueller@utexas.edu

Damian Osterwalder

University of Zurich

Department of Economics

Schönberggasse 1, Room SOF-E21

Zurich 8001

Switzerland
Josef Zweimüller

Department of Economics

University of Zurich

Schoenberggasse 1

8001, Zurich

Switzerland

josef.zweimueller@econ.uzh.ch

Andreas Kettemann

Department of Economics, University of Zurich

Schoenberggasse 1

8001 Zurich

Switzerland

andreas.kettemann@uzh.ch 


\section{Introduction}

A central question in search-theoretic models of the labor market is how firms and workers form employment relationships. The canonical search and matching model posits the existence of a matching function, which randomly matches workers and firms, given the number of vacancies and job seekers in the labor market. However, recent evidence by Davis, Faberman and Haltiwanger (2013) - henceforth DFH - shows that the number of vacancies as measured in JOLTS survey data is an imperfect predictor of hiring outcomes across U.S. establishments. Their evidence suggests that firms rely heavily on additional instruments to recruit workers, which has important implications for aggregate labor market dynamics (Kaas and Kircher, 2015; Gavazza, Mongey and Violante, 2018). Despite this important contribution, many aspects of vacancy posting and filling are still poorly understood, mainly due to the lack of detailed micro data.

The aim of this paper is to explore the empirical relation between the duration of a vacancy and the entry wage of a filled position. Despite the central role of the vacancy-filling rate in search and matching models of the labor market, our empirical knowledge about the determinants of vacancy durations and their relation to entry wages (and other labor market outcomes) is very limited. This gap in knowledge is striking given the large body of empirical evidence on unemployment durations and workers' re-employment wages and, more generally, on the role of worker search behavior in the formation of new employment relationships. To understand the matching process in the labor market, it seems important to understand both the role of worker and employer behavior. In this paper, we aim to fill this gap by shedding light on the role of employer behavior for the creation of - and wages paid in - new job matches.

To study the relationship between vacancy durations and entry wages, we use a linked dataset comprising information on (i) characteristics and durations of posted vacancies, (ii) employment of and wages paid by the establishment posting the vacancy, and (iii) the earnings history of the worker eventually filling the vacancy. The vacancy data come from the Austrian public labor market administration ("Arbeitsmarktservice", AMS), which contains the universe of vacancies posted through the AMS platform. The AMS is by far the most important platform of vacancy posting by Austrian establishments and covers almost 60\% (!) of all vacancies posted by Austrian establishments. ${ }^{1}$ The AMS vacancy dataset contains an (anonymized) employer-identifier which allows us to link the posting establishment to the Austrian Social Security Database (ASSD). The link at the establishment level allows us to study AMS vacancy posting by Austrian establishments in a very similar way as DFH did for all US vacancies using JOLTS data. For vacancies that were filled through direct mediation of the AMS, the information on vacancy durations and characteristics can be linked to the earnings history of the worker eventually filling the vacancy.

\footnotetext{
${ }^{1}$ Statistics Austria runs a large quarterly vacancy survey ("Offene Stellen Erhebung (OStE)") providing evidence on vacancy posting by Austrian establishment on all platforms. The survey asks, for each single vacancy reported by the sampled establishment, whether the vacancy was posted on the AMS platform. On average, $57 \%$ of vacancies were posted at the AMS. During the period 2009 to 2017 the AMS coverage rate was 57\% and fluctuated between 53\% (2009) and 61\% (2013) without showing a trend.
} 
We exploit the link at the worker level to study the association between vacancy durations and entry wages. ${ }^{2}$

The rich information contained in this dataset allows us to study in detail the vacancy filling patterns and their relation to wages in newly filled jobs. Our main empirical analysis proceeds in two steps. First, we relate the duration of a vacancy to the starting wage. We find that - conditional on worker observables - vacancy durations are negatively correlated with the starting wage, with an elasticity of -0.04 for our preferred specification. Given the large-scale, administrative nature of our data, this elasticity is precisely estimated, with a standard error of 0.01 . The negative relationship is masked in the raw data, where we find an positive correlation between vacancy duration and starting wages. The evidence that emerges thus from our empirical analysis is that, with sufficient controls for worker heterogeneity, the correlation between vacancy durations and starting wages turns from positive to negative. This is particularly evident when we control for worker fixed effects in the regression analysis, comparing the outcomes of the matching process for the same individual across different unemployment spells.

Second, we go one step further by decomposing starting wages into fixed worker- and establishment-characteristics using the technique proposed by Abowd, Kramarz and Margolis (1999) (AKM). This allows us to look directly at the association between the vacancy duration and the establishment-, worker- and residual-components of the starting wage. Our results confirm important worker-level heterogeneity in vacancy durations, with AKM worker fixed effects being strongly positively correlated with vacancy duration and thus accounting for the overall positive association between vacancy duration and starting wages in the raw data. At the same time, we find that the establishment and residual component of the starting wage are negatively correlated with the starting wage, with an elasticity of -0.10 and -0.03 , respectively, for our preferred specification. Again, these elasticities are precisely estimated, with standard errors of 0.02 and 0.01 , respectively.

In summary, our analysis reveals the importance of using matched data to distinguish the effect of establishments and matches from worker-level heterogeneity in the analysis of the determinants of vacancy duration. Conditional on observables, vacancy durations are negatively correlated with the starting wage and its establishment component. We perform a broad set of empirical checks and find our main result to be very robust.

The evidence presented in this paper allows to shed new light on the predictions of searchtheoretic models of the labor market. The canonical search and matching model with random

\footnotetext{
${ }^{2}$ The Austrian vacancy database has so far not been extensively used for academic research. Among the few studies exploiting these data is the study of Lalive, Landais and Zweimüller (2015) on market externalities of UI (and who use the AMS vacancy data to determine which workers are competing for the same vacancies); and work in progress by Card, Colella and Lalive (2018) on gender discrimination in vacancy posting and -filling. See also Riese and Bruckbauer (1987) for an early descriptive study using individual vacancy data from the Austrian public employment service. The ASSD has been extensively used in previous studies (see e.g. Lalive, van Ours and Zweimüller (2006); Card, Chetty and Weber (2007); Card, Lee, Pei and Weber (2015); Alvarez, Borovickova and Shimer (2016); Borovickova and Shimer (2019)). For a detailed description of the ASSD, see Zweimüller, Winter-Ebmer, Lalive, Kuhn, Wuellrich, Ruf and Büchi (2009).
} 
search and wage bargaining cannot account for the empirical observations that high-wage firms face shorter vacancy durations, as it predicts that firms that face tighter labor markets pay higher wages but also experience longer vacancy durations. Instead, our evidence is consistent with theories of wage posting where firms face a trade-off between the wage they pay the worker and how long they have to search until the vacancy is filled. This includes both theories of directed search (Moen, 1997), where high-wage vacancies attract more applications, and theories of random search (Burdett and Mortensen, 1998), where high-wage offers face a higher probability of acceptance by the worker.

While our results are qualitatively consistent with models of wage posting, it is important to shed light on the quantitative implications of our findings. A key question is whether firms' wage policies can account for the sharp rise in vacancy filling for growing firms, as documented by $\mathrm{DFH}$. Their findings have been interpreted as evidence for the importance of recruiting effort in hiring, including firms' wage policies. Our measured elasticities, however, imply that starting wages predict only a small amount of variation in vacancy durations by establishment growth and hiring. We find that starting wages are increasing in the establishment hires rate, with an elasticity of 0.05 or less. Combined with our estimated elasticity of vacancy duration to the starting wage, this implies that the vacancy-filling rate is predicted to increase by one percent or less for establishments with a hires rate of 0.9 compared to establishments with a hires rate of 0.1. In stark contrast, we replicate the DFH-type evidence with the Austrian data and find that the vacancy-filling rate actually is 47 percent higher for establishments with a hires rate of 0.9 compared to establishments with a hires rate of 0.1 . This back-of-the-envelope calculation thus suggests that starting wages can account only for a very small fraction of the variation in vacancy filling by hires rates. We conclude that firms' wage policies are unlikely to serve as an important recruiting instrument, as in Kaas and Kircher (2015), at least not in a manner that is quantitatively important and could account for the patterns in vacancy filling by firm growth and hiring. ${ }^{3}$ We discuss potential caveats to this conclusion, such as wage-tenure contracts or non-wage amenities, but find that these are unlikely to bridge the large gap that exists between the actual patterns of vacancy filling by hires rates and the patterns predicted by starting wages. Overall, our evidence thus points to the importance of theories that allow for alternative measures of recruiting effort or hiring standards, as in Sedlacek (2014), Gavazza, Mongey and Violante (2018) and Carrillo-Tudela, Gartner and Kaas (2020).

We argue that our analysis is interesting not only for the Austrian labor market, but also for a better understanding of vacancy-posting and -filling behavior of firms more generally. First, the information content and quality of our data is very high. The linking of information on vacancy durations and -characteristics to information on the wage of the worker filling the vacancy for a large administrative data set is unique. Additionally, the Austrian vacancy data provide information, on a daily basis, on the vacancy-posting date, the desired start date of the job (= date

\footnotetext{
${ }^{3}$ In the model of Kaas and Kircher (2015), the posted wage acts as the main recruiting mechanism to expand firm-level employment. We calibrate their model to the patterns of vacancy filling and job finding in Austria and show that it predicts a wage-duration elasticity that is two orders of magnitude larger than in our data.
} 
when the job become available), and the vacancy-filling date, allowing us to precisely estimate the vacancy-filling rate. AMS staff frequently checks with the posting establishment on inactive vacancies and documents in the data when a vacancy lapses. Hence the AMS job posting site is not plagued with inactive ("phantom") vacancies that have been found important in privately operated job posting sites (Albrecht, Decreuse and Vroman, 2019).

Second, the patterns of vacancy posting and hiring by Austrian establishments are similar to those in other countries, even in countries with quite different labor market institutions. In fact, comparing vacancy patterns in the Austrian data to US evidence by DFH shows a surprising degree of similarity. For instance, hiring and separations rates of Austrian establishments are of a similar order of magnitude as those of the US. Similar to DFH we find: (i) growing establishments do not only generate more hires per vacancies but also fill their vacancies more quickly, (ii) vacancy rates and vacancy yields (= hires per vacancy) vary strongly with the establishments' industry, size and employment turnover, (iii) more than $30 \%$ of workers are employed in establishments that do not hire any worker in a given month, (iv) a large fraction of establishments posting no vacancy at the end of the previous month hire workers in the subsequent month and (v) the majority of vacancies are posted by establishments that post more than one vacancy in the same month. In sum, this suggests that our results highlight mechanisms that are likely at work also in other settings and can contribute to a better understanding of employer search on the labor market.

Our paper proceeds as follows: Section 2 discusses the related empirical literature and Section 3 discusses the institutional background. Section 4 introduces the data, discusses the vacancy duration concepts, and discusses the procedure linking vacancy data to employer-employee data. Section 5 replicates previous evidence on vacancy posting, hiring, and employment growth in our linked data set. Section 6 conducts the main analysis in our paper by analyzing the relationship between vacancy duration and entry wages. Section 7 discusses the implications of our findings and Section 8 concludes.

\section{Related Empirical Literature}

Our paper aims at a better understanding of the role of entry wages in vacancy filling and hiring outcomes across firms. While search models with wage posting have become important theoretical frameworks in labor and macroeconomics, evidence on predictions of these theories in general - and the trade-off between vacancy durations and entry wages in particular - is very scarce. Faberman and Menzio (2018) is the only paper we are aware of that has studied this trade-off. They find a positive correlation in data from the Earnings and Opportunities Pilot Project (EOPP) in the U.S. in the early 1980s. ${ }^{4}$ Our research builds on theirs and assesses the extent to which the positive correlation is confounded by the presence of worker heterogeneity. Our analysis is

\footnotetext{
${ }^{4}$ Interestingly, Holzer, Katz and Krueger (1991) find in the same data set that vacancies from firms in high-wage industries and larger firms attract a higher number of job applications.
} 
particularly well suited to address this issue because we observe the entire labor market history of the workers matched to a vacancy and thus can use wage and employment histories as additional controls. Moreover, for a subset of workers in our data, we observe multiple unemployment spells and thus we can assess the within-person correlation of starting wages and vacancy durations faced by the establishments hiring the worker.

A few recent studies provide interesting findings on the relationship between number of applications and the posted wage. Banfi and Villena-Roldan (2019) and Marinescu and Wolthoff (2020) document a positive association of posted wages and job applications using data from a Chilean and U.S. online job boards, respectively. Belot, Kircher and Muller (2018) provide similar evidence from a field experiment that assigned wages randomly to pairs of otherwise similar vacancies. The positive relationship between wages and applications is interesting because, in models of directed search, a higher number of applications is the channel through which firms are able to fill vacancies more quickly. Unlike our dataset, the above empirical analyses do not directly observe the duration of a vacancy, which is the key variable entering the firm's posting and recruiting decisions. The fact that our data contain precise information on the duration of a vacancy allows for a much more straightforward mapping from entry wages to hiring outcomes and the quantitative predictions of search-theoretic models with wage posting. We find that entry wages can account for only a small fraction of the variation in vacancy filling across firms.

Our contribution also relates to a number of studies of vacancy-posting and -filling behavior. Most prominently, DFH show with data from the Job Openings and Labor Turnover Survey (JOLTS) for the US that faster growing establishments not only post more vacancies but also exhibit a higher vacancy yield, i.e. a higher number of realized hires per vacancy. More recently, Mongey and Violante (2019) extend the analysis of DFH in the JOLTS data and show that their results hold within establishment size, age and wage groups. ${ }^{5}$ DFH's findings have attracted considerable attention as it suggests that firms use other channels to recruit workers if they quickly expand their workforce, and a reduction in aggregate recruiting intensity may be responsible for the shift of the U.S. Beveridge Curve during the Great Recession. We replicate the findings of DFH in our vacancy data from Austria. We find that the relationship between firm growth and the vacancy yield is surprisingly similar to the one documented by DFH in the JOLTS data.

Since the JOLTS started in December 2000, earlier studies focused on the Help Wanted Index (Abraham (1983); Abraham (1987); Blanchard and Diamond (1989)). While Shimer (2005) and Barnichon (2010) note that the Help Wanted Index tracks the movements in the JOLTS well, it does not allow for an analysis at the micro level. Micro studies of vacancy-posting behavior are mainly based on surveys (e.g. DFH; van Ours and Ridder (1991); van Ours and Ridder (1992); Holzer (1994); Gorter, Nijkamp and Rietveld (1996); Burdett and Cunningham (1998); Dickerson (2003); Davis, Röttger, Warning and Weber (2014); Ehrenfried and Holzner (2019); Faberman and Menzio (2018)) or online job board data (e.g. Barron, Berger and Black (1999); Banfi and Villena-

\footnotetext{
${ }^{5}$ See also Bagger, Fontaine, Galenianos and Trapeznikova (2020) for an analysis of vacancy posting and firm growth based on Danish vacancy data.
} 
Roldan (2019); Marinescu (2017); Marinescu and Wolthoff (2020); Modestino, Shoag and Ballance (Forthcoming); Hershbein and Kahn (2018); see also Kuhn (2014) for a general discussion of internet job search). A few earlier studies are based on administrative vacancy data (e.g., Coles and Smith (1996); Berman (1997); Yashiv (2000); Andrews, Bradley, Stott and Upward (2008); Sunde (2007)).

Compared to existing datasets on vacancies that we are aware of, our data have several advantages: First and foremost, none of the studies match the individual-level vacancy data to the employment history of the matched worker. An exception is the recent paper by Carrillo-Tudela, Gartner and Kaas (2020), which does, however, not analyze the connection between vacancy durations and entry wages. Second, while most of the mentioned studies were mainly based on survey or career services data, we have administrative data, which should decrease the extent of measurement error due both to more accurate data and a larger sample size. The mentioned studies that do use administrative data are mostly based on aggregated data, except for Andrews et al. (2008) who cover the labor market for teenagers in the UK. Third, datasets usually record repeated stocks of vacancies, such as the most prominent example, the JOLTS, which records the stock of vacancies at the end of the month. This poses the problem that vacancies with short durations (opened and closed between two survey rounds) are under-sampled (length-biased sampling/aggregation bias), which is especially severe as vacancies with very short durations are quantitatively relevant. This problem does not arise in our data as every vacancy is recorded, irrespective of its length.

\section{Institutional Background}

In this section, we discuss the institutional background relevant for our analysis of vacancy durations and entry wages. Since we are looking at vacancies posted at the Austrian public employment service ("Arbeitsmarktservice", AMS) we start with a brief discussion of the role of the AMS as a player on the Austrian labor market. We then discuss institutions and relevant features of the wage setting process in Austria.

\subsection{The AMS on the Austrian Labor Market}

The AMS is by far the most important job-matching platform in Austria, comprising almost $60 \%$ of all vacancies posted by Austrian firms. The mission of the AMS is bringing together job seekers and employers and reducing search frictions on the labor market to a minimum. Targeted workers include both employed or unemployed workers looking for a job as well firms with open vacancies of all kinds. AMS services are free of charge, both for workers and for firms.

The AMS is organized in one federal, nine state and 104 local (labor market district) offices. Social partners (employer federations and worker organizations) are involved at all levels and instrumental in monitoring the organization's corporate governance. Social partners are also involved in designing labor market policies, including measures to improve the efficiency of the matching process (such as "eAMS," the implementation and improvement of online services). 
Besides its central role as a mediator between workers and employers on the Austrian labor market, the AMS administers income support programs (UI benefits, unemployment assistance, and related transfers) and is in charge of providing and organizing active labor market policies. ${ }^{6}$ In 2017, the AMS employed 6,284 (5,606 full-time equivalent) workers and managed income support payments of about 6.2 billion Euros and active labor market policy subsidies (for 364,000 job seekers) of about 1.3 billion Euros (see AMS (2018)).

\subsection{The Wage Setting Process in Austria}

Wage setting in Austria is subject to collective bargaining agreements that cover about $95 \%$ of Austrian workers. These agreements are the outcome of negotiations between unions and employer associations at the industry level. Importantly for our purpose, these collective bargaining agreements only set wage floors. Ultimately, wages are determined by supplementary establishment bargaining as well as bilaterally between workers and firms. ${ }^{7}$ As a consequence most wages are substantially above the wage floor. For instance, Leoni and Pollan (2011) study "overpayments" (the ratio of effective wages over collectively bargained wages). They find that, in the years when the regional extended benefit program was in place in the late 1980s and early 1990s, effective wages of blue collar workers were, on average, between 20 to $25 \%$ above the collectively bargained minimum wages.

\section{Data and Conceptual Issues}

Here we start with describing the AMS vacancy database, focusing in particular on the information on the timing and characteristics of AMS vacancies. The rich information on vacancy timing raises conceptual issues relating to the measurement of the vacancy duration of a vacancy, which we discuss in the following subsection. Finally, we describe how we link AMS vacancies to establishment- and worker information from the social security register (ASSD). This link will eventually allow us to analyze the association between vacancy durations and entry wages.

\subsection{The AMS Vacancy Database}

The AMS vacancy register database contains information on all vacancies posted through the AMS and covers the years 1987-2014. The data quality has been initially low but has substantially

\footnotetext{
${ }^{6}$ An additional task of the AMS is the economy-wide management of the admission process of immigrants to the Austrian labor market.

${ }^{7}$ Moreover, Austrian collective bargaining agreements typically feature clauses that require wages in ongoing employment relationships ("Istlöhne") to rise in lockstep with the wage growth of the wage floors ("Kollektivvertragslöhne"), although those clauses sometimes specify lower wage growth. In the context of the present analysis this is less relevant because we concentrate on entry wages in newly formed job matches rather than on wages (and wages changes) in ongoing employment relationships.
} 
improved over time. In what follows, our analysis focuses on the period 1997-2014, as for these years all the variables of interest for our analysis are available, including industry codes and worker-level identifiers that allow matching to the ASSD.

A particular advantage of the AMS vacancy register is the detailed (daily) information on vacancy timing. More precisely, the data contain: (i) the date when the vacancy is posted, (ii) the desired start date of the job, and (iii) the date when the vacancy is filled. In addition to the timing and duration of a vacancy, the data report job characteristics and skill requirements, as well as characteristics of the posting firm such as the region, industry, and firm size.

The information on timing and duration of a vacancy corresponds to three different outcomes. First, a vacancy posted at the AMS can either result in a hiring directly mediated by the AMS. In this case, a personal worker identifier is recorded in the data. The information on the identity of the worker allows to link the vacancy information in the social security data on both worker's earnings and employment history and the hiring firm's (past and present) employment and wage dynamics. A second outcome is that the firm ends up hiring a worker outside the AMS system. This will happen if the firm does not only rely exclusively on the AMS as a search platform but also employs other search channels (other internet platforms, newspaper ads, etc.). In the latter case, the personal identifier for the worker who fills the vacancy is unknown, but the vacancy duration is reported in the vacancy data. The third possibility is that the vacancy lapses, either because it has become obsolete or because the firm cannot be contacted any longer. In correspondence with the AMS, we verified that the AMS frequently follows up with the posting firm - at least once every two weeks. This suggests that the AMS job posting site is plagued much less with issues related to inactive vacancies than in many privately operated job-posting sites. ${ }^{8}$

Table A1 in the Appendix gives an overview of the AMS vacancy data. The AMS vacancy dataset provides information on 5,291,897 vacancies (with completed durations) posted by 267,122 firms over the period 1997-2014. Among these vacancies, $86 \%$ got filled and $14 \%$ never resulted in a hire. Among the filled vacancies, $27 \%$ got filled through direct mediation of the AMS system, while the remaining $73 \%$ were filled through a different channel. A further strength of the AMS vacancy data is that it separately records outcomes for vacancies for multiple workers. It turns out that the majority of vacancies comes from firms posting at least one other vacancy, and that many (though not all) of the multiple vacancies have identical characteristics and job requirements. Vacancies with at least one other identical vacancy account for one third of all vacancies in the AMS vacancy data base, see panel B of Table A1 and Figure A1 in the Appendix.

We can also compare the number of vacancies filled through the AMS system to the number of hires in the ASSD database. We find that AMS hires (those filed through the AMS system) account for about 19 percent of total hires from unemployment in the ASSD universe over the same sample

\footnotetext{
${ }^{8}$ On private job boards, vacancies often continue to be advertised even though the vacancy has already been filled. Albrecht, Decreuse and Vroman (2019) study such "phantom vacancies" in a model of directed search and find that phantom vacancies create sizable negative informational externalities that are a quantitatively important part of overall search frictions in the labor market.
} 
Figure 1: AMS Vacancy Data vs. Representative Vacancy Survey

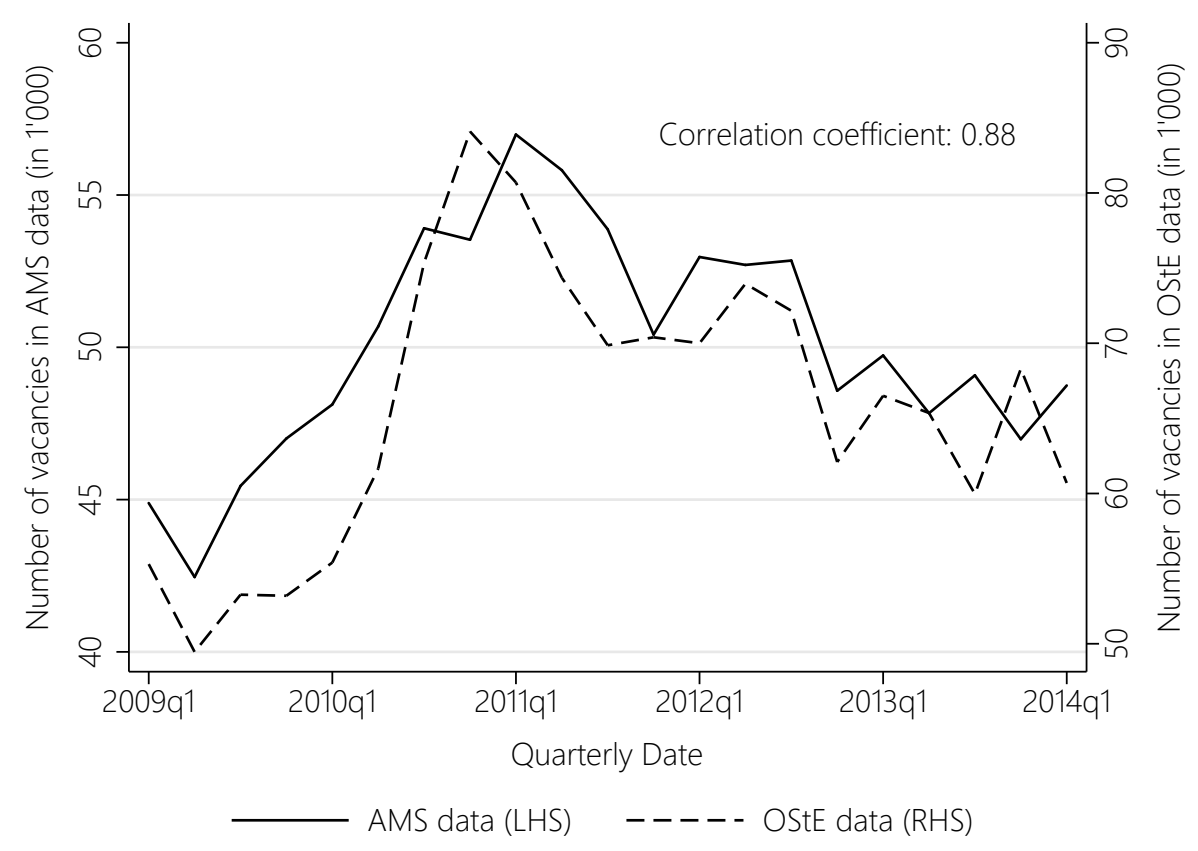

Notes: Comparison of the number of AMS vacancies with the number of vacancies in a representative vacancy survey (Offene Stellenerhebung, OStE) 2009q1-2014q1.

period and 31 percent when we exclude recalls to the previous employer (see Figure A2 in the Appendix). This shows that hiring through the AMS system covers a sizeable share of total hiring out of unemployment in Austria.

One obvious concern is that the vacancies posted on the AMS platform are not a representative window of the universe of vacancies posted by Austrian firms. To assess this potential concern, we compare the number of vacancies in the vacancy register with the total number of vacancies based on a representative vacancy survey ("Offene-Stellen-Erhebung" OStE, akin to the JOLTS) and conducted by Statistik Austria since 2009. Figure 1 shows that the AMS and OStE vacancy stocks co-move very closely, with a correlation coefficient of 0.89 . While the similarity of the two timeseries is reassuring, calculating an AMS coverage rate (= AMS-stock / OStE-stock) is problematic because the underlying vacancy concepts are different. ${ }^{9}$

Fortunately, the OStE survey asks firms whether a particular open vacancy is actually posted on the AMS platform. It turns out that the AMS platform has a very high coverage: Over the period 2009-2019, when data from the OStE are available, as many as $57 \%$ of all vacancies by Austrian firms were posted on the AMS platform (see Table A5 in the Appendix). It is important to note, however, that the coverage rate differs across labor market segments. For instance, the AMS coverage rate is $63 \%$ and $68 \%$ in the manufacturing and construction industries, respectively, while it is only

\footnotetext{
${ }^{9}$ The vacancy concept underlying the OStE survey is more vague than the vacancy concept underlying AMS stock. The AMS stock displayed in Figure 1 includes all posted vacancies, including those that are not immediately available. In contrast, the OStE stock includes vacancies that are "available within a certain period". This implies that the latter stock is based on a more narrow definition than the former, thus overestimating the AMS coverage rate.
} 
$36 \%, 40 \%$ and $50 \%$ in finance, education, and health, respectively. In these latter industries, firms are typically looking for workers with specific skills more likely to find on occupation-specific job boards rather than on a general platform like the AMS. This conjecture is supported by the education gradient of AMS posting: Among vacancies requiring apprenticeship training or less, two out of three vacancies are posted on AMS platform. In contrast, only one in three vacancies is posted on the AMS platform when the open job requires a tertiary education. Interestingly, there is not much difference in AMS posting behavior between small and large firms, except for very large firms with 5000 employees or more where the AMS coverage rate is just below 50\%. Appendix Figure A3 also shows that the AMS coverage rate does not vary systematically by employment growth. Growing firms appear to have a similar coverage rate compared to stable or shrinking firms. ${ }^{10}$

\subsection{Measuring the Duration of AMS Vacancies}

A first issue to be clarified is the definition of a vacancy and how we measure a vacancy's duration. Our starting point is the BLS definition of an open position, which is applied in the collection of the JOLTS data and according to which a job is open only if the following criteria are met: (1) A specific job exists and there is work available for that position, (2) the job could start within 30 days, and (3) there is active recruiting for workers from outside the establishment. These criteria were set in analogy to how the BLS and the ILO define and measure unemployment.

Applying the BLS definition to the AMS vacancy data is not straightforward. The AMS vacancy data contains a measure of vacancy duration, measured in days, defined as the difference between the date the vacancy is filled and the desired start date of the job (= the date when the job becomes available). In what follows, we refer to this concept as the AMS duration. This is similar to the concepts of a vacancy in JOLTS, except that the job must be immediately available rather than within the next 30 days. To gain a more comprehensive view of vacancy filling, we define two alternative vacancy durations: the JOLTS duration, which measures the duration since posting, but at most 30 days in advance of the date of availability; and the Posting duration, which measures the (unrestricted) duration since posting. To be precise, the three vacancy concepts translate into the following duration measures:

1. AMS duration: $d^{A M S} \equiv \max \left\{t_{\text {filled }}-t_{\text {available }}, 0\right\}$

2. JOLTS duration: $d^{\text {JOLTS }} \equiv \max \left\{t_{\text {filled }}-\max \left\{t_{\text {posted }}, t_{\text {available }}-30\right\}, 0\right\}$

3. Posting duration: $d^{\text {Posting }} \equiv t_{\text {filled }}-t_{\text {posted }}$

\footnotetext{
${ }^{10}$ For a comparison of AMS vacancies to all vacancies as captured by the OStE survey, see also Edelhofer and Knittler (2013). Their evidence shows that, compared to the representative OStE survey, AMS vacancies are more concentrated on occupations in the middle of the skill spectrum and have somewhat lower education requirements than vacancies not posted via the AMS. This is consistent with the education gradient of AMS posting reported in Appendix Table A5.
} 
Table 1: Summary Statistics for Different Measures of Vacancy Duration

\begin{tabular}{lrrr}
\hline & \multicolumn{3}{c}{ Vacancy Duration Concept } \\
\cline { 2 - 5 } & AMS & JOLTS & Posting \\
\cline { 2 - 4 } & & & \\
\hline A. All Filled Vacancies & 30.5 & 40.2 & 49.4 \\
Mean days & 15.0 & 27.0 & 33.0 \\
Median days & 24.3 & 3.0 & 0.9 \\
Percent with duration = 0 days & 13.1 & 16.7 & 10.7 \\
Percent with duration = 1-7 days & 30.9 & 35.7 & 36.3 \\
Percent with duration = 8-30 days & 24.4 & 35.2 & 38.7 \\
Percent with duration = 31-90 days & 7.4 & 9.4 & 13.5 \\
Percent with duration $>$ 90 days & $4,574,340$ & $4,574,340$ & $4,574,340$ \\
Observations & & &
\end{tabular}

\section{B. AMS Filled Vacancies}

Mean days

Median days

Percent with duration $=0$ days

Percent with duration $=1-7$ days

Percent with duration $=8-30$ days

Percent with duration $=31-90$ days

Percent with duration $>90$ days

Observations
18.8

7.0

33.5

19.7

29.4

13.8

3.7

$1,234,556$
28.5

18.0

1.9

25.8

43.2

24.4

4.7
37.4

21.0

0.8

19.3

44.1

27.5

8.3

Notes: Authors' tabulations of different vacancy duration measures using filled vacancy outflows for the years 1997-2014 in the AMS universe.

where $t_{\text {posted }}$ is the date when the vacancy is posted in the AMS system, $t_{\text {available }}$ is the date when the job becomes available and $t_{\text {filled }}$ is the date when the vacancy is filled. The AMS data contain $d^{A M S}$ for the entire sample period, measured in days. However, the exact (daily) date of $t_{\text {posted }}, t_{\text {available, }}$, and $t_{\text {filled }}$ is available not before 2007. Before 2007, we know $t_{\text {posted }}, t_{\text {available, }}$ and $t_{\text {filled }}$ only at monthly precision. To have a comparable measure for the full length of the sample period, we approximate these dates for the earlier period by the 15th of each month and compute the JOLTS and posting vacancy duration measures accordingly. ${ }^{11}$

Note that it is not a priori clear, which vacancy concept should be applied for our analysis. Ideally, vacancy duration (just like unemployment duration) should measure the duration of the recruiting (search) spell. Thus, if a firm posts a vacancy but does not actively try to fill it or cannot

\footnotetext{
${ }^{11}$ We checked whether this approximation may lead to biased estimates of vacancy durations. It turns out that there is little difference between the exact and proxied JOLTS- and the Posting duration measures for the period 2007-2014, where the relevant dates are observed at daily precision (see Appendix Figure A4). See also Elsby, Michaels and Ratner (2015) for a more detailed discussion of the concept of a vacancy in the JOLTS.
} 
Figure 2: Comparison of Different Measures of Vacancy Duration

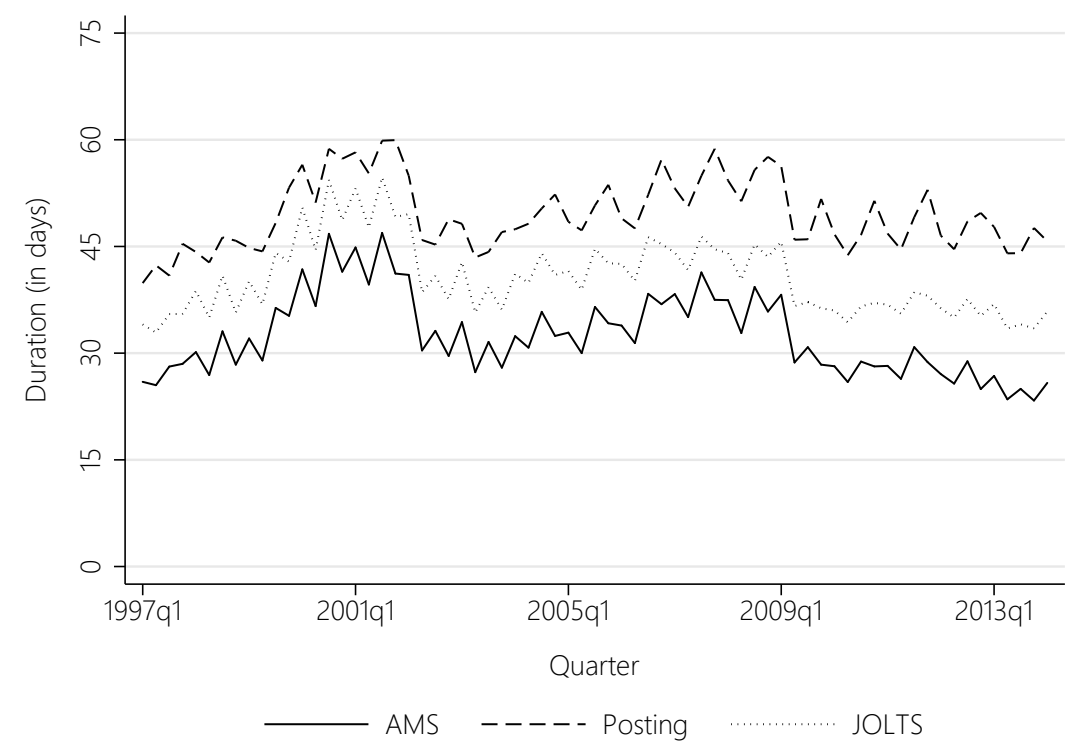

Notes: Comparison of different measures of vacancy duration for filled vacancy outflows in the AMS universe 1997-2014.

fill it because it is posted too far in advance of the date of availability, it should not be counted as part of the vacancy stock. However, it is difficult to draw the line in practice since recruiting effort is not directly observable. Our analysis below uses all three vacancy duration measures. A key advantage of our data is that we can accurately calculate the daily vacancy-filling rate without imposing any assumptions. This is different from previous studies (such as DFH) relying on repeated observations of the vacancy stock, which cannot observe the vacancy-filling rate directly but have to impose assumptions to infer this rate from stock samples and total hires.

Table 1 shows summary statistics for the three different vacancy duration concepts among the set of vacancies that are eventually filled (i.e., do not lapse). ${ }^{12}$ Panel A of the table looks at all filled vacancies, while Panel B looks at vacancies filled through mediation of the AMS. For the universe of AMS vacancies, it turns out the average AMS duration is 30.5 days, the average JOLTS duration is 40.2 days, and the average Posting duration is 49.4 days. Panel B looks at the same indicators when only vacancies eventually filled through mediation of the AMS are considered. It turns out that, irrespective of the particular vacancy measure, vacancies filled with AMS mediation last substantially shorter.

An important reason for the shorter duration of vacancies filled through mediation of the AMS is delayed reporting. Vacancies filled through the AMS system are tracked in real time and the recorded filling date typically corresponds to the true filling date. Information on vacancies filled outside the AMS system is collected by AMS staff who frequently checks up with the posting establishment. Since AMS staff only checks whether the vacancy is still active or not (rather

\footnotetext{
${ }^{12}$ The statistics look very similar when we restrict the sample to the years 2007 and later, where the JOLTS and Posting duration is measured in exact days.
} 
Figure 3: Vacancy-Filling Hazard, Relative to Date of Availability of Job

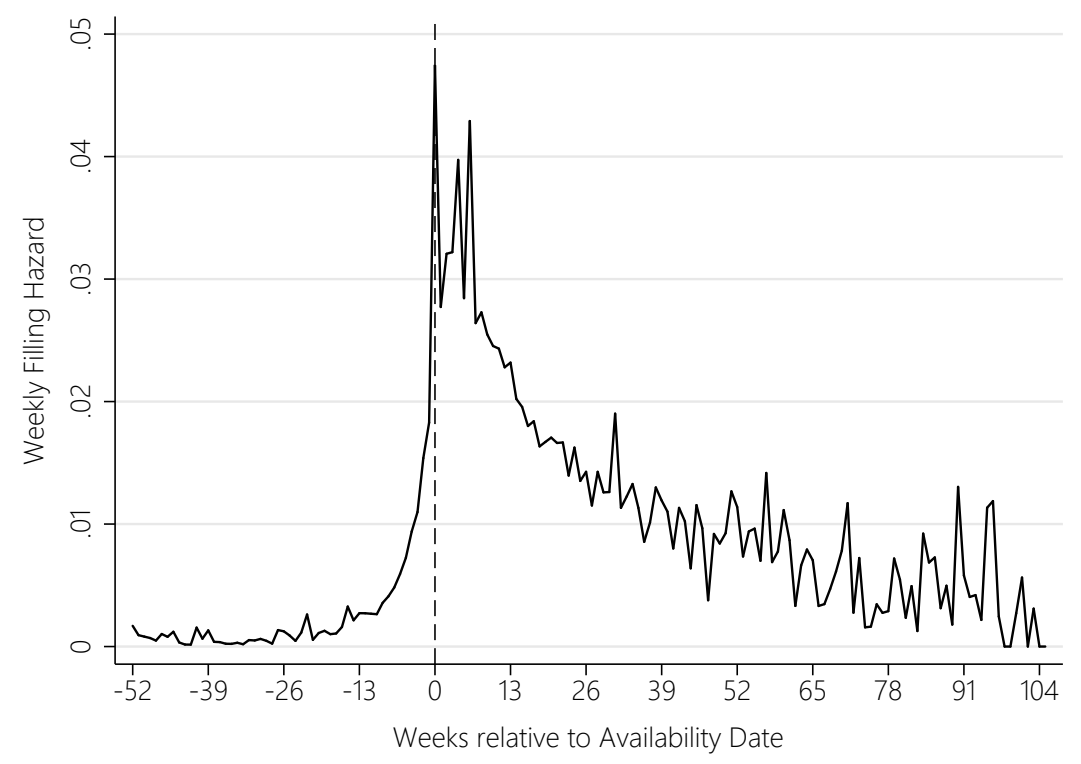

Notes: Vacancy-filling hazard relative to date of availability of job in the AMS universe based on exact dates for the years 2007-2014.

than the filling or lapsing date), the recorded filling date is typically later than the true filling date, leading to systematically longer vacancy durations for vacancies filled outside the system. ${ }^{13}$ Another potential reason why durations are shorter for vacancies mediated through the AMS is that firms post vacancies at the AMS and only turn to other recruiting channels if the search through the AMS was not successful, though it seems just as plausible that the opposite holds true.

The three vacancy concepts show a very strong correlation over time, both at seasonal and business-cycle frequency. This is shown in Figure 2. The correlation coefficient of the quarterly average of the AMS vacancy duration and the Posting duration is 0.81 and the correlation coefficient of the AMS vacancy duration and the JOLTS duration is $0.97 .{ }^{14}$

The vacancy timing information in the AMS data allows us to explore how vacancy filling varies with the duration of a vacancy. To shed light on this question, Figure 3 draws the vacancyfilling hazard against "time to job availability", which is defined as $\tilde{d}=t_{\text {filled }}-t_{\text {available }}$. Notice that $\tilde{d}$ coincides with $A M S$ duration for positive values of $\tilde{d}$, but counts a duration as negative when it is filled prior to the date of availability (when AMS duration is zero). $\tilde{d}$ is zero for vacancies posted and filled at the desired start date. ${ }^{15}$ Figure 3 shows how the weekly filling rate varies with $\tilde{d}$. The

${ }^{13}$ Comparing Panels A and B of Table 1 shows that the difference is larger for JOLTS and Posting durations than for AMS duration. This is consistent with AMS staff following up immediately available vacancies more frequently than vacancies that are not yet available, leading to larger reporting delay for not immediately available vacancies. Delayed reporting can also explain why the discrepancy is smaller for JOLTS duration than for Posting duration, as the latter measure is based on a broader vacancy stock (with a larger fraction of not immediately available vacancies).

${ }^{14}$ In the Appendix Figure A6, we also show that he vacancy-filling rate observed in our data exhibits realistic business-cycle patterns, with an elasticity with respect to the labor market tightness of between -0.37 and -0.47 , which is consistent with estimates of the matching function.

${ }^{15}$ When calculating the filling rate as in Figure 3, we have to take into account that different vacancies start out at different points in time. Specifically, the vacancy-filling hazard after $\tau$ periods relative to the desired start date is given 
Figure 4: Cumulative Fraction Posted, Filled and Lapsed, Relative to Date of Availability of Job

(a) Cumulative fraction posted

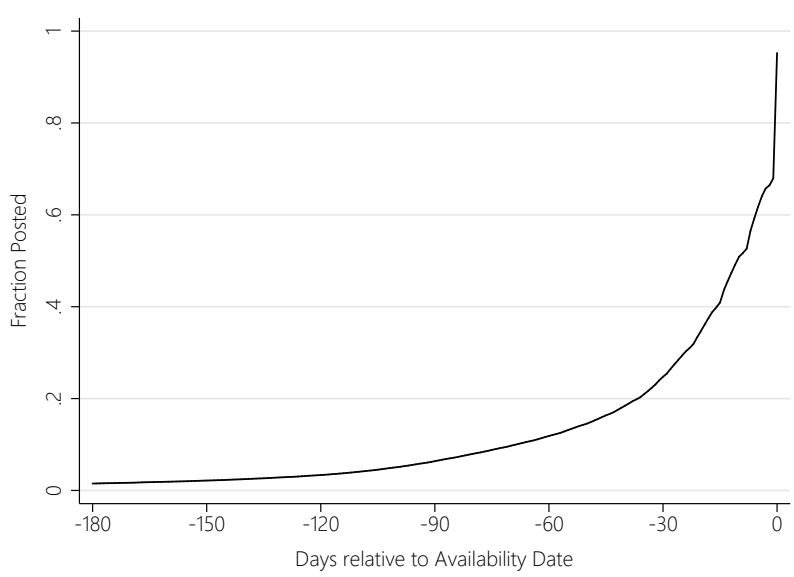

(b) Cum. fraction filled (solid) and lapsed (dashed)

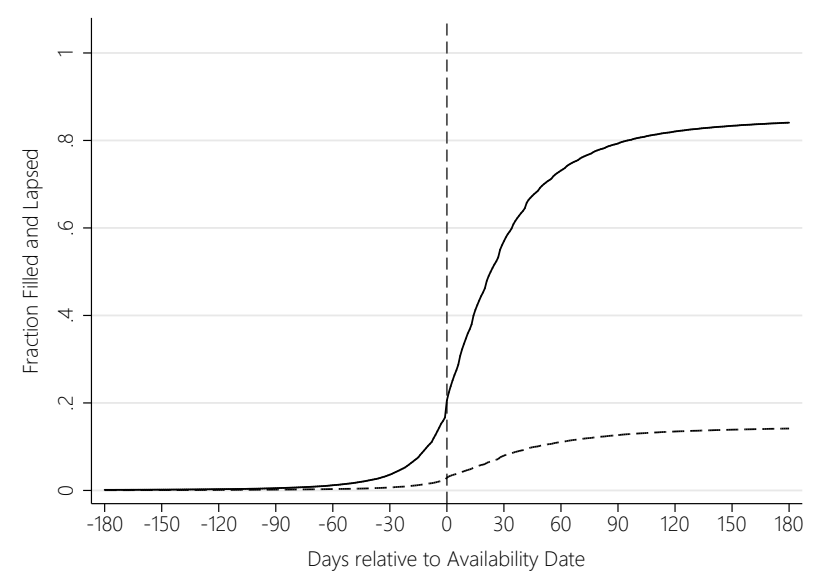

Notes: Cumulative fraction of posted, filled, and lapsed vacancies in the AMS universe based on exact dates for the years 2007-2014.

graph reveals that the filling rate gradually increases before, peaks at, and gradually falls after the desired start date. ${ }^{16}$ Clearly, these dynamic patterns reflect both duration dependence and heterogeneity and it is not possible to disentangle these two factors. ${ }^{17}$

Figure 4 plots the cumulative fraction of posted vacancies (Panel a) and the cumulative fraction of filled and lapsed vacancies (Panel b) against $\tilde{d}$. Panel (a) reveals that two thirds of AMS vacancies are posted before the desired start date, and roughly one quarter are posted earlier than one month before that date. Panel (b) shows that a non-negligible fraction of AMS vacancies are filled (while very few lapse) before the desired start date. The vast majority (86\%) of AMS vacancies gets eventually filled. In sum, Figures 3 and 4 show that early posting and filling are quantitatively relevant. This is interesting per se and points to a margin of employment adjustment that has so far not been recognized.

by $\lambda(\tau)=\lim _{h \rightarrow 0}[\operatorname{Pr}(\tau \leq \tilde{d} \leq \tau+h) / h] /\left[\operatorname{Pr}\left(t_{\text {posted }}-t_{\text {available }} \leq \tau \leq \tilde{d}\right)\right]$, where we only count vacancies after they were posted, i.e. $\tau \geq t_{\text {posted }}-t_{\text {available, }}$ at any given time $\tau$.

${ }^{16}$ Appendix Figure A5 shows similar patterns for the vacancy lapse hazard.

${ }^{17}$ True negative duration dependence in vacancy-filling rates may arise in the presence of stock-flow matching (Coles and Smith, 1998), in the presence of phantom vacancies (Albrecht, Decreuse and Vroman, 2019) or due to nonsequential search where employers select a pool of applicants and then make a job offer (Davis and Samaniego de la Parra, 2017). Dynamic selection due to unobserved heterogeneity arises when there are vacancies with an intrinsically high filling rate that leave the sample early while the "surviving" vacancies at longer duration exhibit low filling rates. For examples of models with heterogeneous filling rates, see Davis (2001), where vacancies for high-productivity jobs exhibit higher filling rates, or Kaas and Kircher (2015), where fast-growing firms post higher wages to attract more applicants. There could also be positive dynamic selection before the desired start date as firms expecting a low filling rate could increase the probability of filling their vacancy by the desired start date by posting early, which could explain part of the upward slope to the left of the desired start date. See also Ehrenfried and Holzner (2019) for similar patterns in duration dependence of the vacancy-filling hazard in German data. 


\subsection{Linking AMS vacancies to the ASSD}

In the empirical analysis below, we will primarily focus on the empirical association of vacancy durations and entry wages. This is based on a dataset linking AMS vacancies to information on workers and establishments from the Austrian social security database (ASSD). The ASSD, explained in detail in Zweimüller et al. (2009), is a linked employer-employee dataset and covers the universe of all private sector workers (about $80 \%$ of the total workforce) from 1972 onwards. The ASSD collects all information necessary to verify old-age pension claims. For this purpose, it records the complete earnings- and employment history for each worker. Moreover, the ASSD provides information on unemployment insurance spells, and spells on other social insurance programs (e.g., disability) and also includes a limited set of worker and establishment characteristics.

We exploit AMS information on the identity of the establishment posting the vacancy and the worker eventually filling the vacancy to construct two linked vacancy-employer-employee datasets: (i) a "firm sample", which links AMS vacancy information to ASSD information on the establishments' employment dynamics (employment, hirings, separations, etc.); and (ii) a "worker sample", which links AMS vacancy information to the ASSD earnings- and employment history of the worker filling a vacancy. We use the firm sample for our analysis of the relationship between vacancy filling and firm growth in Section 5 and the worker sample for our main analysis in the paper of the relationship between vacancy durations and entry wages in Section 6. Note that we exclude vacancies for part-time jobs from our firm and worker samples to limit any issues regarding the hours margin in our wage analysis, since the ASSD only measures daily but not hourly wages.

To construct the firm sample, we use the information on establishment identifiers both in the ASSD and AMS vacancy data, and the mapping translating them based on a firm cross-walk provided by the Bundesministerium fuer Arbeit, Soziales und Konsumentenschutz in Austria. Unfortunately, the mapping is not unambiguous, so we confine the analysis to the set of firms that can be unambiguously matched based on the firm cross-walk, covering around $52 \%$ of the firm identifiers recorded in the vacancy data. ${ }^{18}$ Note that we calculated this matching rate by excluding vacancies for part-time jobs from both the AMS universe and the firm sample.

To construct the worker sample, we exploit information in the AMS vacancy data on the identity (= the anonymized social security number) of the worker filling the vacancy. This information is available for hires mediated through the AMS, which happens to be the case for about $27 \%$ of all filled AMS vacancies (see Table A1). These AMS vacancies can be linked to ASSD information on earnings and employment of the worker filling the vacancy. In the worker sample, we establish a link at the establishment-level to the ASSD data, using the same cross-walk as for the firm sample. In addition, in cases where the cross-walk is ambiguous, we link the establishment based

\footnotetext{
${ }^{18}$ The main reason for the non-uniqueness of the matching is that the vacancy register and the ASSD use a different firm/establishment logic, which is a not an uncommon problem with data sources stemming from different data providers.
} 
Table 2: Vacancy Characteristics: AMS Universe vs. Matched Subsamples

\begin{tabular}{|c|c|c|c|}
\hline & \multicolumn{3}{|c|}{ Sample } \\
\hline & AMS & Firm & Worker \\
\hline \multicolumn{4}{|l|}{ Vacancy Characteristics } \\
\hline At least apprenticeship (\%) & 50.2 & 54.5 & 46.7 \\
\hline Permanent contract $(\%)$ & 78.3 & 75.0 & 80.9 \\
\hline Hired through system (\%) & 23.3 & 24.0 & 100.0 \\
\hline Fixed working time $(\%)$ & 21.3 & 23.7 & 27.3 \\
\hline Full time $(\%)$ & 75.5 & 100.0 & 100.0 \\
\hline Small firm (\%) & 44.5 & 38.2 & 40.4 \\
\hline Vienna $(\%)$ & 17.0 & 13.3 & 10.2 \\
\hline \multicolumn{4}{|l|}{ Selected Industries } \\
\hline Manufacturing, Mining, and Quarrying (\%) & 10.3 & 14.1 & 17.1 \\
\hline Construction $(\%)$ & 7.1 & 9.2 & 10.6 \\
\hline Wholesale and Retail (\%) & 14.8 & 11.1 & 14.1 \\
\hline Tourism, Hotels, and Restaurants (\%) & 23.4 & 26.9 & 18.5 \\
\hline Other Services $(\%)$ & 32.2 & 30.6 & 29.8 \\
\hline Number of Vacancies & $5,291,897$ & $2,820,511$ & 802,966 \\
\hline Number of Establishments & 267,122 & 109,855 & 119,030 \\
\hline
\end{tabular}

on the employment history of the worker matched to the vacancy. More precisely, we identify the establishment in the ASSD data by the (unique) employment spell that starts within 31 days of the vacancy-filling date. This additional step in the merging procedure substantially increases the number of vacancies in the worker sample to which we can assign a unique firm identifier in the ASSD data, matching $93 \%$ of the firm identifiers. For the same reason the worker sample is not a strict sub-sample of the firm sample because of this additional step in the merging procedure that is based on workers' employment history.

To check the quality of the linking procedure, we compare vacancy characteristics in the linked firm- and worker samples to the AMS universe to vacancy characteristics in the AMS universe. This checks whether the linkable vacancies are a representative subset of the AMS universe. In Table 2, we report summary statistics, comparing the universe of vacancies to our matched subsamples. ${ }^{19}$ In moving from the AMS universe to the firm sample, we exclude non-linkable firms leaving us

\footnotetext{
${ }^{19}$ In line with published statistics of Statistik Austria, we exclude vacancies for apprenticeships, vacancies from firms in agriculture and fishing, and extraterritorial organizations from the data. The data with these sample restrictions closely replicates the official time series on AMS vacancies published by Statistik Austria.
} 
Figure 5: Distribution of Firm Wage Effects: ASSD Universe vs. Matched Samples

(a) Firm Sample

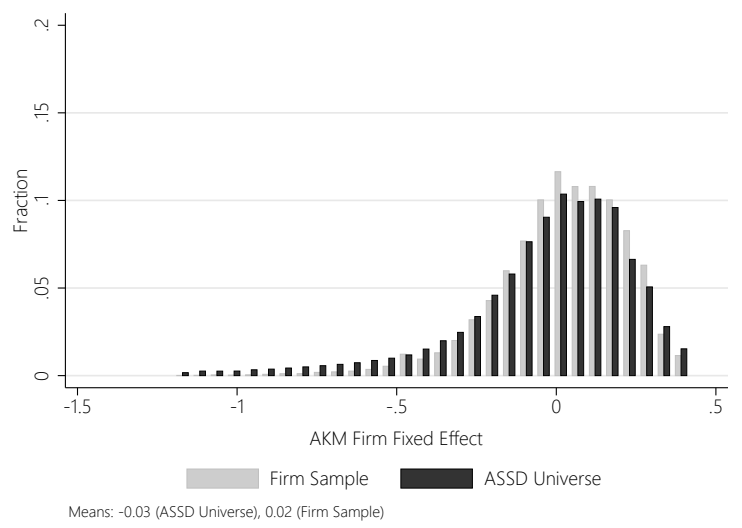

(b) Worker Sample

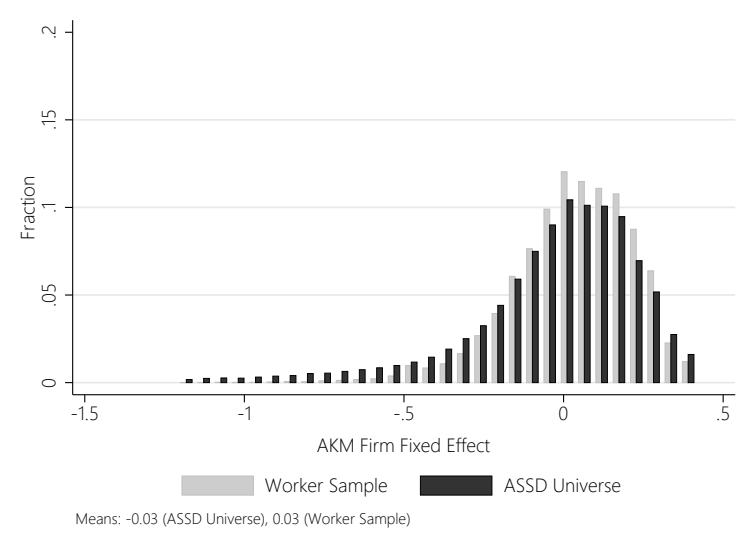

Notes: Distribution of firm wage effects for the ASSD universe and the matched firm and worker subsample, weighted by average employment.

with $71 \%$ of the full-time vacancies in the AMS universe. In moving from the AMS universe to the worker sample, we only include vacancies resulting in a hire through mediation of the AMS system where a worker identifier was available leaving us with $86 \%$ of the full-time vacancies mediated through the AMS. ${ }^{20}$ While the worker sample - the sample used to explore vacancy durations and entry wages - is substantially smaller than the AMS universe, the descriptive statistics suggest that it is not that different in terms of vacancy characteristics. Overall, the evidence in Table 2 suggests that the linking procedure works well and is unlikely to be contaminated by the fact that a substantial number of AMS vacancies cannot be linked due to missing establishment- or person identifiers. ${ }^{21}$ In particular, the worker sample looks quite similar to the full sample of vacancies in terms required formal education, contract type and size of the posting firm.

A second check assessing the representativeness of our linked vacancy-employer-employee dataset compares the establishments posting linkable vacancies to the universe of establishments in the ASSD, which covers all private sector establishments. This checks whether the establishments to which we can link AMS vacancies are a representative subset of the ASSD establishment universe. In Figure 5, we plot the distribution of firm-wage effect estimated following Abowd, Kramarz and Margolis (1999). Panels (a) and (b) compare the distribution in the ASSD establishment universe to the corresponding distributions but considering only establishments in the firm and the worker subsample, respectively. While we discuss this concept in more detail below, it is an estimate of the average wage paid in a firm, controlling for observed and unobserved worker characteristics. Clearly, the distributions look very similar, with less mass at both ends of the distributions compared to the ASSD Universe. In Table A2 in the Appendix, we also checked whether

\footnotetext{
${ }^{20}$ We also exclude observations where the observed starting wage was zero (69 cases).

${ }^{21}$ The regression samples in Section 6 are somewhat smaller than this number because most regressions use the natural logarithm of vacancy duration as the dependent variable, which is not defined for the sizeable fraction of the sample with a vacancy duration of zero. See further below in this section for a discussion of this issue. In addition, some control variables are not available for all observations in the worker sample.
} 
the firm sample is similar to the ASSD universe in terms of industry composition, employer size and worker turnover. It turns out that the firm sample is somewhat more concentrated in manufacturing, construction, retail trade and tourism. Subsamples are also more likely medium sized, while very small and very large establishments are underrepresented. The subsamples compare very well to the universe in terms of the distribution across employment turnover categories.

In sum, while many vacancies cannot be linked, the characteristics of linkable vacancies look very similar to characteristics of the AMS vacancy universe. This suggests that the linking procedure works and is unlikely invalidated by missing establishment or person identifiers. However, with respect to industry and firm size the composition of establishments in the linked samples is somewhat different from the one in the ASSD establishment universe. This is likely due to either differences in the likelihood to post vacancies or selectivity in establishments' propensity to post vacancies on the AMS platform. While this calls for a cautious interpretation of our results, our main takeaway is that the linked vacancy-employer-employee data is a highly informative data source for studying vacancy durations and entry wages. We also probe the robustness of our main findings in Section 6 below and find that they are not sensitive to controlling for establishment size nor to splitting the sample by establishment size.

\section{Vacancy Filling and Firm Growth}

One of the major contributions of DFH is the finding that, at the firm level, the stock of vacancies is an insufficient statistic for hiring. They document that faster growing firms have higher vacancy yields (= hire more workers per vacancy posted). Their results are based on the JOLTS, a monthly survey of the vacancy stocks, gross hires and separations. As argued above, the JOLTS is subject to aggregation bias, leading to under-sampling of vacancies with short durations. Moreover, JOLTS does not collect direct information on the duration of a given vacancy. While DFH compute a daily vacancy-filling rate based on gross hires, separations and vacancy postings and correct for biases due to time aggregation, it makes sense to reconsider their findings, as our data sample from the flow and provide a direct measure of vacancy filling. Moreover, it is also interesting to analyze whether the same patterns emerge with different institutions, such as those of Austria.

We calculate the monthly employment growth rates in establishment size using the ASSD. Following DFH, we calculate growth rates allowing for entries and exits, defined as

$$
g_{t}=\frac{n_{t}-n_{t-1}}{0.5\left(n_{t}+n_{t-1}\right)}
$$

where $n_{t}$ denotes the establishment size in period $t$. We merge these growth rates and the establishment size to the vacancy register. Following DFH, we define 207 growth rate bins, allowing for mass points at -2 and 2, choosing the bins to be narrower for growth rates close to 0 . We then calculate the average vacancy-filling rate within these bins. As DFH, we smooth the results using 
Figure 6: Vacancy-Filling Hazard by Establishment Growth and Hiring

(a) Vacancy-Filling Hazards by Empl. Growth Rates

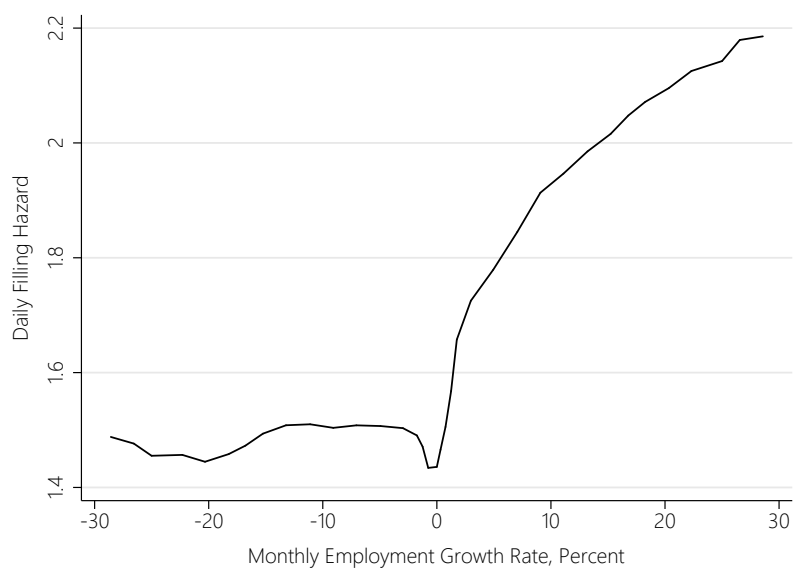

(b) Vacancy-Filling Hazards by Hires Rates

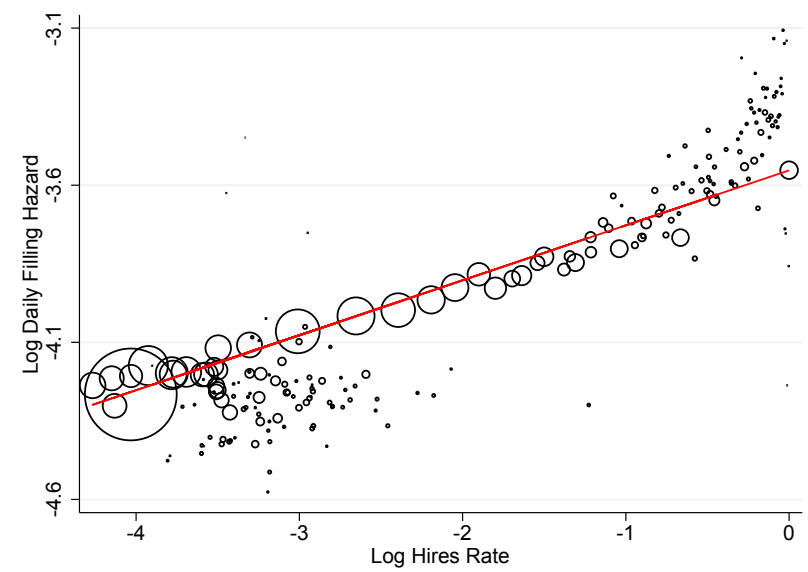

Notes: Panel (a) shows average vacancy-filling hazards by monthly employment growth rates and Panel (b) shows average $(\log )$ vacancy-filling hazards by $(\log )$ monthly hires rates in the matched firm sample for the years 1997-2014. The circles in Panel (b) are based on the averages of log vacancy-filling hazards and log hires rates in the employment growth rate bins in Panel (a), but including bins with growth rates below $-30 \%$ and above $30 \%$. The size of each circle is drawn in proportion to the number of observations in the bin and the red line shows the hires-weighted least-square estimate with a slope (s.e.) of $0.175(0.000)$ and $R^{2}=0.91$.

a centered five-bin moving average.

The result of this exercise can be seen in Panel (a) of Figure $6 .{ }^{22}$ We find that same hockeystick type pattern as for DFH's model implied vacancy-filling rate: a strong positive relationship between vacancy filling and employment growth for growing firms and a constant filling rate for shrinking firms. Quantitatively, the patterns are not as strong as in DFH who find that the daily vacancy-filling rate increases fivefold from 0.05 for shrinking firms to around 0.25 for firms growing 30\%, whereas in our data the vacancy-filling rate increases by more than $50 \%$ from 0.014 to just below 0.022 . This conclusion is confirmed when we compute the elasticity of vacancy-filling rates to gross hires rates, as shown in Panel (b) of Figure 6. We find a robust positive relationship, which indicates that firms that hire more workers not only post more vacancies but also fill a given vacancy faster. The elasticity of the daily filling hazard to the hires rate is substantially smaller in our data, with a value of 0.18 compared to the elasticity of 0.82 in DFH. Still, our elasticity implies that vacancy filling increases substantially for establishments with a higher hires rate. The elasticity, e.g., predicts that the vacancy-filling hazard increases by $47 \%$ for establishments with a hires rate of 0.9 compared to establishments with a hires rate of 0.1 .

It is not clear whether the discrepancy in the magnitude between our estimates and DFH is due to differences in the measurement of the vacancy-filling rate or differences in the labor market setting between the U.S. and Austria. Unfortunately, we cannot compute DFH's model implied filling rate, because DFH's method requires the entire stock of vacancies for each firm whereas we only observe the subset of vacancies posted on the AMS website and thus we cannot distinguish

\footnotetext{
${ }^{22}$ Appendix Figure B1 shows the same pattern for the sample of immediately available vacancies.
} 
Table 3: Additional Statistics on Hires and Vacancies

\begin{tabular}{|c|c|c|c|}
\hline & \multicolumn{2}{|c|}{ AMS } & \multirow[t]{2}{*}{ DFH } \\
\hline & $\begin{array}{c}\text { All } \\
\text { Vacancies }\end{array}$ & $\begin{array}{l}\text { Immediately } \\
\text { Available }\end{array}$ & \\
\hline $\begin{array}{l}\text { Employment at establishments with } \\
\text { no hires in } \mathrm{t}\end{array}$ & 26.4 & 26.4 & 34.8 \\
\hline $\begin{array}{l}\text { Employment at establishments with } \\
\text { no vacancies at end of } \mathrm{t}-1\end{array}$ & 71.4 & 78.2 & 45.1 \\
\hline $\begin{array}{l}\text { Hires in } \mathrm{t} \text { at establishments with no } \\
\text { vacancies at end of } \mathrm{t}-1\end{array}$ & 61.1 & 68.6 & 41.6 \\
\hline $\begin{array}{l}\text { Vacancies at end of } \mathrm{t} \text { at establishments } \\
\text { with no vacancies at end of } \mathrm{t}-1\end{array}$ & 20.3 & 23.7 & 17.9 \\
\hline
\end{tabular}

the two potential sources of the discrepancy in the magnitude of the elasticity. ${ }^{23}$ In any event, we believe a direct measure of vacancy filling as in the AMS data is preferable. Note that the fact that we only observe AMS vacancies, shouldn't bias the elasticity, as long as the filling and hiring patterns are the same for AMS vacancies as for other job openings. Although we cannot check empirically, there is no a priori reason to believe that the relationship between vacancy filling and hiring is different for AMS vacancies and vacancies posted elsewhere. Figure A3 in the Appendix also shows that, in the Austrian vacancy survey, the share of vacancies posted on the AMS website does not change systematically with establishment growth.

In summary, the evidence here confirms the view that vacancy postings are not a sufficient statistic for hiring at the firm level and that firms that grow quickly use other recruiting channels to attract workers. Appendix Table A4 also shows patterns of hiring and vacancy posting in the Austrian data similar to those presented by DFH for the US. While AMS vacancy rates tend to be smaller and AMS vacancy yields larger when compared to DFH, this is not surprising as JOLTS measures all vacancies at surveyed establishments whereas the AMS vacancy database only covers vacancies posted at the AMS. For this reason our analysis below focuses on outcomes at the vacancy level such as vacancy duration rather than outcomes at the establishment level such as vacancy yields. Finally, in Table 3 we look at further vacancy and hiring indicators. We find that establishments with no hires at the monthly frequency account for $26 \%$ of employment, which compares to $35 \%$ in DFH. We also find that $71 \%$ of employment is in establishments with no AMS

\footnotetext{
${ }^{23}$ Appendix Figure B1 also shows that the vacancy yield has the same hockey-stick patterns as in DFH. Again, because we don't observe all vacancies at given firm, we prefer to focus here directly on the object of interest, which is the rate of vacancy filling.
} 
vacancy posted during the previous month; and $61 \%$ of employment is in establishments that hire in the current month but did not post an AMS vacancy in the previous month. The corresponding numbers in DFH are $45 \%$ and $42 \%$, respectively. Note that higher numbers are to be expected in the Austrian data, as AMS vacancies make up only $60 \%$ of all posted vacancies. Finally, we find a high degree of persistence in the establishment-level incidence of AMS vacancies: only $20 \%$ of vacancies are posted in establishments with no vacancy in the previous month, similar to DFH.

In the Appendix Table A3, we present further evidence showing that hiring and separations rates are of a similar order of magnitude in the ASSD as in JOLTS. The fact that labor turnover among Austrian firms is at least as high as in the US has been pointed out in Stiglbauer et al. 2003. Similar to DFH, we find that vacancy rates and vacancy yields vary substantially across industries (see Table A4 in the Appendix). While we find remarkably similar vacancy patterns, AMS vacancy patterns differ from JOLTS with respect to employer size: DFH report that vacancy rates increase (and vacancy yields decrease) with employer size, the opposite is true in the Austrian data. As discussed above, the AMS coverage rate is fairly stable across establishment size classes (see Table A5) and thus differential coverage in the AMS data cannot account for these patterns.

\section{Vacancy Durations and Wages on New Jobs}

A central assumption in many search-theoretic models of the labor market is that firms post wages or commit to a wage offer, and that the promised wage affects the likelihood of filling a job opening. This is true both in models of directed search such as Moen (1997), where a higher posted wage increases the number of workers applying to the job, or in models of random search such as Burdett and Mortensen (1998), where a higher posted wage increases the likelihood for a given worker to accept the job offer.

Evidence on the relationship between vacancy filling and entry wages is scarce, with the exception of Faberman and Menzio (2018) who use data from the Earnings and Opportunities Pilot Project (EOPP) in the U.S. for the years 1980 and 1982. In stark contrast with the above canonical search models, they document a positive relationship between vacancy durations and entry wages, even after controlling for firm- and worker characteristics. Faberman and Menzio interpret their evidence cautiously, arguing that is not necessarily in contradiction with search theory because their controls may be insufficient to account for all the relevant heterogeneity that bears on the relationship between starting wages and vacancy duration.

With the matched vacancy-employer-employee data we can go one step further. Since we can link the posted vacancy to the earnings history of the worker filling the vacancy, we can look in more detail on the relationship between vacancy durations and entry wages of eventually filled vacancies. In what follows, we first analyze the relationship between vacancy durations and entry wages. In a second step, we decompose the entry wage in its establishment-, worker- and match-components and analyze the relationship of each with the duration of vacancies. 
Figure 7: Log Entry Wage and Log Vacancy Duration

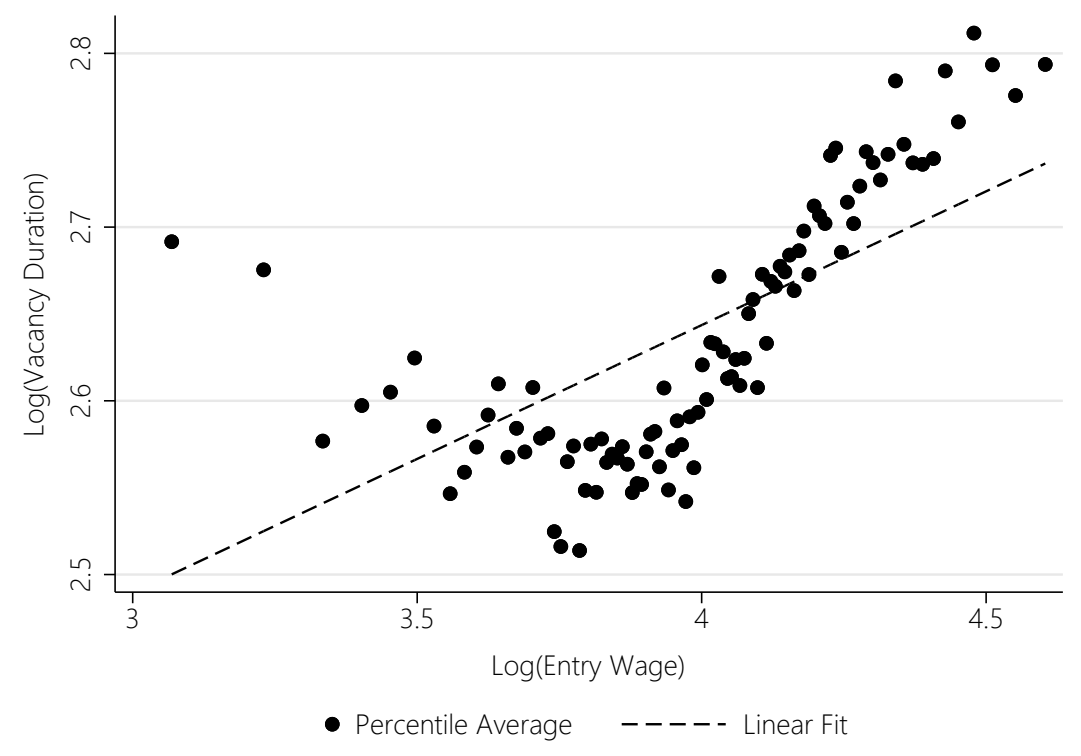

Notes: Each data point corresponds to the average within a given wage percentile of the sample. The sample is trimmed for wage values below the first and above the 99th percentile.

\subsection{Vacancy Durations and Entry Wages}

We start our empirical analysis in Figure 7 by plotting the raw averages of log vacancy durations for each percentile bin of the distribution of entry wages. As evident from the figure, the relationship between entry wages and vacancy duration appears to be non-linear. There is a negative slope in the lowest percentiles of the entry-wage distribution, but a strongly positive relationship at medium and high percentiles of the entry wage distribution. While the linear regression line clearly does not provide a good fit to the data, it is drawn for comparison purposes with the paper of Faberman and Menzio (2018) whose sample of around 1,500 job openings was too small to assess non-linearities in the relationship between entry wages and vacancy duration.

Table 4 further analyzes the relationship between vacancy durations and entry wages. Column 1 documents an overall positive relationship between vacancy durations and entry wages when controlling for time fixed effects. In Column 2 we include control variables for the region, industry and the required education level of the job, as well as the gender, age, age squared and the year of labor market entry of the person matched to the job. While the conditional correlation remains positive, it becomes smaller in magnitude, suggesting that observed characteristics are important correlates for vacancy durations. In Column 2 we also include indicators for early posting (dummies for 0-7 days, 8-30 days, 31-60 days, and more than 60 days). The inclusion of early-posting dummies addresses the concern that firms trying to fill their vacancies quickly may be posting early. We find that the reported coefficient in Column 2 remains very similar when we exclude this set of dummies from the regression. Therefore, posting ahead of time of the date of job availability does not seem to confound the duration/entry-wage relationship. 
Table 4: Regressions with Log Vacancy Duration as Dependent Variable

\begin{tabular}{|c|c|c|c|c|c|}
\hline & \multicolumn{5}{|c|}{ Log Vacancy Duration } \\
\hline & (1) & $(2)$ & (3) & (4) & (5) \\
\hline Log entry wage & $\begin{array}{c}0.230 \\
(0.014)^{* * *}\end{array}$ & $\begin{array}{c}0.053 \\
(0.010)^{* * *}\end{array}$ & $\begin{array}{c}-0.037 \\
(0.009)^{* * *}\end{array}$ & $\begin{array}{c}-0.057 \\
(0.016)^{* * *}\end{array}$ & $\begin{array}{c}-0.044 \\
(0.015)^{* * *}\end{array}$ \\
\hline Log job duration & & & & $\begin{array}{c}0.033 \\
(0.003)^{* * *}\end{array}$ & \\
\hline On-job wage growth & & & & $\begin{array}{c}-0.033 \\
(0.017)^{*}\end{array}$ & \\
\hline Firm empl. growth & & & & $\begin{array}{l}-0.007 \\
(0.010)\end{array}$ & \\
\hline Firm age & & & & $\begin{array}{c}-0.001 \\
(0.000)^{* * *}\end{array}$ & \\
\hline Log firm size & & & & $\begin{array}{c}0.035 \\
(0.004)^{* * *}\end{array}$ & \\
\hline Observations & 535357 & 535357 & 535357 & 205783 & 294208 \\
\hline$R^{2}$ & 0.010 & 0.174 & 0.211 & 0.236 & 0.589 \\
\hline Baseline Controls & No & Yes & Yes & Yes & Yes \\
\hline Occ. FE (6 digits) & No & No & Yes & Yes & No \\
\hline Individual FE & No & No & No & No & Yes \\
\hline
\end{tabular}

Notes: Authors' regressions with the worker sample for the years 1997-2014. Standard errors are clustered at the establishment level, except for column 5 where clustered standard errors did not converge due to the presence of many dummy variables. All regressions include a quarter fixed effect. Baseline controls include gender, age, age squared, dummies for the minimum educational requirement of the job and the year of labor market entry, as well as region \& industry and an early posting fixed effect, where early posting fixed effects are dummies for posting the vacancy 0-7 days, 8-30 days, 31-60 days, and more than 60 days prior to the desired start date.

Column 3 is our preferred specification. In this column, we additionally control for 6-digitoccupation-fixed effects. The conditional correlation suggests an elasticity of vacancy durations with respect to the entry wage of -0.037 . Note that the negative sign is in line with the qualitative prediction of wage-posting models. The fact that the sign on the wage changes when including the various control variables as well as a fine grid of occupation dummies (i.e. when moving from Column 1 to Column 3 in Table 4) suggests that heterogeneity at the worker- and match level is an important confounder of the relationship between vacancy durations and entry wages. These results also echo the results in Marinescu and Wolthoff (2020), who find that the relationship between applications and posted wages has the expected (positive) sign only when including job 
title fixed effects in the regression. ${ }^{24}$ Overall, however, the relation remains economically small, with a $1 \%$ increase in the entry wage being associated with a $0.04 \%$ decrease in vacancy duration.

In Column 4, we show that the relation is robust to the inclusion of further worker- and firm covariates, which are available only for a subsample of firms in our data. It turns out that vacancies with longer durations are associated with longer subsequent job durations and lower wage growth on the filled job. Including these variables in the regression, however, does not alter significantly the coefficient of the entry wage, suggesting that these variables are not systematically correlated with the entry wage. This alleviates concerns that the coefficient of the entry wage is biased due to a possible negative correlation with wage growth on the job. This latter robustness check is important, because theories of posted wages ultimately apply to wages over the entire duration of the job and not just the entry wage. We also find that smaller and older firms are filling vacancies more quickly. ${ }^{25}$ The final Column 5 shows results for a subsample of workers with at least two unemployment spells. This allows to include individual fixed effects in the regression model to control for any time-invariant observed and unobserved worker heterogeneity. The regression coefficient on the entry wage is remarkably similar to the one in Column 3. Based on the evidence of Table 4 we conclude that there exists a robust, negative, and significant association between vacancy durations and entry wages, but the economic significance of the relationship is small. ${ }^{26}$

\subsection{Vacancy Durations and Firm Wage Premia}

In this sub-section, we decompose the entry wage in its establishment, worker and match components and relate each of them to vacancy durations. As demonstrated by the results in Table 4, worker- and job-specific heterogeneity as captured by occupation dummies and individual worker fixed-effects are an important confounder of the relationship between vacancy durations and entry wages. Since our vacancy-employer-employee data let us observe the earnings histories of those workers who are matched to a given vacancy for many years before and after the match, we can go one step further. We decompose the starting wage into worker- and firm effects using the framework of Abowd, Kramarz and Margolis (1999) (AKM) and then relate each component of the wage to vacancy durations. More precisely, we build a yearly panel of daily wages (always looking at the job held on June 30) of the universe of workers and firms observed in the Austrian

\footnotetext{
${ }^{24}$ To be precise, in their results the sign only changes when they include job title fixed effects but not when they just include 6-digit SOC codes.

${ }^{25}$ Consistent with Figure 6, the effect of employment growth is negative, though it is not significant. If we control for dummies for bins of employment growth in the regressions in Table 4, the effect is negative and significant, capturing better the non-linear nature of the relationship between employment growth and vacancy filling. The estimated coefficient on the wage remains unaffected.

${ }^{26}$ In the Appendix Table C9, we report results where we regress the log of vacancy duration on the log of the present discounted value (PDV) of wages over the employment spell. The estimated elasticities are negative, but remain small. See Appendix C.3 for details of how we compute the PDV of wages of a job.
} 
Figure 8: AKM Worker Effects and Log Vacancy Duration
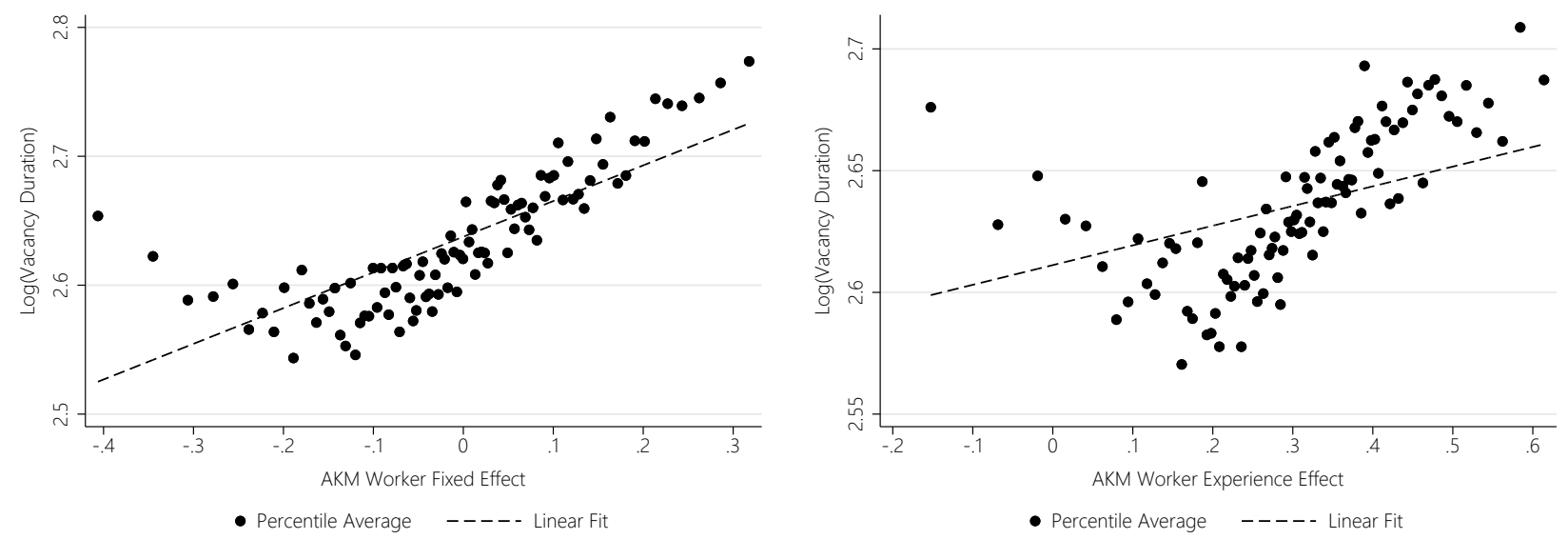

Notes: The figures show partial correlations of AKM worker effects and log vacancy duration, i.e. controlling for the AKM establishment effects, the AKM residuals and the AKM person experience effect (left) resp. the AKM person experience effect (right). Each data point corresponds to the average within a given percentile of the AKM worker effect in the sample. The sample is trimmed for wage values below the first and above the 99th percentile.

matched employer-employee data (ASSD) and estimate the model

$$
\log w_{i t}=\theta_{i}+\psi_{\mathbf{J}(i, t)}+x_{i t}^{\prime} \rho+d_{t}+\varepsilon_{i j t}
$$

where $w_{i t}$ denotes the wage of worker $i$ in year $t, \theta_{i}$ identifies the worker effect, $\psi_{\mathbf{J}(i, t)}$ identifies the firm effect (where $\mathbf{J}(i, t)$ denotes the firm where $i$ is employed in year $t$ ). We also control for observable time-varying worker characteristics $x_{i t}$ (specifically, we control for a fourth-order polynomial in experience and firm tenure), year dummies $d_{t}$ and $\varepsilon_{i j t}$ denotes the residual. Since the model is computationally very demanding, we use the years 1985 to 2014 of the ASSD data to estimate (1). ${ }^{27}$ We then relate the components of the entry wage to vacancy duration by estimating

$$
\log d_{i j k t}=\beta_{0}+\hat{\psi}_{j} \beta_{\psi}+\hat{\theta}_{i} \beta_{\theta}+x_{i t}^{\prime} \hat{\rho} \beta_{\rho}+\hat{\varepsilon}_{i j t} \beta_{\varepsilon}+z_{i j k t}^{\prime} \gamma+\eta_{i j k t}
$$

where $d_{i j k t}$ denotes the vacancy duration of vacancy $k$ posted by firm $j$ and eventually matched to worker $i$ at time $t . \hat{\psi}_{j}, \hat{\theta}_{i}, x_{i t}^{\prime} \hat{\rho}$ and $\hat{\varepsilon}_{i j t}$ denote the estimated coefficients from equation (1) and $z_{i j k t}$ is a vector of additional characteristics of the firm-worker pair. Note that $x_{i t}^{\prime} \hat{\rho}$ is a pure worker experience effect as tenure is zero by definition for entry wages.

Figures 8-10 present partial correlation graphs of vacancy durations and the various wage components. The points in the graph correspond to the percentile bins of the distribution of wage components, which are drawn against the average $(\log )$ vacancy durations associated with

\footnotetext{
${ }^{27}$ The basic assumption of the AKM framework is additive separability between firm and worker effects. To assess how well this describes the data, we computed the average residual $\varepsilon_{i j t}$ according to the decile of the firm and worker effect, as proposed by Card, Heining and Kline (2013). Generally, deviations from additive separability appear to be mild (the absolute value always stays below 0.015 ) and concentrated among establishments paying high wages. See Figure $\mathrm{C} 1$ in the Appendix for details.
} 
Figure 9: AKM Establishment Effect and Log Vacancy Duration

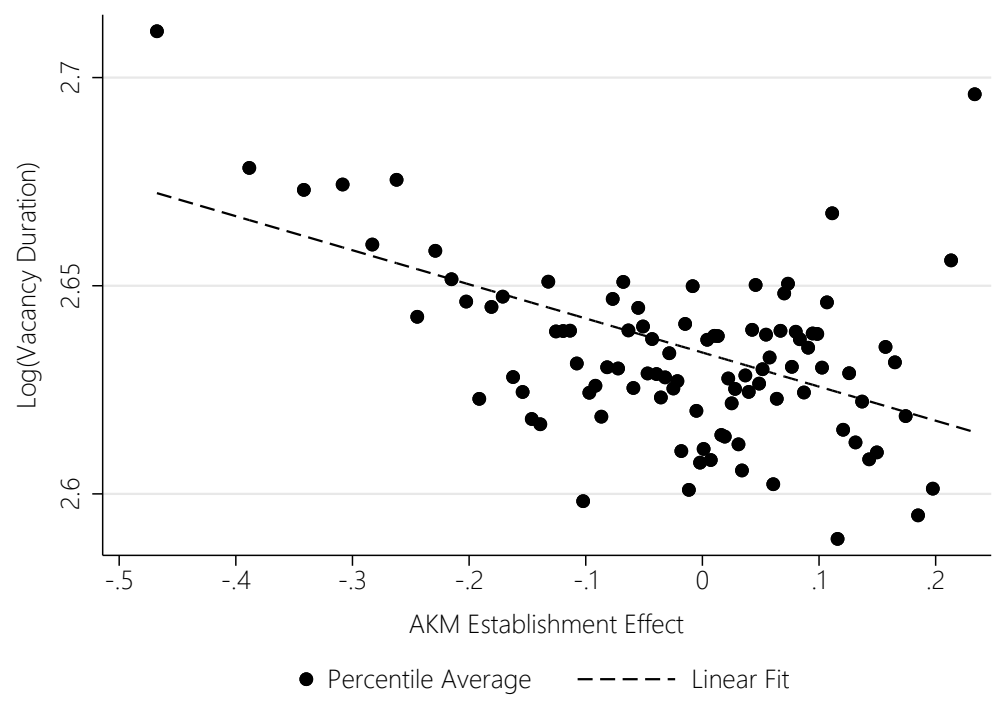

Notes: The figure shows partial correlations of AKM establishment effects and $\log$ vacancy duration, i.e. controlling for AKM worker effects and the AKM residual. Each data point corresponds to the average within a given percentile of the AKM establishment effects in the sample. The sample is trimmed for wage values below the first and above the 99th percentile.

the respective bin. Figure 8 draws the vacancy durations, respectively, against the AKM person (pre-experience) effect (left panel), and the AKM experience effect (right panel). Both graphs reveal a clear positive relationship suggesting that both dimension of worker heterogeneity are strongly associated with longer vacancy durations which, in terms of magnitude, seem equally relevant. Figure 9 plots vacancy durations against the AKM establishment effect and reveals a clear negative relationship. Taken together, Figures 8 and 9 reveal a clear picture: Vacancies posted by high-wage firms last shorter, vacancies filled by high-wage workers last longer. In Figure 10, we plot the percentile bins of the residual wage distribution against vacancy durations. The conditional correlation is less clear. This is reassuring as we would have expected that there are many unobserved wage determinants (not attributable to permanent worker- or establishmentdifferences) correlating with vacancy durations in both directions, thus yielding a less clear-cut association. In addition, the AKM person and AKM establishment effects are measured with error and thus these person- and firm-level measurement errors also go into the residual.

We proceed by presenting regression results that include the components of the AKM decomposition (2) instead of the log entry wage as regressors (Panel A of Table 5). The interesting benchmark for comparison is the naive regression of log vacancy duration on the starting wage in Column 2 of Table 4. The regression is now based on the smaller sample (where AKM firm effects can be identified) and yields a coefficient of 0.066 , the same order of magnitude as before. Column 2 of Table 5 shows the results corresponding to the figures 8-10. In particular, the regression reveals the most notable result visible from Figure 9: high-wage firms manage to fill their vacancies more 
Figure 10: AKM Residual and Log Vacancy Duration

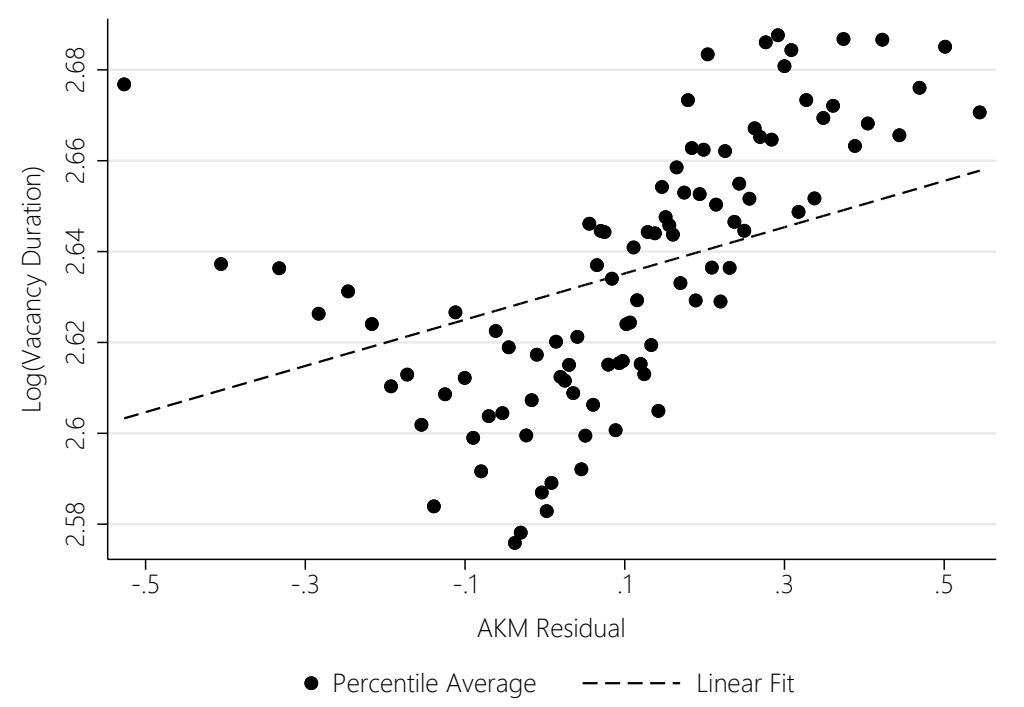

Notes: The figure shows partial correlations of AKM residuals and log vacancy duration, i.e. controlling for AKM worker and establishment effects. Each data point corresponds to the average within a given percentile of the AKM residual in the sample. The sample is trimmed for wage values below the first and above the 99th percentile.

quickly. ${ }^{28}$ The elasticity of the vacancy duration with respect to the firm (log-)wage component is -0.082 and highly statistically significant. The point estimates becomes somewhat larger when we add occupation fixed effects (Column 3), additional controls (Column 4), and when we confine the sample by workers who are repeatedly observed filling a vacancy so that individual fixed effects can be included instead of the worker's AKM wage component (Column 5). ${ }^{29}$ Qualitatively, this result appears consistent with a model in which some firms post higher wages to attract more workers and fill vacancies more quickly, but the effect appears economically small with a $1 \%$ increase in the firm effect being associated with a $0.1 \%$ decrease in the duration of the vacancy for our preferred specification in Column 3. In the next section, we discuss the magnitude of our findings and relate them to the findings in DFH as well as the predictions of search-theoretic models of firm dynamics. As discussed in detail, the estimated effect of wages on vacancy duration in our data can account only for a very small fraction of the variation in vacancy filling across firms.

Column 2 of Table 5 also reports the estimates of the remaining wage components on vacancy durations. Both the AKM worker and the AKM experience components are positively associated with vacancy durations. This suggests that, in the raw data, worker heterogeneity is the dominant force behind the overall positive relationship of vacancy durations and entry wages. If we interpret

\footnotetext{
${ }^{28}$ Note that the coefficients on the AKM effects in Column 2 do not have to add up to the coefficient on the entry wage in column 1. E.g., consider the case where the variance of one of the components is tiny but its effect on vacancy duration is large, then the regression coefficient on the log entry wage in column 1 will do little to reflect the effect of the component with the small variance, whereas the regression in column 2 will because it breaks out all components of the entry wage.

${ }^{29}$ We do not control for 6-digit occupation effects in this specification due to possible multicollinearity introduced by the presence of a large set of dummy variables.
} 
Table 5: Regressions with Log AMS Vacancy Duration as Dependent Variable

Log Vacancy Duration
(1)
(2)
(3)
(4)

(5)

\section{Panel A.}

Log entry wage

0.066

$(0.010)^{* * *}$

AKM establishment effect

$$
\begin{array}{cccc}
-0.082 & -0.098 & -0.175 & -0.158 \\
(0.023)^{* * *} & (0.019)^{* * *} & (0.026)^{* * *} & (0.029)^{* * *}
\end{array}
$$

AKM worker fixed effect

$\begin{array}{ccc}0.279 & 0.057 & 0.045 \\ (0.013)^{* * *} & (0.013)^{* * *} & (0.021)^{* *}\end{array}$

AKM worker exp. effect

$$
\begin{array}{cccc}
0.079 & -0.020 & -0.038 & -0.007 \\
(0.015)^{* * *} & (0.011)^{*} & (0.020)^{*} & (0.029)
\end{array}
$$

\begin{tabular}{|c|c|c|c|c|c|}
\hline AKM residual & & $\begin{array}{c}0.056 \\
(0.010)^{* * *}\end{array}$ & $\begin{array}{c}-0.029 \\
(0.009)^{* * *}\end{array}$ & $\begin{array}{c}-0.041 \\
(0.019)^{* *}\end{array}$ & $\begin{array}{l}-0.011 \\
(0.016)\end{array}$ \\
\hline Observations & 486997 & 486997 & 486997 & 188290 & 275967 \\
\hline$R^{2}$ & 0.178 & 0.179 & 0.216 & 0.239 & 0.589 \\
\hline
\end{tabular}

\section{Panel B.}

Log entry wage $\quad 0.053$

$$
(0.010)^{* * *}
$$

Avg. establish. log earnings

$$
\begin{array}{cccc}
-0.007 & -0.071 & -0.106 & -0.103 \\
(0.015) & (0.014)^{* * *} & (0.020)^{* * *} & (0.021)^{* * *}
\end{array}
$$

$\begin{array}{lcccc}\text { Residual entry wage } & 0.090 & -0.021 & -0.027 & -0.015 \\ (0.010)^{* * *} & (0.009)^{* *} & (0.017) & (0.015)\end{array}$

$\begin{array}{lccccc}\text { Observations } & 535087 & 535087 & 535087 & 205783 & 294043 \\ R^{2} & 0.174 & 0.174 & 0.211 & 0.236 & 0.589\end{array}$

\begin{tabular}{llllll}
\hline Baseline Controls & Yes & Yes & Yes & Yes & Yes \\
Additional Controls & No & No & No & Yes & No \\
Occ. FE (6 digits) & No & No & Yes & Yes & No \\
Individual FE & No & No & No & No & Yes \\
\hline
\end{tabular}

Notes: Authors' regressions with the worker sample for the years 1997-2014. Standard errors are clustered at the establishment level. All regressions include a quarter fixed effect. Baseline controls include gender, age, age squared, dummies for the minimum educational requirement of the job and the year of labor market entry, as well as region \& industry and an early posting fixed effect, where early posting fixed effects are dummies for posting the vacancy 0-7 days, 8-30 days, 31-60 days, and more than 60 days prior to the desired start date. Additional controls include on-job wage growth, $\log$ (job duration), lagged firm employment growth, firm age and log(firm size). 
these AKM worker effects as proxy for innate and accumulated human capital, these patterns may be either the result of longer decision lags in the hiring process of high-skilled workers or due to more competition among firms the high-skill segments of the labor market (i.e., a tighter labor market). The fact that unemployment durations tend to be shorter for higherskilled workers lends support for the latter view, though it does not preclude the presence of both mechanisms. Introducing occupation fixed effects in Column 3 strongly reduces the size of both estimated coefficients, but a robust, significantly positive association remains. The size of the coefficients further decline when we introduce additional controls (Column 4), suggesting that controls/occupation dummies and AKM worker effects are substitutes. All regressions in Columns 2-5 include the AKM residual that captures unobserved earnings-determinants not attributable to permanent worker- or firm-differences. The correlation of these factors with vacancy durations is positive in Columns 2, but turns negative once 6-digit occupation effects and other controls are included, which mirrors the results in Table 4.

In Panel B of Table 5 we use an alternative decomposition of the entry wage based on the yearly average of the log of earnings at the establishment (capturing the establishment-component of the wage) and the deviation of the entry wage from it (capturing the match-specific component of the wage). Unlike AKM, however, this decomposition does not adjust for fixed heterogeneity in wages across workers, but we do control for the same worker-level controls as in Panel A. In any event, the patterns are similar to those of Panel A. The average establishment wage turns significantly negative as soon as we start to control for 6-digit occupation suggesting that individual heterogeneity confounds the naive regression of Column 1. Including further controls (Column 4) or individual fixed effects (Column 5) confirms the picture. The main takeaway of Table 5 is clear: vacancies that are eventually filled by high-wage workers last longer; vacancies that are posted by high-wage firms last shorter. However, the association is quantitatively small suggesting a duration elasticity with respect to the establishment component of the wage of about -0.1.

\subsection{Robustness}

In this section, we perform a series of robustness checks for the results in Tables 4 and 5 .

As discussed in section 4.2 above, the richness of the vacancy data leads to alternative definitions of a vacancy. The measurement concept underlying the results reported so far is AMS duration. In Table 6, we repeat the analysis in Tables 4 and 5 for the two alternative definitions of vacancy duration. Column 1 repeats the results from our preferred specification (Column 3 in Tables 4 and 5). In Columns 2 and 3, we use as a dependent variable the duration of a vacancy according as measured by the JOLTS duration and Posting duration concepts, respectively. Panel A reports the results for the entry wage, whereas Panel $B$ includes the AKM wage components and in Panel $\mathrm{C}$ includes the average establishment wage and the deviation of the entry wage from the average establishment wage. The alternative vacancy duration measures do lead to very similar results, with vacancy durations being significantly negatively associated with the entry wage and 
its establishment component. While the estimated correlations are somewhat smaller, the overall picture remains: shorter durations of vacancies with high entry wages, in particular those posted by high-wage firms; longer durations of vacancies filled by high-wage workers. ${ }^{30}$ The fact that the elasticities are somewhat smaller is mainly due to the fact that the average duration for these alternative measures is (by construction) somewhat longer.

In Appendix $C$ we provide further results and robustness checks on the association between vacancy duration and the entry wage and its establishment component. Table C2 shows results for all three vacancy duration concepts where we measure vacancy duration in days rather than in logs. We report the results for our preferred specification and find that the association between the entry wage and its AKM establishment component and vacancy duration is significantly negative but economically small. Depending on which vacancy concept we use, the results imply that a 10 percent increase in the entry wage reduces vacancy duration by 0.15 to 0.26 days. Similarly, a 10 percent increase in the establishment component reduces the duration of a vacancy by 0.21 to 0.49 days. The results on the AKM worker effect are not as robust, though this specification controls for a lot of worker-level controls. In separate results not shown in the Appendix, the AKM worker effect was strongly positively associated with vacancy duration when not using worker-level controls in the regression.

Tables C7 and C8 also show that the results are robust to trimming the sample below the 1st and above 99th percentile of the distribution of starting wages, restricting the sample to men, excluding recalls or controlling for the quintiles of average turnover at the establishment over the sample period. Tables C3 and C6 in the Appendix also show that our results are not affected when we use weights that adjust for selection of our worker sample relative to the AMS universe based on educational requirements of the job, industry and region for each year in the sample period (see the table notes for further details).

In the Appendix Table C8, we provide further evidence on the relationship between vacancy durations and the AKM components of the entry wages. A potential concern is that assumptions underlying the AKM decomposition are too restrictive. For instance, they could be biased due to endogenous mobility. Postel-Vinay and Robin (2002) argue that the estimated person effects might be driven by the sequential sampling of alternative (high) wages leading to persistent differences between otherwise identical individuals. We address this concern by looking only at job changes associated with an intermediate spell of unemployment. Intermediate unemployment spells break the link of sequential sampling, as a wage offered to a currently unemployed worker will only depend on worker and firm type and not on the employment history. Nevertheless, estimating our preferred specification on this sample reveals that the conclusions are unchanged. ${ }^{31}$

\footnotetext{
${ }^{30}$ In the Appendix, we provide the full set of results using the JOLTS vacancy concept (Panel A of Table C3 and Table C4) and the time-since-posting measure (Panel B of Table C3 and Table C5).

${ }^{31}$ Re-estimating the worker and firm effects restricting our panel to job changes interrupted by registered unemployment spells implies that, for every firm and worker, we lose a large number of observations leading to less precise estimates. In addition, we cannot identify either the firm or worker effect for some vacancies.
} 
Table 6: Results for Alternative Specifications and Vacancy Concepts

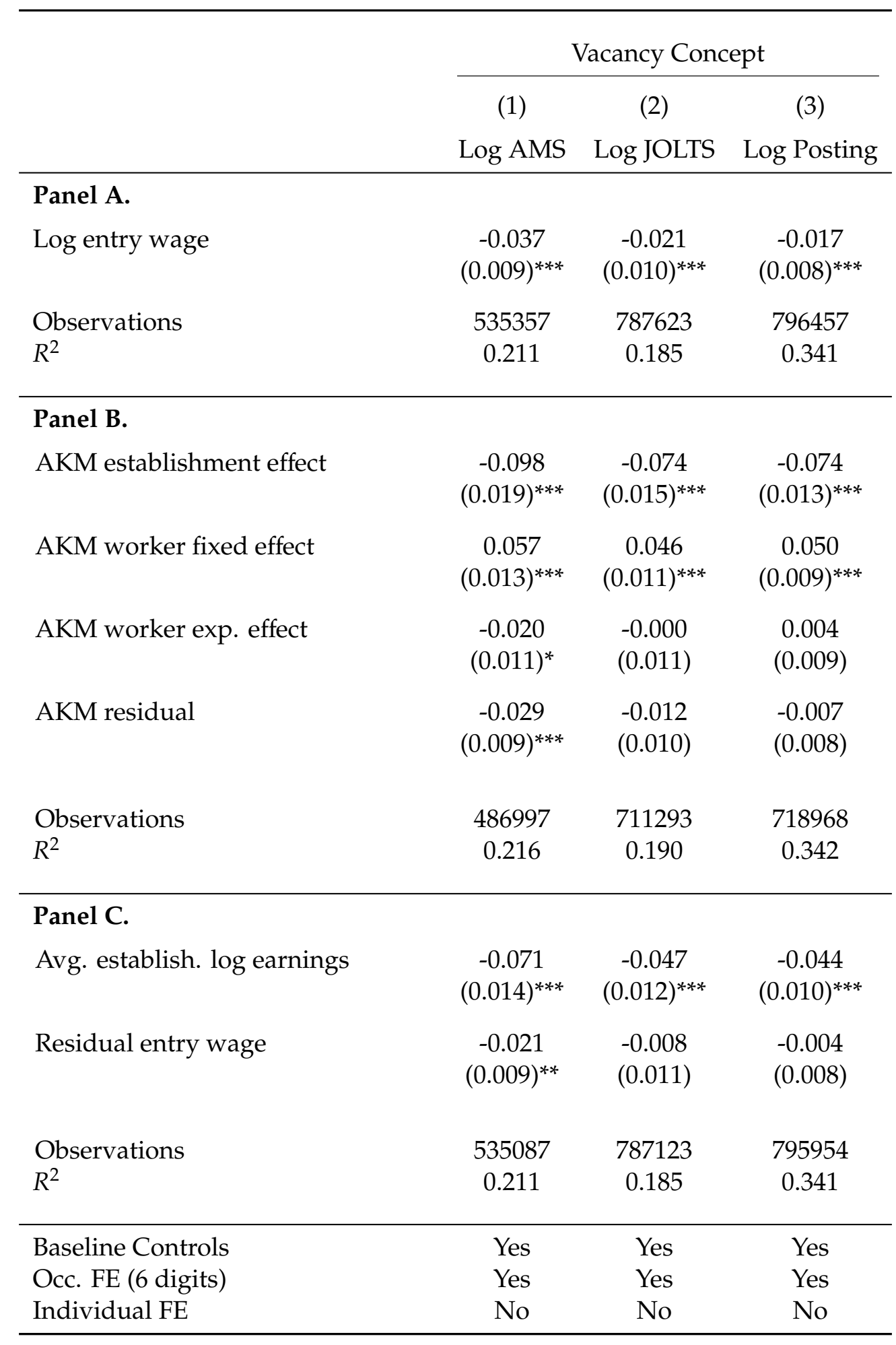

Notes: Authors' regressions with the worker sample for the years 1997-2014. Standard errors are clustered at the establishment level. The results in Column (1) are the same as the results in Column 3 of Table 5, whereas the other columns report results with different dependent variables: Column (2) uses the log of JOLTS duration; Column (3) uses the log of duration since posting as dependent variable. See footnote of Table 5 for further details regarding the control variables. 
An alternative robustness check in Table C8 is based on the subsample of observations where we can rely on at least 10 observations per worker and 10 observations per firm in the earnings regression retrieving AKM worker and AKM establishment effects. This yields slightly stronger association on AKM worker fixed- and experience-effects, but almost no change in the association of vacancy durations and AKM establishment effects. Finally, we report results where we split the sample by establishment size. We find that the coefficient on the AKM establishment coefficient is very similar for both small and large establishments. This is reassuring given that large establishments are somewhat under-represented in our sample, and it suggests that our main results would not change if we had more large establishments in our sample. Overall, our robustness checks confirm that the estimates presented in Tables 4 and 5 are stable and of similar size.

We conclude that our vacancy-employer-employee data reveal a clear-cut and robust relationship between vacancy durations and entry wages: vacancy durations bear a negative association with entry wages and firm-wage premia, though the economic significance of these effects are small. Moreover, vacancies filled by high-wage workers are associated with longer vacancy durations, pointing to the importance of worker-heterogeneity to explain observed vacancy durations.

\section{Implications for Search-Theoretic Models with Wage Posting and Recruiting Intensity}

In this section, we relate our evidence on the association between entry wages and vacancy durations to predictions of search-theoretic models of the labor market and firm dynamics.

Qualitatively, our results are consistent with search models where firms post and commit to a wage offer, where high-wage offers either attract more applications (in models directed search; see Moen (1997)) or face a higher probability of acceptance (in models of random search; see Burdett and Mortensen (1998)). While our evidence cannot discriminate between these two mechanisms, both generate a negative relationship of vacancy duration with starting wages - as in our data, when we control sufficiently for worker heterogeneity. ${ }^{32}$

While these results are qualitatively consistent with models of wage posting, it is important to shed light on the quantitative implications of the measured elasticity of vacancy duration to the starting wage. A key question is whether firms' wage policies can account for the sharp rise in vacancy filling for growing firms, as documented by DFH. Their findings have been interpreted as evidence for the importance of recruiting effort in hiring, including firms' wage policies. To assess the quantitative importance of our findings, we proceed in two ways.

\footnotetext{
${ }^{32}$ The Burdett and Mortensen model generates a negative relationship of vacancy durations and wages due to the presence of on-the-job search, where employed workers on different rungs of the job ladder have different acceptance probabilities of outside offers, whereas in our data we only observe the matching process of unemployed workers. It would, however, be easy to extend the model to allow for heterogeneous values in leisure (as, e.g., in Albrecht and Axell (1984)) to generate differences in reservation wages and acceptance probabilities among the unemployed.
} 
First, we compute the patterns of vacancy filling by establishment hires rates as predicted by our elasticity of vacancy duration to entry wages. For the purpose of this analysis, we assume that changes in log duration are equal to changes in log vacancy-filling rates (with opposite sign), which holds exactly in the absence of duration dependence. We also estimate in the ASSD universe to what extent entry wages differ by hires rates. We find a positive but small relationship in the data that is robust to controlling for additional worker and establishment characteristics. We find an elasticity of entry wages to hires rates of between 0.03 (controlling for time) to 0.05 (controlling for time and establishment fixed effects), see Figure B2 in the Appendix for further details. ${ }^{33}$ Combined with this evidence, we can then use our estimated wage-duration elasticities to predict the vacancy-filling hazard by establishment hires rates. If we use our preferred elasticity of vacancy duration to entry wages of -0.04 , combined with an elasticity of entry wages to hires rates of 0.05 , this implies an elasticity of vacancy filling to hires rates of 0.002 . If we compare, e.g., an establishment with a hires rate of 0.9 to an establishment with a hires rate of 0.1 , this elasticity predicts that the vacancy-filling rate is $0.4 \%$ higher for the establishment with the hires rate of 0.9. Even if we use the elasticity of vacancy duration to the establishment component of the entry wage (-0.1), the predicted vacancy-filling rate will increase only by $1.1 \%$ for the establishment with the higher hires rate. In stark contrast, in Panel (b) of Figure 6 we replicated the DFH-type evidence with the Austrian data and found that the vacancy-filling rate increases strongly with the hires rate, with an elasticity of 0.175 , implying that establishments with a hires rate of 0.9 have a vacancy-filling rate that is $47 \%$ higher compared to establishments with a hires rate of 0.1 . This back-of-the-envelope calculation thus suggests that firms' wage policies can account only for a very small fraction of the variation in vacancy filling by establishment hiring.

Second, we evaluate the quantitative predictions of models with wage posting and contrast them to our findings. Kaas and Kircher (2015) set up a model of firm dynamics with wage posting and directed search, calibrated towards matching the facts in DFH and other relevant facts about firm dynamics. Their model is thus a natural starting point to evaluate the quantitative importance of our findings. In Appendix D.1, we re-calibrate the model of Kaas and Kircher to match the average job-filling rate and job-finding rate in the Austrian data. The implied elasticity of vacancy duration to starting wages is -17.9 , which is more than two orders of magnitude larger than our preferred estimates of the elasticity in columns 3 of Tables 4 and 5 . The implied elasticity becomes substantially smaller in a version of their model where the cost of posting a vacancy is nearly linear in vacancies. In this case, however, the model predicts a nearly flat relationship between hiring and vacancy filling and thus is inconsistent with the facts in DFH. ${ }^{34}$ This suggests that -

\footnotetext{
${ }^{33}$ The elasticity becomes somewhat smaller when we control for establishment and worker characteristics, see Figure B2 in the Appendix. These results are also consistent with the results in Carrillo-Tudela, Gartner and Kaas (2020) who find that wages increase by 4-7 log points for firms with a hires rate of 0.25 compared to those with a zero hires rate.

${ }^{34}$ In Table D4, we explore various alternative calibrations of the model and find that the model predicts a high elasticity of vacancy duration to starting wages for all of these calibrations. Table D3 also shows that there is fundamental tension between matching the DFH-type facts, summarized by the elasticity of vacancy filling to hires rates, on the one hand and our new evidence on the elasticity of vacancy duration to starting wages on the other hand.
} 
while qualitatively consistent with models of wage posting - the measured elasticity of vacancy duration to wage posting is too small to explain meaningful variation in hires rates across firms.

To conclude, both of these exercises suggest that firms' wage policies are unlikely to serve as an important recruiting instrument, at least not in a manner that is quantitatively important and could account for the patterns in vacancy filling by establishment growth and hires rates. There are, however, a number of important potential caveats to this conclusion.

First, our empirical analysis shows that worker heterogeneity is important in explaining vacancy duration and confounds the empirical relationship between starting wages and vacancy duration at the firm and job level. For this reason, in Appendix D.1 we extend the model of Kaas and Kircher to allow for ex-ante heterogeneity in productivity across workers. We calibrate workertype specific vacancy-posting costs such as to match the evidence on the relationship between vacancy duration and AKM worker fixed effects: if vacancy-posting costs are not fully proportional to worker-specific productivity, firms post more vacancies for high-productivity/high-wage workers, which lowers the filling rate per vacancy and thus lengthens vacancy duration. While this model generates an overall positive correlation between vacancy duration and starting wages, the relationship between vacancy duration and starting wages remains negative at the firm and job level. However, the relationship predicted by the model is an order of magnitude larger than measured in our data, unless we assume nearly linear vacancy-posting costs. ${ }^{35}$ Our conclusion from above - wage posting explains only little firm-level variation in vacancy filling - thus appears to be robust in a model with worker heterogeneity.

Second, there could be a potential endogeneity issue, in the sense that firms may post higher wages for vacancies they expect to take longer to fill. This type of heterogeneity in vacancy-filling rates would lead the coefficient on the entry wage and its AKM establishment effect to be biased towards zero or even a positive number. Yet, if this were the case, firms should respond also on other margins. In particular, firms expecting long vacancy durations should post further in advance of their desired start date. Our empirical results, however, are not strongly affected once we control for the duration between dates of posting and desired job start (which we observed in the data for each single vacancy). In other words, even when we line up vacancies that were posted equally early (= equally long before the desired job start date), the relationship between vacancy posting and starting wages remains similar. Furthermore, one may argue that even if firms don't respond by how much in advance they post the vacancy, firms with high quit rates may find it more difficult to fill vacancies for replacement hiring and thus post higher wages. Again, this would bias the relationship between entry wages and vacancy durations upward. Tables C7 and

The key model parameter is the elasticity of vacancy-posting costs, $\gamma$ : a high cost-elasticity implies that it is costly for growing firms to post many vacancies at once and thus they would rather rely on posting vacancies with high wage offers; a low cost-elasticity implies that growing firms would rather offer low wages and post many vacancies instead.

${ }^{35}$ To be more precise, we simulate the model and then estimate the AKM decomposition on the model simulated data. We find that in the model simulated data, vacancy duration remains highly elastic to the AKM firm effect and AKM residual. We also find this conclusion is not affected by whether our model features positive assortative matching between workers and firms or not, see Appendix Table D3 for details. 
C8 in the Appendix show, however, that the estimated elasticities remain unaffected when we control for the quintiles of average turnover at the establishment over the sample period. The fact that the coefficients are nearly unaffected when we control for turnover suggests that the potential endogeneity of the entry wage to the expected vacancy duration is a minor issue. Thus it cannot close the gap that exists between the actual patterns in vacancy filling by establishment hires rates and the ones predicted by our wage-duration elasticities.

Third, our model simulations are based on a version of the model of Kaas and Kircher with flatwage contracts. Allowing for wage-tenure contracts may break the link between starting wages and the value of a job if wage growth is inversely related to the starting wage. It is important to note here, however, that our regressions results in the empirical section are not affected when we control for wage growth on the job and the duration of the job, suggesting that the restriction to flat-wage contracts in our model is reasonable, at least in the present empirical application. Furthermore, we estimated the expected present discounted value of wage payments for each firm in the ASSD data base. We estimate the expected present discounted value of wage payments of a job based on firm-level wage-tenure profiles and industry-level tenure-separation profiles (see the Appendix C.3 for details). Table C9 in the Appendix shows that the estimated elasticity between vacancy duration and the presented discounted value is negative, but remains small.

Finally, measurement error in wages or the presence of non-wage amenities could bias the coefficients on the AKM firm effect and the residual toward zero. While measurement error is likely to be small in administrative data, the presence of non-wage amenities may attenuate the estimated relationship between entry wages and vacancy duration. E.g., recent work by Hall and Mueller (2018) and Sorkin (2018) suggests that non-wage amenities are important to understand the job-acceptance behavior of unemployed workers or worker flows across firms. In Appendix D.2, using the log-linear structure in Hall and Mueller (2018), we show that attenuation bias in our regression framework only arises when wages and non-wage amenities are negatively correlated, but are unbiased if the two are uncorrelated. Hall and Mueller (2018) estimate that wages and non-wage amenities are moderately negatively correlated, which results in a bias by a factor of 0.75. I.e., if the measured elasticity between vacancy duration and the wage is 0.10 as in Column 3 of Table 5 , then the true elasticity would be 0.13 . This remains a far cry from reconciling the two order of magnitude difference between the model prediction and its empirical counterpart. ${ }^{36}$

Overall, these results suggest that firms are not using posted wages as an active recruiting device, at least not in a manner that is quantitatively large enough to explain the sharp increase in vacancy filling for growing firms. Rather, the results in DFH - and our replication of their results appear to be driven by other channels of recruiting effort, as in Gavazza et al. (2018), or by growing firms relaxing their hiring standards, as in Sedlacek (2014) and Carrillo-Tudela et al. (2020).

\footnotetext{
${ }^{36}$ Hall and Mueller (2018) assume that the flow value of the job $v$ is the sum of the wage $y$ and the non-wage amenity $n$, where the latter is correlated with wages according to $n=\eta-\kappa(y-\bar{y})$ and where $\eta$ is the idiosyncratic component of the non-wage amenity, $\kappa$ determines the negative correlation with $y$ and $\bar{y}$ is the mean wage. We show in Appendix D. 2 that the OLS regression coefficient of log duration on starting wages is downward biased by a factor $1-\kappa$ relative to the coefficient of a regression of $\log$ duration on the total job value $v$. Hall and Mueller (2018) estimate that $\kappa=0.25$.
} 


\section{Conclusion}

In this paper, we study how vacancy durations are related to entry wages of workers filling a position. We exploit data from a new linked data set combining information on (durations and characteristics of) individual vacancies with matched employer-employee data. The resulting vacancy-employer-employee dataset allows us to link vacancy information to the employment dynamics (growth, hirings, separations) of the posting firm as well as to the wages of the workers eventually filling a vacancy. Exploiting the link of the vacancy to the worker allows us to study the association between vacancy durations and entry wages. We find that starting wages and vacancy durations are positively correlated in raw data, but the correlation turns negative when controlling sufficiently for worker-level heterogeneity. Moreover, we find that the negative association is particularly strong with the establishment component of the starting wage.

The link of the vacancy to the firm also allows us to replicate in the Austrian data the results of Davis, Faberman and Haltiwanger (2013) that growing firms fill their vacancies faster. DFH's evidence suggests that firms rely heavily on additional instruments to recruit workers, with important implications for aggregate labor market dynamics and shifts in the Beveridge curve. While we find a negative association between entry wages and vacancy duration, we argue that the estimated elasticity remains economically small. We find that the elasticity between the entry wage and vacancy duration is at least an order of magnitude too small to account for the substantial variation of matching efficiency that exists across establishments. Overall, our findings thus suggest that firms' wage policies do not constitute an important margin of recruiting effort. Instead, hiring standards or other channels of recruiting effort such as spending on third-party recruiters, employee referral systems, professional networking sites, recruiting events, etc., are likely to be more important drivers of matching efficiency. Gavazza, Mongey and Violante (2018) also show that the way recruiting effort is modelled has important and distinct implications for the evolution aggregate matching efficiency over the business cycle. For these reasons, we believe that more empirical and theoretical research on the different potential channels of recruiting effort is a promising area for future research.

\section{References}

Abowd, John M., Francis Kramarz, and David N. Margolis, "High Wage Workers and High Wage Firms," Econometrica, 1999, 67 (2), 251-334.

Abraham, Katharine G, "Structural-Frictional vs. Deficient Demand Unemployment: Some New Evidence," American Economic Review, 1983, 73 (4), 708-24.

Abraham, Katharine G., "Help-Wanted Advertising, Job Vacancies, and Unemployment," Brookings Papers on Economic Activity, 1987, 18 (1), 207-248.

Albrecht, James, Bruno Decreuse, and Susan Vroman, "Directed Search and Phantom Vacancies," Mimeo, 2019. 
Albrecht, James W. and Bo Axell, "An Equilibrium Model of Search Unemployment," Journal of Political Economy, 1984, 92 (5), 824-840.

Alvarez, Fernando, Katarina Borovickova, and Robert Shimer, "The Proportional Hazard Model:

Estimation and Testing using Price Change and Labor Market Data," NBER Working Paper No. 22188, 2016.

AMS, "Geschäftsbericht 2017, Trendwende am Arbeitsmarkt.," 2018.

Andrews, M. J., S. Bradley, D. Stott, and R. Upward, "Successful Employer Search? An Empirical Analysis of Vacancy Duration Using Micro Data," Economica, 2008, 75 (299), 455-480.

Bagger, Jesper, Francois Fontaine, Manolis Galenianos, and Ija Trapeznikova, "Vacancies, Employment Outcomes and Firm Growth: Evidence From Denmark," Mimeo, 2020.

Banfi, Stefano and Benjamin Villena-Roldan, "Do High-Wage Jobs Attract More Applicants?

Directed Search Evidence from the Online Labor Market," Journal of Labor Economics, 2019, 37 (3), 715-746.

Barnichon, Regis, "Building a composite Help-Wanted Index," Economics Letters, 2010, 109 (3), 175-178.

Barron, John M, Mark C Berger, and Dan A Black, "Employer Search, Training, and Vacancy Duration," Economic Inquiry, 1999, 35 (1), 167-192.

Belot, Michele, Philipp Kircher, and Paul Muller, "How Wage Announcements Affect Job Search Behavior: A Field Experiment," IZA Discussion Paper Series No. 11814, 2018.

Berman, Eli, "Help Wanted, Job Needed: Estimates of a Matching Function from Employment Service Data," Journal of Labor Economics, 1997, 15 (1), S251-92.

Blanchard, Oliver Jean and Peter Diamond, "The Beveridge Curve," Brookings Papers on Economic Activity, 1989, 20 (1), 1-76.

Borovickova, Katarina and Robert Shimer, "High Wage Workers Work for High Wage Firms," NBER Worker Paper No. 24074, 2019.

Burdett, Kenneth and Dale T. Mortensen, "Wage Differentials, Employer Size,and Unemployment," International Economic Review, 1998, 39 (2), 257-273. and Elizabeth J Cunningham, "Toward a Theory of Vacancies," Journal of Labor Economics, 1998, 16 (3), 445-78.

Card, David, David S. Lee, Zhuan Pei, and Andrea Weber, "Inference on Causal Effects in a Generalized Regression Kink Design," Econometrica, 2015, 83 (6), 2453-2483.

__ , Fabrizio Colella, and Rafael Lalive, “Does Stated Gender Preference Affect Recruiting?," Mimeo, University of Lausanne, 2018.

, Jörg Heining, and Patrick Kline, "Workplace Heterogeneity and the Rise of West German Wage Inequality," Quarterly Journal of Economics, 2013, 128 (3), 967-1015.

, Raj Chetty, and Andrea Weber, "Cash-On-Hand and Competing Models of Intertemporal Behavior: New Evidence from the Labor Market," Quarterly Journal of Economics, 2007, 122 (4), 1511-1560.

Carrillo-Tudela, Carlos, Hermann Gartner, and Leo Kaas, "Recruiting Policies, Job Filling Rates, and Matching Efficiency," CEPR Discussion Paper No. 14727, 2020. 
Coles, Melvyn G and Eric Smith, "Cross-Section Estimation of the Matching Function: Evidence from England and Wales," Economica, 1996, 63 (252), 589-97. and ___ "Marketplaces and Matching," International Economic Review, 1998, 39 (1), 239-54.

Davis, Steven J., "The Quality Distribution of Jobs and the Structure of Wages in Search Equilibrium," NBER Working Paper No. 8434, 2001. and Brenda Samaniego de la Parra, "Application Flows," Mimeo, 2017.

, Christof Röttger, Anja Warning, and Enzo Weber, “Job Recruitment and Vacancy Durations in Germany," Regensburger Diskussionsbeiträge zur Wirtschaftswissenschaft No. 481, 2014.

, R. Jason Faberman, and John C. Haltiwanger, "The Establishment-Level Behavior of Vacancies and Hiring," Quarterly Journal of Economics, 2013, 128 (2), 581-622.

Dickerson, Andy, "The Distribution and Determinants of Job Vacancies: Evidence From the 2001 Employers Skill Survey," Royal Economic Society Annual Conference 2003 Paper No. 63, 2003.

Edelhofer, Edith and Käthe Knittler, "Analyse der Arbeitsmarktnachfrage in Österreich," Statistische Nachrichten, November 2013, pp. 1033-1045.

Eeckhout, Jan and Philipp Kircher, "Assortative Matching With Large Firms," Econometrica, 2018, $86,85-132$.

Ehrenfried, Felix and Christian Holzner, "Dynamics and endogeneity of firms' recruitment behaviour," Labour Economics, 2019, 57, 63 - 84.

Elsby, Michael W. L., Ryan Michaels, and David Ratner, "The Beveridge Curve: A Survey," Journal of Economic Literature, 2015, 53 (3), 571-630.

Engbom, Niklas and Christian Moser, "Earnings Inequality and the Minimum Wage: Evidence from Brazil," Opportunity and Inclusive Growth Institute Working Paper No. 7, 2018.

Faberman, R. Jason and Guido Menzio, "Evidence on the Relationship between Recruiting and the Starting Wage," Labour Economics, 2018, 50, 67-79.

Gavazza, Alessandro, Simon Mongey, and Gianluca Violante, "Aggregate Recruiting Intensity," American Economic Review, 2018, 108 (8), 2088-2127.

Gorter, Cees, Peter Nijkamp, and Piet Rietveld, “Employers' Recruitment Behaviour and Vacancy Duration: An Empirical Analysis for the Dutch Labour Market," Applied Economics, 1996, 28 (11), 1463-1474.

Hall, Robert E. and Andreas I. Mueller, "Wage Dispersion and Search Behavior: The Importance of Non-Wage Job Values," Journal of Political Economy, 2018, 126 (4), 1594-1637.

Hershbein, Brad and Lisa B. Kahn, "Do Recessions Accelerate Routine-Biased Technological Change? Evidence from Vacancy Postings," American Economic Review, 2018, 108 (7), 1737-72. Holzer, Harry J, "Job Vacancy Rates in the Firm: An Empirical Analysis," Economica, 1994, 61 (241), 17-36.

Holzer, Harry J., Lawrence F. Katz, and Alan B. Krueger, "Job Queues and Wages," Quarterly Journal of Economics, 1991, 106 (3), 739-768.

Kaas, Leo and Philipp Kircher, "Efficient Firm Dynamics in a Frictional Labor Market," American Economic Review, 2015, 105 (10), 3030-60.

Kuhn, Peter, “The Internet as a Labor Market Matchmaker," IZA World of Labor, May 2014, p. 18. 
Lalive, Rafael, Jan van Ours, and Josef Zweimüller, "How Changes in Financial Incentives Affect the Duration of Unemployment," Review of Economic Studies, 2006, 73 (4), 1009-1038.

Leoni, Thomas and Wolfgang Pollan, "Lohnentwicklung und Lohnunterschiede in der Industrie seit 2000," WIFO Monatsberichte, October 2011.

Marinescu, Ioana Elean and Ronald Wolthoff, "Opening the Black Box of the Matching Function: The Power of Words," Journal of Labor Economics, 2020, 38 (2), 535-568.

Marinescu, Ioana Elena, "The General Equilibrium Impacts of Unemployment Insurance: Evidence from a Large Online Job Board," Journal of Public Economics, 2017, 150, 14-29.

Modestino, Alicia, Daniel Shoag, and Joshua Ballance, "Upskilling: Do Employers Demand Greater Skill When Workers are Plentiful?," Review of Economics and Statistics, Forthcoming.

Moen, Espen R., “Competitive Search Equilibrium," Journal of Political Economy, 1997, 105 (2), 385-411.

Mongey, Simon and Giovanni L. Violante, "Macro Recruiting Intensity from Micro Data," NBER Working Paper No. 26231, 2019.

Postel-Vinay, Fabien and Jean-Marc Robin, "Equilibrium Wage Dispersion with Worker and Employer Heterogeneity," Econometrica, 2002, 70 (6), 2295-2350.

Riese, Martin and Stefan Bruckbauer, "Die Laufzeit der offenen Stellen in Österreich 1984 1986," in: Bundesministerium für Arbeit und Soziales (Hrsg.), Die Dynamik des Arbeitsmarktes. Forschungsberichte aus Sozial- und Arbeitsmarktpolitik Nr. 19, 1987, pp. 9-62.

Sedlacek, Petr, "Match efficiency and firms' hiring standards," Journal of Monetary Economics, 2014, $62,123-133$.

Shimer, Robert, "The Cyclical Behavior of Equilibrium Unemployment and Vacancies," American Economic Review, 2005, 95 (1), 25-49.

Sorkin, Isaac, "Ranking Firms Using Revealed Preference," Quarterly Journal of Economics, 2018, 133 (3), 1331-1393.

Stiglbauer, Alfred, Florian Stahl, Rudolf Winter-Ebmer, and Josef Zweimüller, "Job Creation and Job Destruction in a Regulated Labor Market: The Case of Austria," Empirica, 2003, 30, 127-148.

Sunde, Uwe, "Empirical Matching Functions: Searchers, Vacancies, and (Un-)biased Elasticities," Economica, 2007, 74 (295), 537-560.

van Ours, Jan and Geert Ridder, "Cyclical Variation in Vacancy Durations and Vacancy Flows : An Empirical Analysis," European Economic Review, 1991, 35 (5), 1143-1155. and __ "Vacancies and the Recruitment of New Employees," Journal of Labor Economics, $1992,10(2), 138-55$.

Yashiv, Eran, "The Determinants of Equilibrium Unemployment," American Economic Review, 2000, 90 (5), 1297-1322.

Zweimüller, Josef, Rudolf Winter-Ebmer, Rafael Lalive, Andreas Kuhn, Jean-Philippe Wuellrich, Oliver Ruf, and Simon Büchi, "Austrian Social Security Database," NRN working paper No. 2009-03, 2009. 


\section{Appendix - For Online Publication}

\section{Contents}

A Data 2

A.1 Descriptive Statistics on the AMS Vacancy Database . . . . . . . . . . . . . . . 2

A.2 AMS Vacancies, ASSD Universe and OStE Survey . . . . . . . . . . . . . . . . . 4

A.3 Additional Descriptives: Vacancy Duration Concepts, Vacancy Lapses, and Business Cycle Patterns . . . . . . . . . . . . . . . . . . . . . . . . 10

B Vacancy Filling and Firm Growth 12

C Vacancy Duration and Wages on New Jobs $\quad \mathbf{1 4}$

C.1 AKM Decomposition . . . . . . . . . . . . . . . . . . . . . . 14

C.2 Additional Regression Results . . . . . . . . . . . . . . . . . . . 16

C.3 Estimating the Expected Present Discounted Value of Wages of a Job . . . . . . . . 24

D Implications for Search Theoretic Models 26

D.1 Kaas and Kircher (2015) with Ex-Ante Worker Heterogeneity . . . . . . . . . . 26

D.2 Non-Wage Amenities and Attenuation Bias . . . . . . . . . . . . . . 35 


\section{A Data}

\section{A.1 Descriptive Statistics on the AMS Vacancy Database}

Table A1: Size and structure of the AMS Vacancy Database, 19972014

\begin{tabular}{|c|c|c|c|c|}
\hline & & \multicolumn{2}{|c|}{ Vacancies } & \multirow{2}{*}{$\begin{array}{r}\text { Establishments } \\
\mathrm{N}\end{array}$} \\
\hline & & $\mathrm{N}$ & $\%$ & \\
\hline \multicolumn{5}{|c|}{ A. Vacancies by Exit Status } \\
\hline Total & & $5,291,897$ & 100 & 267,122 \\
\hline Filled Vacancies & & $4,574,340$ & 86 & 254,705 \\
\hline & by AMS & $1,234,556$ & 27 & 162,961 \\
\hline & by Others & $3,339,784$ & 73 & 229,669 \\
\hline Lapsed Vacancies & & 717,557 & 14 & 110,129 \\
\hline \multicolumn{5}{|c|}{ B. Multiple Vacancies } \\
\hline Total & & $5,291,897$ & 100 & 267,122 \\
\hline Single Vacancies & & $1,417,461$ & 27 & 245,934 \\
\hline \multirow[t]{3}{*}{ Multiple Vacancies } & & $3,874,436$ & 73 & 139,300 \\
\hline & Identical & $2,148,453$ & 55 & 93,114 \\
\hline & Not Identical & $1,725,983$ & 45 & 109,186 \\
\hline
\end{tabular}

Notes: Number of vacancies and number of distinct establishments in the AMS universe 1997-2014. Right-censored vacancies are vacancies still in progress in 2014-2, while left-censored spells are vacancies without an inflow in the sample period.

One common issue with job board data is that firms post one vacancy but intend to hire multiple workers for that position. Survey data such as the JOLTS have an advantage in this respect, as they collect information on the number of open positions and do not rely on the number of postings. Luckily, the AMS asks firms about the number of open positions and records multiple and possibly identical vacancies as separate entries in the data. It makes this effort because it would like to know many unemployed workers can be matched to the firm. Figure A1 shows (employmentweighted) distribution of the number of vacancies by firm in a typical month, weighted by the employment share of each firm. About $50 \%$ of employment is in establishments posting exactly one vacancy, $18 \%$ post two vacancies and the remainder of firms posts three or more vacancies. ${ }^{1}$ We also find that many of the multiple vacancies are indeed identical: among firms that post at least two vacancies in a given month, $55 \%$ of vacancies have a twin-sister vacancy, meaning

\footnotetext{
${ }^{1}$ We also find that $77 \%$ of firms in our firm sample do not have any vacancy open in a typical month.
} 
Figure A1: Distribution of Number of Vacancies by Firm and Month

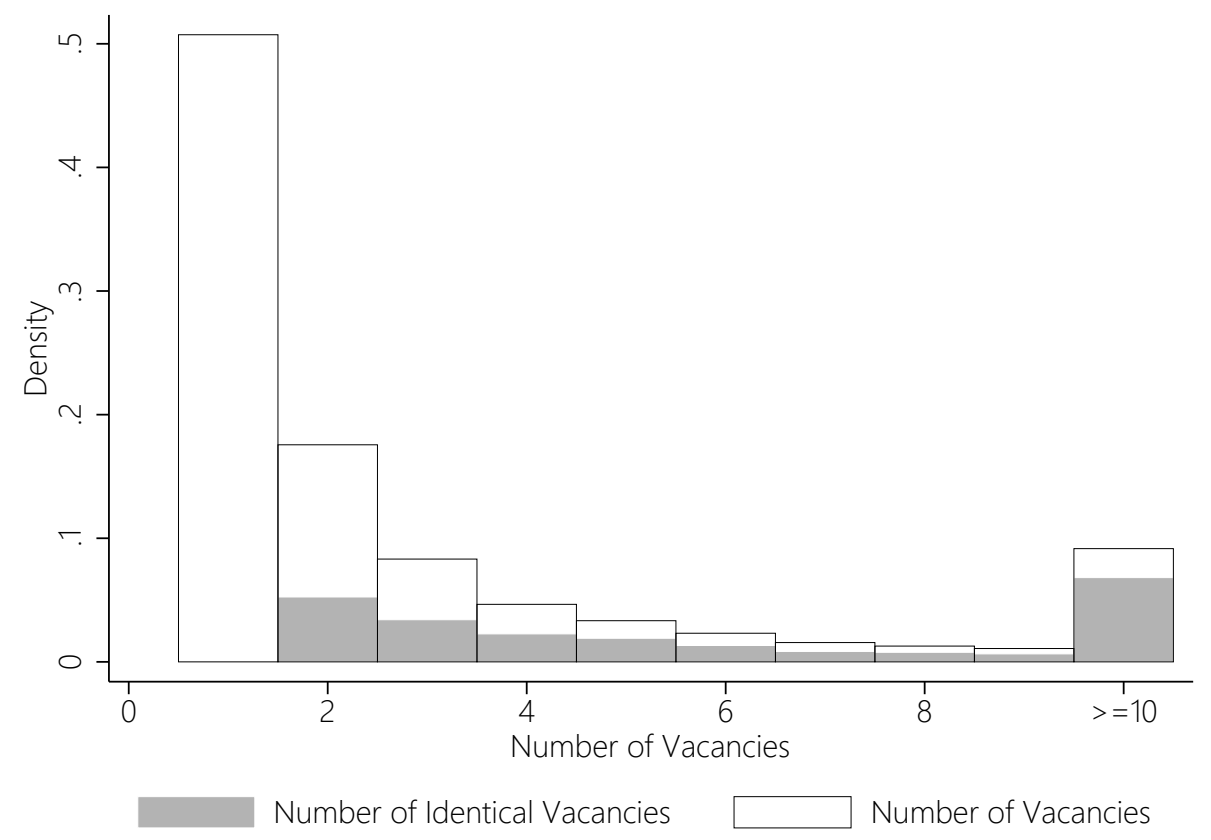

Notes: Employment weighted distribution of number of vacancies by firm and month in the matched firm sample for immediately available vacancy outflows 1997-2014.

that all characteristics of the vacancy are identical (but not the vacancy outcomes such as vacancy duration). As can be seen in Figure A1, the share of identical vacancies is particularly high among firms that post 10 vacancies or more in a given month. 


\section{A.2 AMS Vacancies, ASSD Universe and OStE Survey}

Figure A2: Filled AMS Vacancy Outflows and ASSD Hires from Unemployment

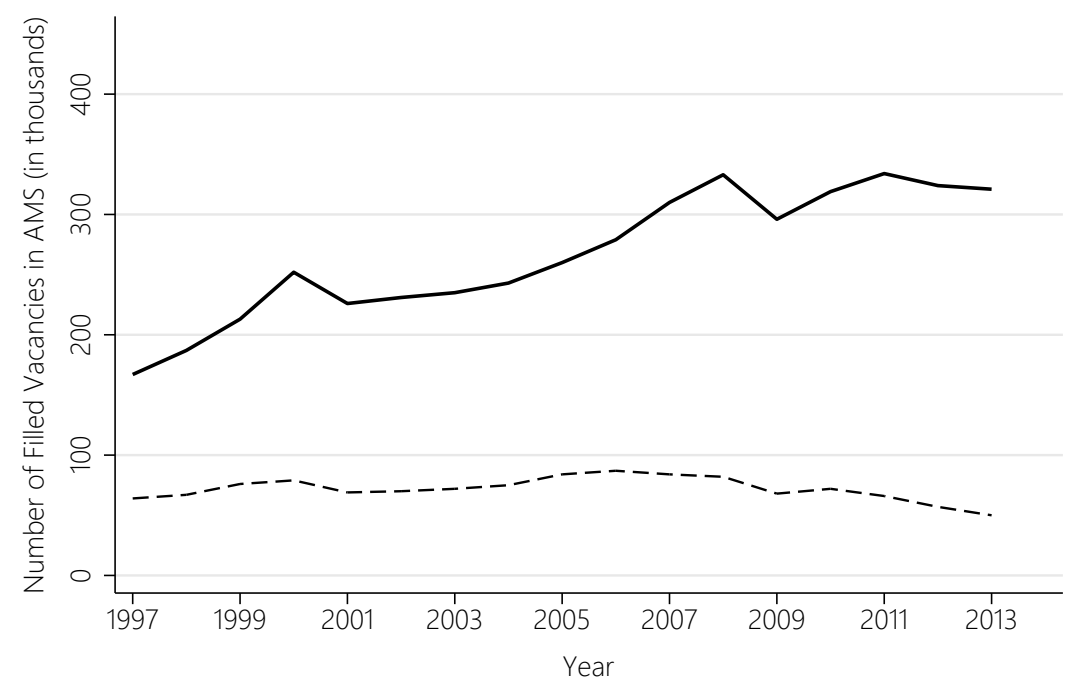

All Filled Outflows - - - - - AMS Filled Outflows

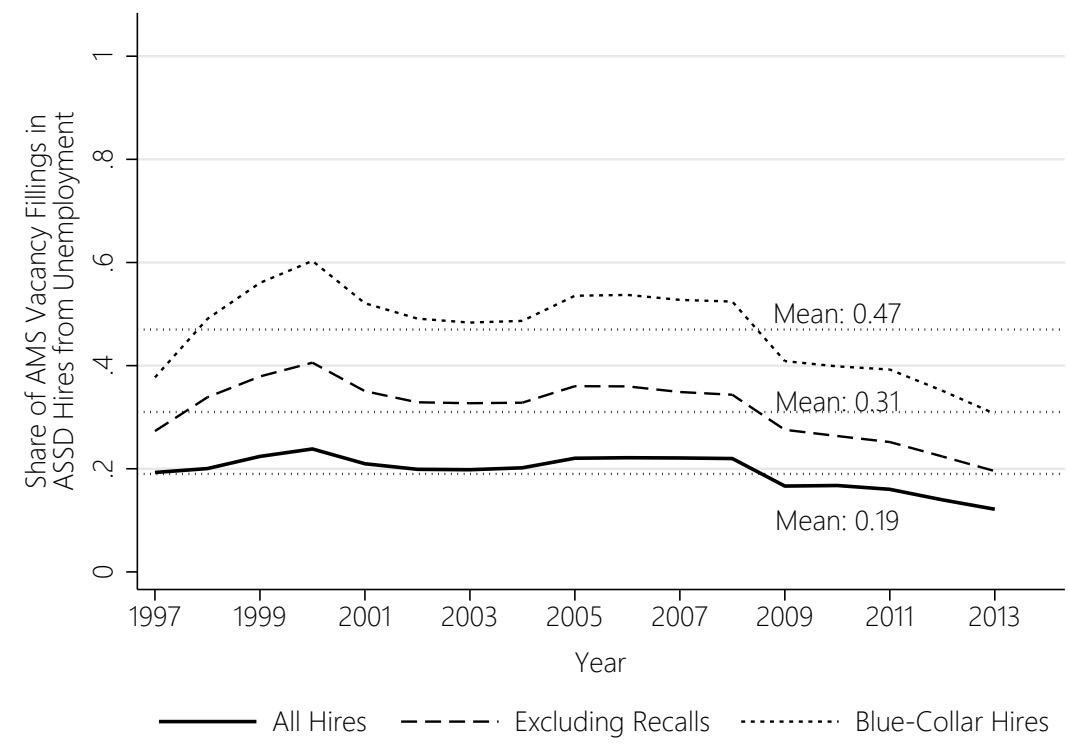

Notes: Panel (a) shows the number of filled vacancy outflows in the AMS (in thousands) 19972013, while Panel (b) shows the number of vacancy outflows filled through the AMS as a share of ASSD hires from unemployment. The solid line shows filled vacancy outflows as a share of all hires from unemployment, while the dashed line exclude recalls and the dotted line only considers hires from unemployment into blue-collar jobs excluding recalls. 
Table A2: Employment Shares: ASSD Universe versus Matched Firm Sample

\begin{tabular}{|c|c|c|}
\hline & \multicolumn{2}{|c|}{ Employment Share } \\
\hline & $\begin{array}{r}\text { ASSD } \\
\text { Universe }\end{array}$ & $\begin{array}{r}\text { Firm } \\
\text { Sample }\end{array}$ \\
\hline Austrian Sample & 100.00 & 100.00 \\
\hline \multicolumn{3}{|l|}{ Major industry } \\
\hline Agriculture, forestry, and fishing & 1.50 & 0.11 \\
\hline Manufacturing, mining, and quarrying & 17.43 & 25.55 \\
\hline Construction & 7.31 & 9.49 \\
\hline Wholesale and retail trade & 15.77 & 16.27 \\
\hline Tourism, hotels, and restaurants & 5.72 & 6.33 \\
\hline Transportation, information, and communication & 8.29 & 6.15 \\
\hline Finance and insurance & 3.49 & 3.85 \\
\hline Education, health, and social services & 8.37 & 7.46 \\
\hline Other services & 30.64 & 23.68 \\
\hline \multicolumn{3}{|l|}{ Establishment size classes } \\
\hline 0 to 9 employees & 19.73 & 10.20 \\
\hline 10 to 49 employees & 21.31 & 24.07 \\
\hline 50 to 249 employees & 20.90 & 26.89 \\
\hline 250 to 999 employees & 16.33 & 21.41 \\
\hline more than 1000 employees & 21.73 & 17.44 \\
\hline \multicolumn{3}{|l|}{ Worker turnover category } \\
\hline No Turnover & 23.67 & 16.10 \\
\hline First Quintile & 15.27 & 16.90 \\
\hline Second Quintile & 15.30 & 16.95 \\
\hline Third Quintile & 15.40 & 16.71 \\
\hline Fourth Quintile & 15.08 & 16.91 \\
\hline Fifth Quintile & 15.27 & 16.44 \\
\hline \multicolumn{3}{|c|}{ Establishment Wage Fixed Effects Quartiles } \\
\hline First Quartile & 4.27 & 6.93 \\
\hline Second Quartile & 10.44 & 16.24 \\
\hline Third Quartile & 29.53 & 27.46 \\
\hline Fourth Quartile & 49.53 & 49.24 \\
\hline \multicolumn{3}{|l|}{ Number of Observations } \\
\hline Number of Vacancies & 0 & $2,820,511$ \\
\hline Number of Establishments & $1,601,249$ & 109,855 \\
\hline Number of Firm-Month & $79,582,304$ & $14,450,183$ \\
\hline
\end{tabular}

Notes: Employment shares based on ASSD data for the ASSD universe and the firm sample 1997-2014. 
Table A3: Monthly Hires and Separation Rates: ASSD Universe versus Matched Firm Sample

\begin{tabular}{|c|c|c|c|c|}
\hline & \multicolumn{2}{|c|}{ ASSD } & \multicolumn{2}{|c|}{ Firm } \\
\hline & Hires & Sep. & Hires & Sep. \\
\hline Austrian Sample & 4.38 & 4.28 & 4.17 & 3.86 \\
\hline \multicolumn{5}{|l|}{ Major industry } \\
\hline Agriculture, forestry, and fishing & 15.88 & 15.67 & 11.12 & 10.71 \\
\hline Manufacturing, mining, and quarrying & 2.62 & 2.63 & 2.51 & 2.29 \\
\hline Construction & 6.10 & 6.18 & 5.52 & 5.34 \\
\hline Wholesale and retail trade & 3.62 & 3.55 & 3.38 & 3.02 \\
\hline Tourism, hotels, and restaurants & 11.37 & 11.18 & 11.70 & 11.24 \\
\hline Transportation, information, and communication & 3.92 & 3.85 & 4.64 & 4.18 \\
\hline Finance and insurance & 2.10 & 2.09 & 1.98 & 1.76 \\
\hline Education, health, and social services & 4.02 & 3.74 & 4.01 & 3.52 \\
\hline Other services & 4.04 & 3.88 & 4.29 & 3.99 \\
\hline \multicolumn{5}{|c|}{ Establishment size classes } \\
\hline 0 to 9 employees & 6.35 & 6.23 & 6.54 & 6.01 \\
\hline 10 to 49 employees & 5.53 & 5.43 & 5.33 & 4.98 \\
\hline 50 to 249 employees & 4.40 & 4.31 & 4.19 & 3.90 \\
\hline 250 to 999 employees & 3.46 & 3.35 & 3.23 & 2.97 \\
\hline more than 1000 employees & 2.14 & 2.06 & 2.29 & 2.08 \\
\hline \multicolumn{5}{|c|}{ Worker turnover category } \\
\hline No Turnover & 0.00 & 0.00 & 0.00 & 0.00 \\
\hline First Quintile & 0.34 & 0.50 & 0.55 & 0.65 \\
\hline Second Quintile & 1.11 & 1.19 & 1.34 & 1.36 \\
\hline Third Quintile & 2.29 & 2.26 & 2.45 & 2.37 \\
\hline Fourth Quintile & 4.78 & 4.57 & 4.61 & 4.33 \\
\hline Fifth Quintile & 20.33 & 19.47 & 16.36 & 14.65 \\
\hline \multicolumn{5}{|c|}{ Establishment Wage Fixed Effects Quartiles } \\
\hline First Quartile & 8.21 & 8.03 & 6.27 & 5.75 \\
\hline Second Quartile & 5.99 & 5.89 & 4.73 & 4.42 \\
\hline Third Quartile & 4.41 & 4.39 & 4.37 & 4.11 \\
\hline Fourth Quartile & 3.43 & 3.29 & 3.52 & 3.21 \\
\hline \multicolumn{5}{|c|}{ Number of Observations } \\
\hline Number of Vacancies & & 0 & \multicolumn{2}{|c|}{$2,820,511$} \\
\hline Number of Establishments & \multirow{2}{*}{\multicolumn{2}{|c|}{$\begin{array}{r}1,601,249 \\
79,582,304\end{array}$}} & \multicolumn{2}{|c|}{109,855} \\
\hline Number of Firm-Month & & & \multicolumn{2}{|c|}{$14,450,183$} \\
\hline
\end{tabular}

Notes: Hires and separation rates based on ASSD data for the ASSD universe and the firm sample 1997-2014. 
Table A4: Vacancy Rates and Vacancy Yields by Industry, Size, Turnover, and Wage Fixed Effect

\begin{tabular}{|c|c|c|c|c|}
\hline & \multicolumn{2}{|c|}{ Vacancy rate } & \multicolumn{2}{|c|}{ Vacancy yield } \\
\hline & \multicolumn{2}{|r|}{ Immediately } & \multicolumn{2}{|r|}{ Immediately } \\
\hline Austrian Sample & 1.18 & 0.76 & 3.73 & 5.68 \\
\hline DFH & 2.5 & . & 1.3 & \\
\hline \multicolumn{5}{|c|}{ Major industry } \\
\hline Agriculture, forestry, and fishing & 1.46 & 0.94 & 20.22 & 43.36 \\
\hline Manufacturing, mining, and quarrying & 0.72 & 0.51 & 3.58 & 5.11 \\
\hline Construction & 1.24 & 0.95 & 4.34 & 5.99 \\
\hline Wholesale and retail trade & 0.79 & 0.53 & 4.42 & 6.63 \\
\hline Tourism, hotels, and restaurants & 4.31 & 1.95 & 3.18 & 6.23 \\
\hline Transportation, information, and communication & 1.02 & 0.64 & 4.88 & 7.83 \\
\hline Finance and insurance & 0.55 & 0.39 & 3.80 & 5.31 \\
\hline Education, health, and social services & 0.56 & 0.29 & 7.34 & 15.07 \\
\hline Other services & 1.48 & 1.09 & 3.53 & 4.74 \\
\hline \multicolumn{5}{|c|}{ Establishment size classes } \\
\hline 0 to 9 employees & 3.40 & 1.88 & 2.03 & 3.60 \\
\hline 10 to 49 employees & 1.49 & 1.03 & 3.72 & 5.38 \\
\hline 50 to 249 employees & 1.04 & 0.75 & 4.52 & 6.21 \\
\hline 250 to 999 employees & 0.54 & 0.37 & 6.62 & 9.59 \\
\hline more than 1000 employees & 0.40 & 0.25 & 6.78 & 11.03 \\
\hline \multicolumn{5}{|c|}{ Worker turnover category } \\
\hline No Turnover & 1.38 & 0.85 & 0.00 & 0.00 \\
\hline First Quintile & 0.27 & 0.16 & 2.74 & 4.70 \\
\hline Second Quintile & 0.45 & 0.29 & 3.38 & 5.28 \\
\hline Third Quintile & 0.63 & 0.41 & 4.18 & 6.30 \\
\hline Fourth Quintile & 1.01 & 0.70 & 5.02 & 7.22 \\
\hline Fifth Quintile & 3.27 & 2.24 & 5.56 & 7.96 \\
\hline \multicolumn{5}{|c|}{ Establishment Wage Fixed Effects Quartiles } \\
\hline First Quartile & 1.43 & 0.92 & 4.54 & 7.35 \\
\hline Second Quartile & 1.16 & 0.76 & 4.18 & 6.49 \\
\hline Third Quartile & 1.34 & 0.89 & 3.45 & 5.13 \\
\hline Fourth Quartile & 1.04 & 0.67 & 3.74 & 5.66 \\
\hline \multicolumn{5}{|c|}{ Number of Observations } \\
\hline Number of Vacancies & $2,820,511$ & $2,758,823$ & $2,820,511$ & $2,758,823$ \\
\hline Number of Establishments & 109,855 & 109,855 & 109,855 & 109,855 \\
\hline Number of Firm-Month & $14,450,183$ & $14,450,183$ & $14,450,183$ & $14,450,183$ \\
\hline
\end{tabular}

Notes: Vacancy rate and vacancy yield based on stock vacancies for the years 1997-2014 in the firm sample. 
Table A5: Vacancy Characteristics in Representative Vacancy Survey

\begin{tabular}{|c|c|c|c|c|}
\hline & \multicolumn{2}{|c|}{ AMS Posting } & \multicolumn{2}{|c|}{ Vacancy Rate } \\
\hline & Share & Vacancies & Rate & $\begin{array}{r}\text { Firm- } \\
\text { Quarters }\end{array}$ \\
\hline \multicolumn{5}{|c|}{ Major industry } \\
\hline Manufacturing & 0.63 & 213,279 & 0.015 & 663,553 \\
\hline Construction & 0.68 & 138,647 & 0.018 & 818,335 \\
\hline Wholesale and Retail Trade & 0.56 & 248,290 & 0.010 & $1,794,662$ \\
\hline Transportation and Storage & 0.52 & 87,514 & 0.015 & 343,884 \\
\hline Accommodation and Food Service & 0.73 & 168,681 & 0.014 & $1,195,458$ \\
\hline Information and Communication & 0.34 & 81,645 & 0.019 & 256,192 \\
\hline Financial and Insurance Activities & 0.36 & 49,977 & 0.017 & 202,798 \\
\hline Real Estate Activities & 0.38 & 20,083 & 0.012 & 244,547 \\
\hline Professional, Scientific and Technical Activities & 0.37 & 142,148 & 0.017 & 951,214 \\
\hline Administrative and Support Activities & 0.73 & 206,879 & 0.018 & 292,157 \\
\hline Public Administration and Defense & 0.50 & 73,586 & 0.003 & 109,083 \\
\hline Education & 0.40 & 25,024 & 0.004 & 135,961 \\
\hline Human Health and Social Work & 0.50 & 69,314 & 0.006 & 659,357 \\
\hline Arts, Entertainment, and Recreation & 0.50 & 10,620 & 0.006 & 153,957 \\
\hline Other Service Activities & 0.63 & 36,550 & 0.012 & 445,534 \\
\hline Total & 0.57 & $1,582,518$ & 0.013 & $8,354,469$ \\
\hline \multicolumn{5}{|c|}{ Establishment size classes } \\
\hline $0-9$ & 0.55 & 426,303 & 0.013 & $6,731,647$ \\
\hline $10-49$ & 0.61 & 422,891 & 0.014 & $1,337,067$ \\
\hline 50-249 & 0.60 & 321,441 & 0.013 & 228,469 \\
\hline 250-999 & 0.58 & 190,233 & 0.009 & 45,585 \\
\hline $1,000-4,999$ & 0.55 & 142,505 & 0.007 & 10,330 \\
\hline $5000+$ & 0.47 & 79,145 & 0.006 & 1,371 \\
\hline Total & 0.57 & $1,582,518$ & 0.013 & $8,354,469$ \\
\hline \multicolumn{5}{|c|}{ Education classes } \\
\hline Compulsory School & 0.65 & 445,193 & & \\
\hline Apprentice & 0.67 & 596,890 & . & \\
\hline Secondary School & 0.53 & 74,710 & . & . \\
\hline "Meister" & 0.54 & 21,546 & . & . \\
\hline Higher School Certificate & 0.42 & 264,971 & . & \\
\hline Above Higher School Certificate & 0.31 & 176,965 & . & . \\
\hline Missing & 0.20 & 2,241 & . & . \\
\hline Total & 0.57 & $1,582,518$ & . & . \\
\hline
\end{tabular}

Notes: Share of vacancies with AMS posting and quarterly vacancy rate based on a representative vacancy survey 2009q1-2018q1 (Offene Stellenerhebung, OStE) excluding part-time, seasonal, and apprentice vacancies. 
Figure A3: Share of Vacancies with AMS Posting by Employment Growth Based on Representative Vacancy Survey

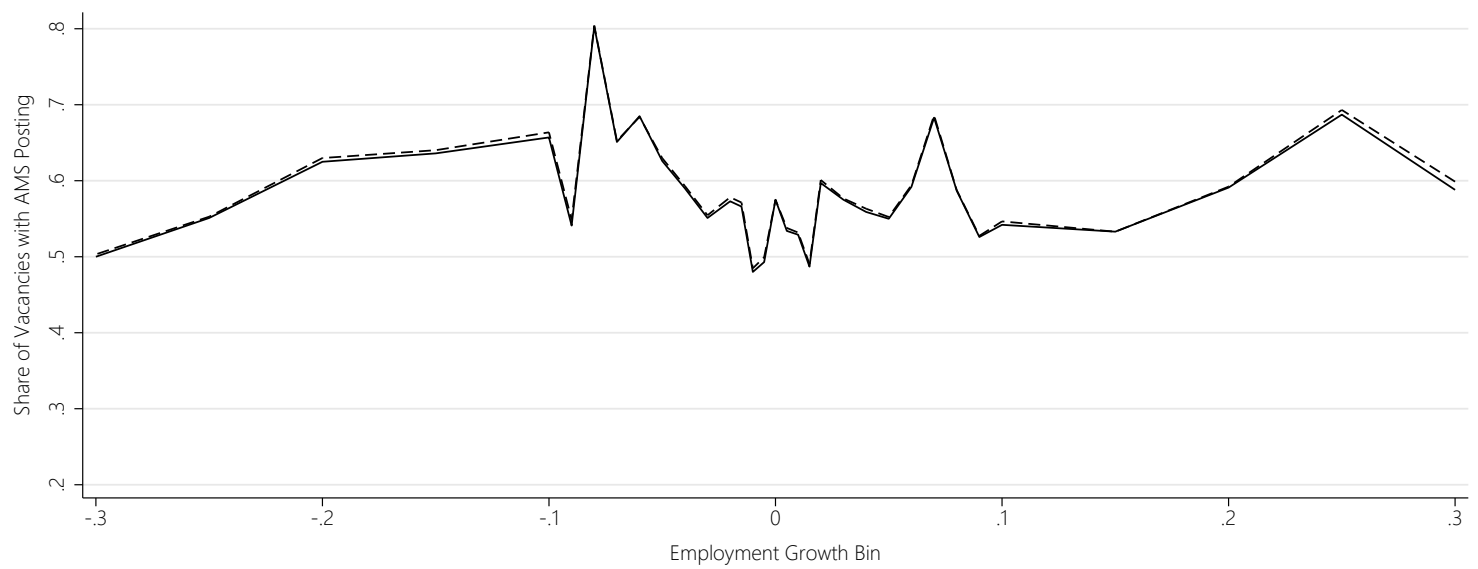

Notes: The figure shows the share of vacancies posted with the AMS by employment growth bin in a representative vacancy survey 2009q1-2018q1 (Offene Stellenerhebung, OStE) excluding part-time, seasonal, and apprentice vacancies. The solid line shows raw data and the dashed line controls for year and quarter effects. 


\section{A.3 Additional Descriptives: Vacancy Duration Concepts, Vacancy Lapses, and Business Cycle Patterns}

Figure A4: Comparison of Duration Measures Based on Exact or Proxied Posting Date

(a) Posting Duration

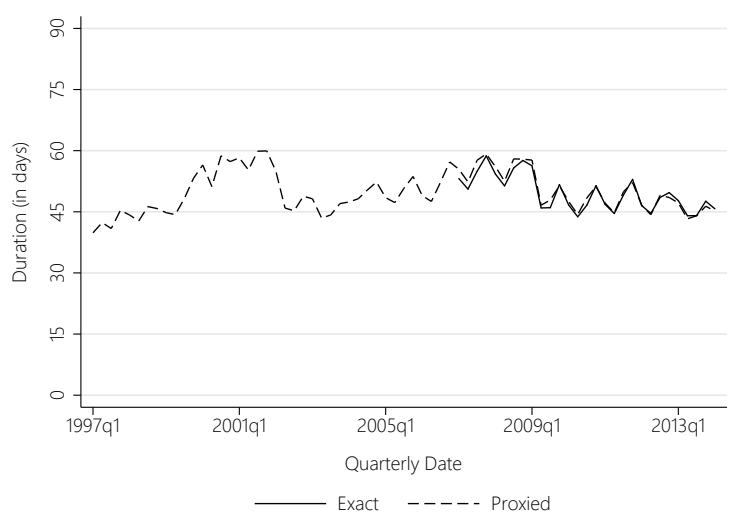

(b) JOLTS Duration

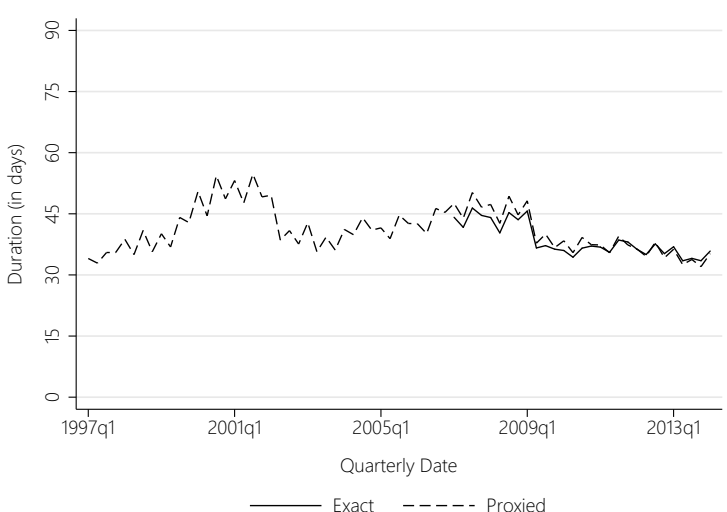

Notes: Comparison of duration measures based on exact and proxied posting date in the AMS universe for the years 1997-2014.

Figure A5: Vacancy-Filling Hazard and Vacancy Lapse Hazard, Relative to the Date of Availability of the Job

(a) Weekly Filling Hazard

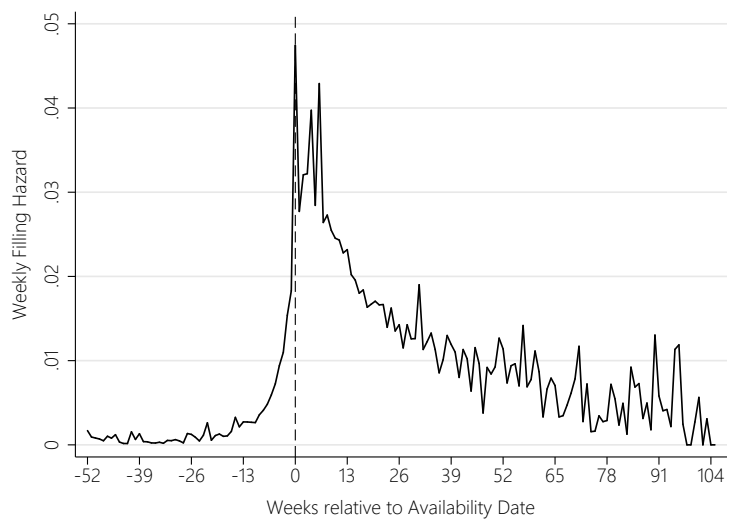

(b) Weekly Lapse Hazard

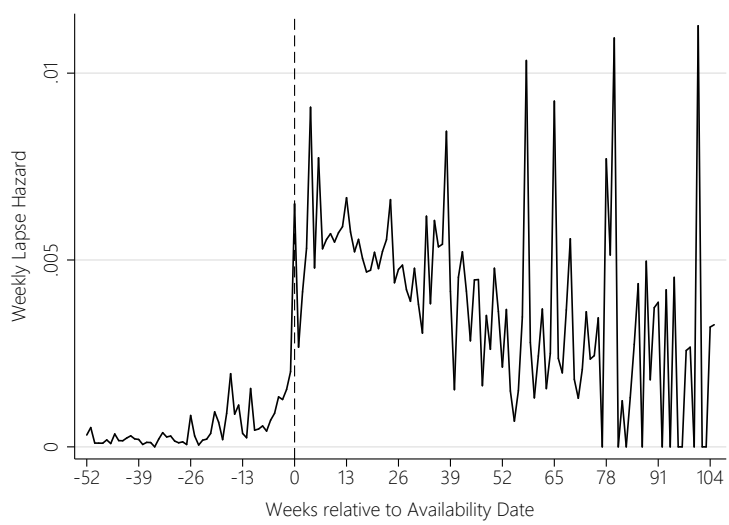

Notes: Weekly vacancy filling and lapse hazard relative to the date of the availability of the job in the AMS universe based on exact vacancy dates for the years 2007-2014. 
Figure A6: The Vacancy-Filling Hazard, the Unemployment Rate and Labor Market Tightness over Time, for All Vacancies (Left) and Immediately Available Vacancies (Right)

\section{Panel A. Vacancy-Filing Hazards and Unemployment}
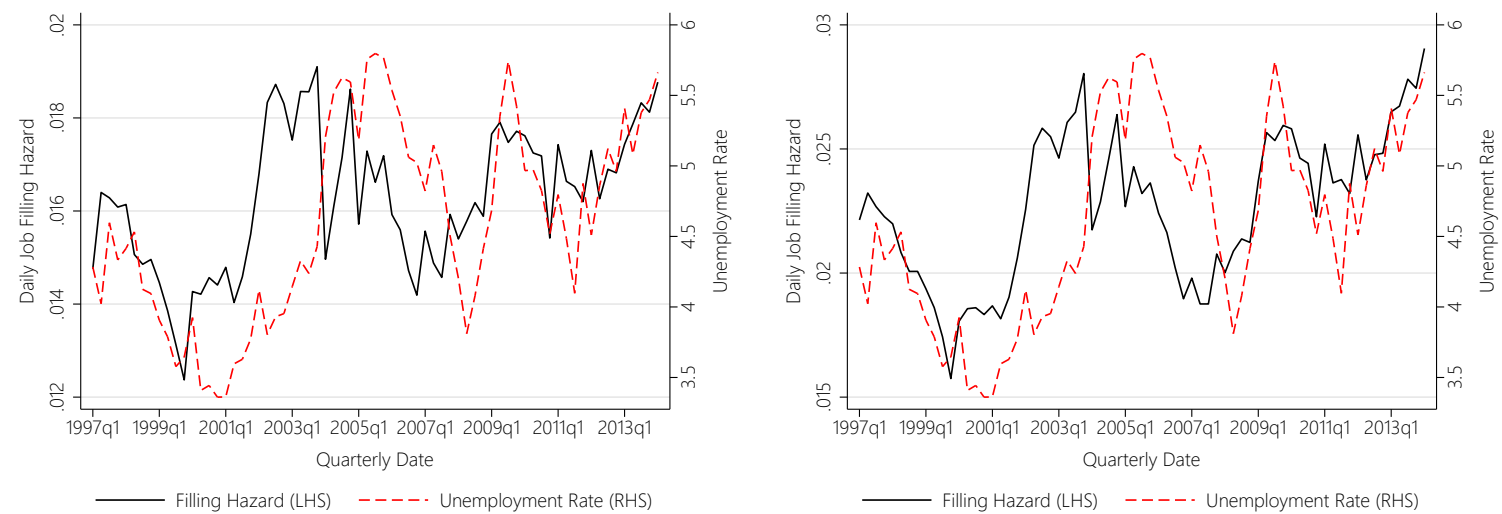

Panel B. Vacancy-Filing Hazards and Labor Market Tightness
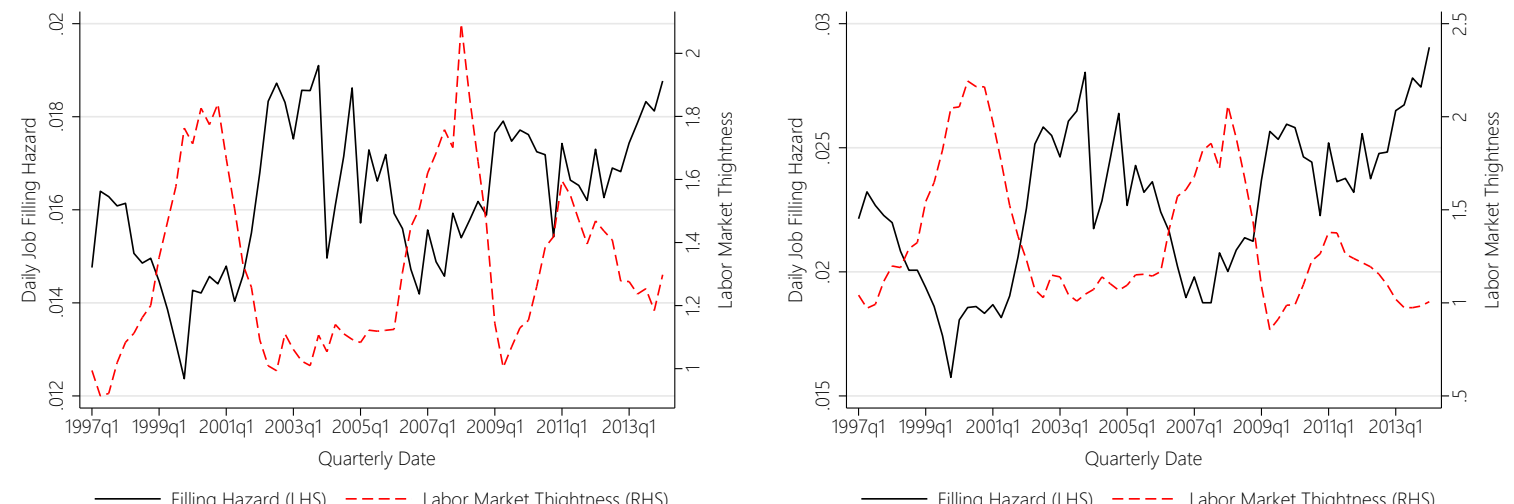

Notes: Labor Market Tightness is defined as the ratio of the stock of vacancies in the AMS data and the number of unemployed from labor force survey data (Source: OECD). Labor Market Tightness is normalized to 1 at the beginning of the sample period. The elasticity of the vacancy-filling hazard to labor market tightness is -0.47 (lower left panel) and -0.37 (lower right panel). 


\section{B Vacancy Filling and Firm Growth}

Figure B1: Vacancy Yields and Vacancy-Filling Hazards, for All Vacancies (Left) and Immediately Available Vacancies (Right)

Panel A. Vacancy Yields by Monthly Employment Growth Rates
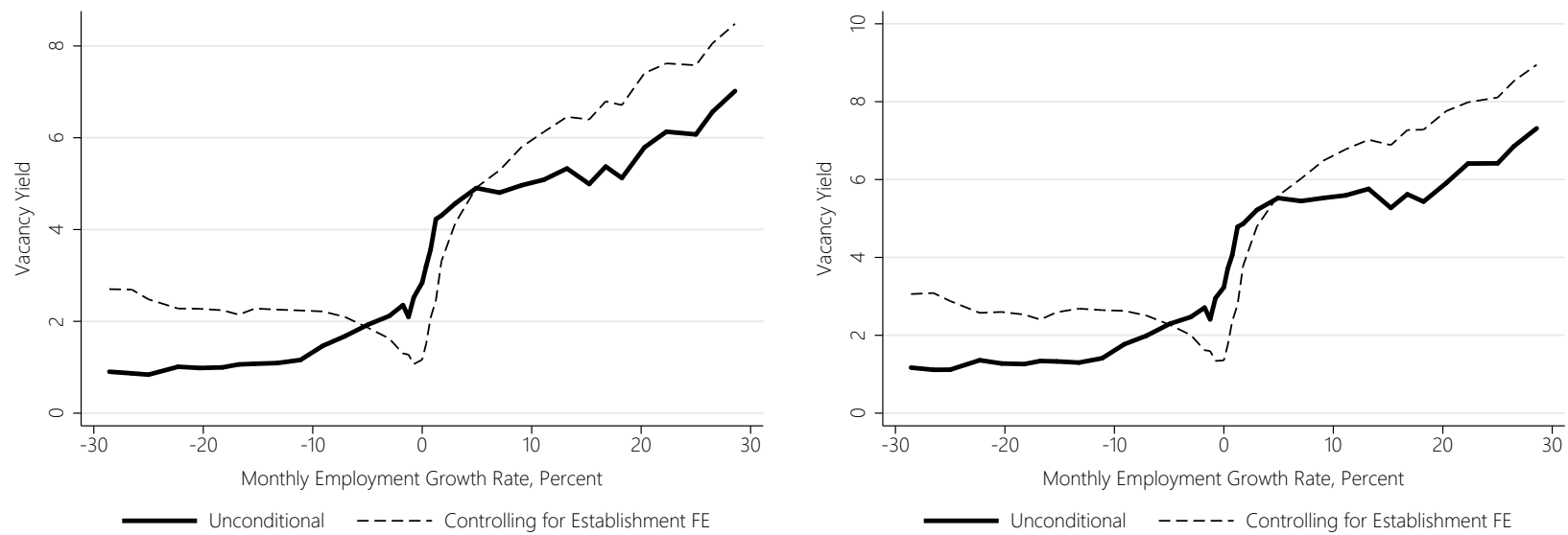

Panel B. Vacancy-Filling Hazards by Monthly Employment Growth Rates
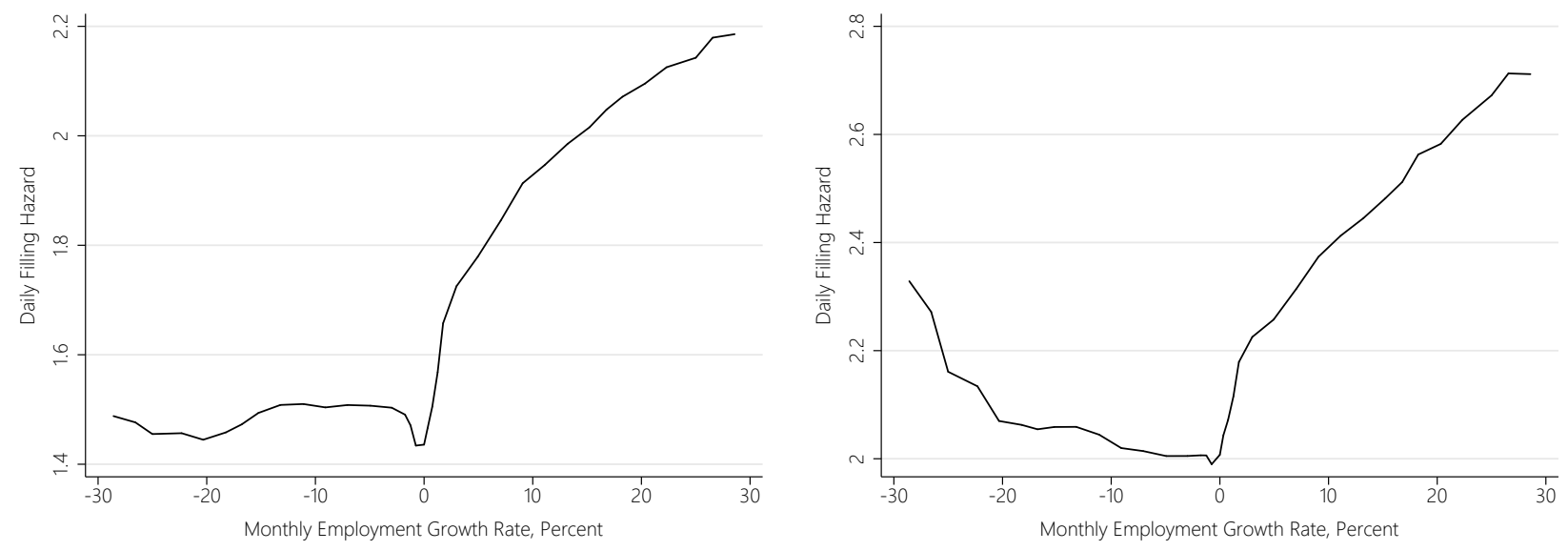

Panel C. Vacancy-Filling Hazards by Monthly Hires Rates

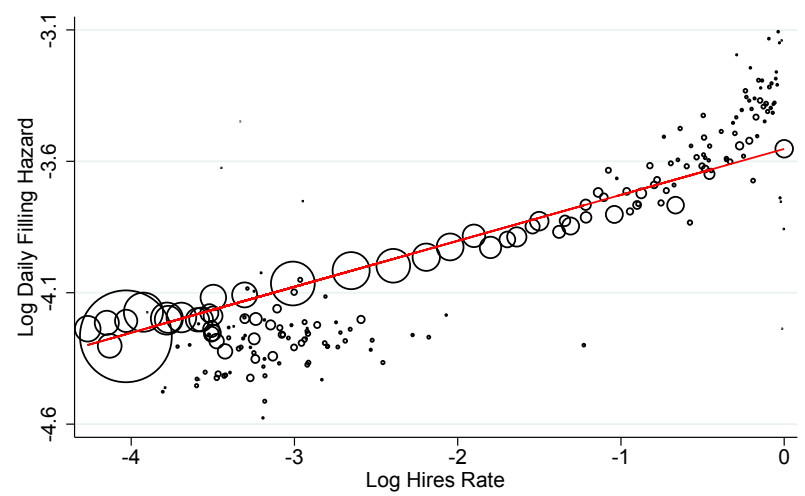

○ Log Daily Filling Hazard Hires-Weighted Least Squares Slope $($ s.e. $)=0.175(0.000)$, R-squared $=0.912$

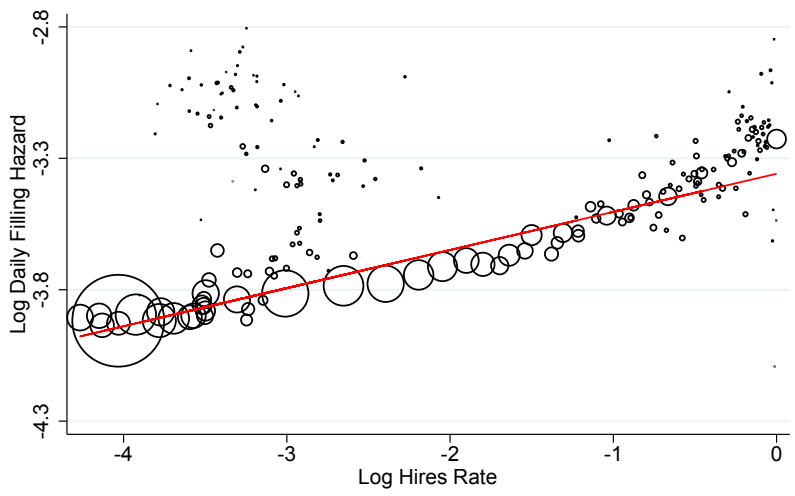

○ Log Daily Filling Hazard — Hires-Weighted Least Squares Slope $($ s.e. $)=0.145(0.000)$, R-squared $=0.857$

Notes: The left-hand-side panels show results for all vacancies, whereas the right-hand-side panels show results for immediately available vacancies. All figures are based on the matched firm sample for the years 1997-2014. 
Figure B2: Entry Wages by Monthly Hires Rate, Across and Within Establishments

\section{Panel A. Controlling for Time Only}
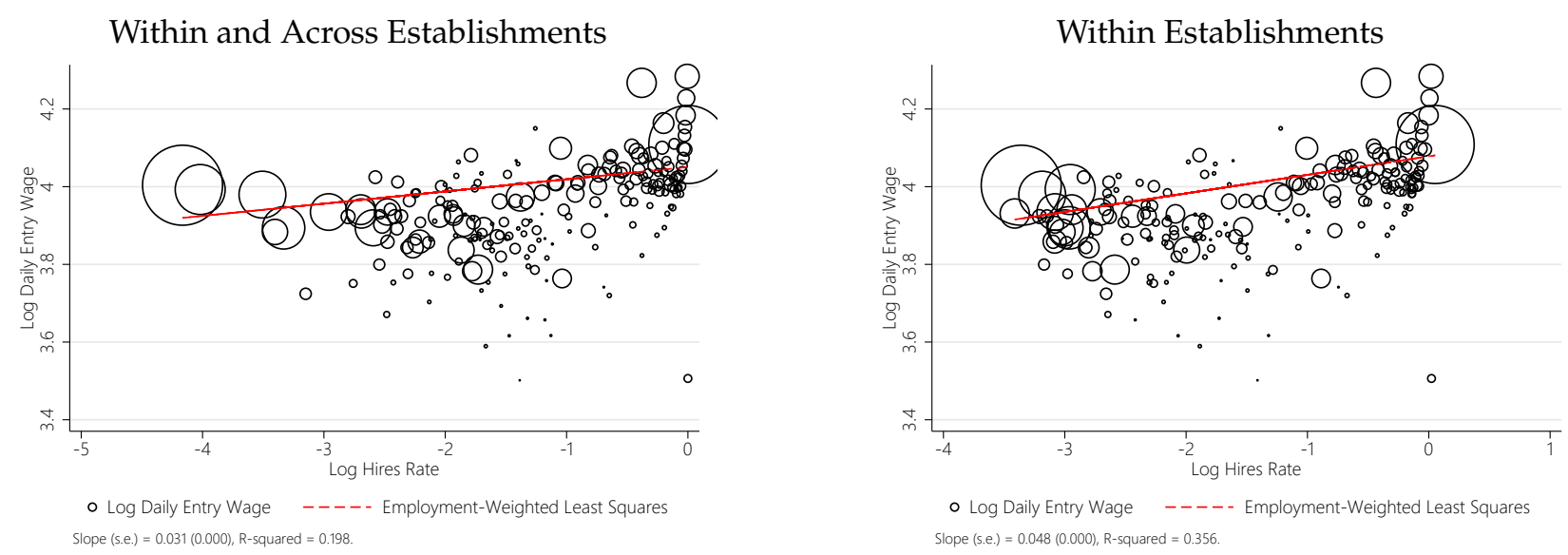

Panel B. Controlling for Establishment and Worker Characteristics and Time

Within and Across Establishments

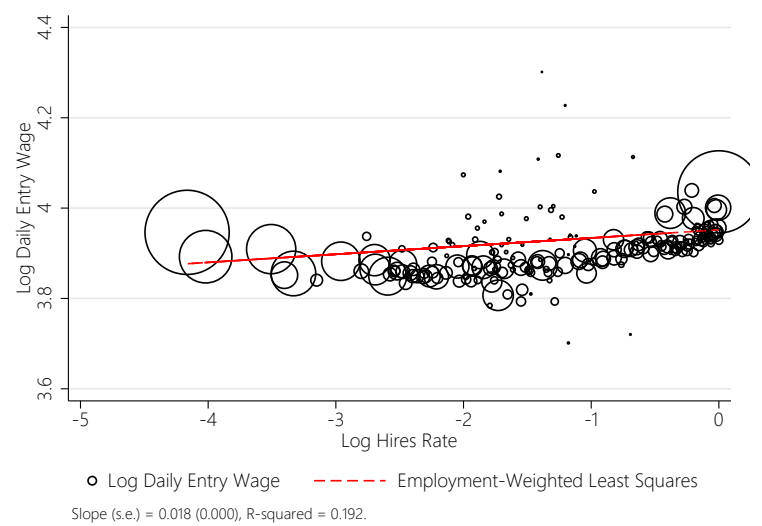

Within Establishments

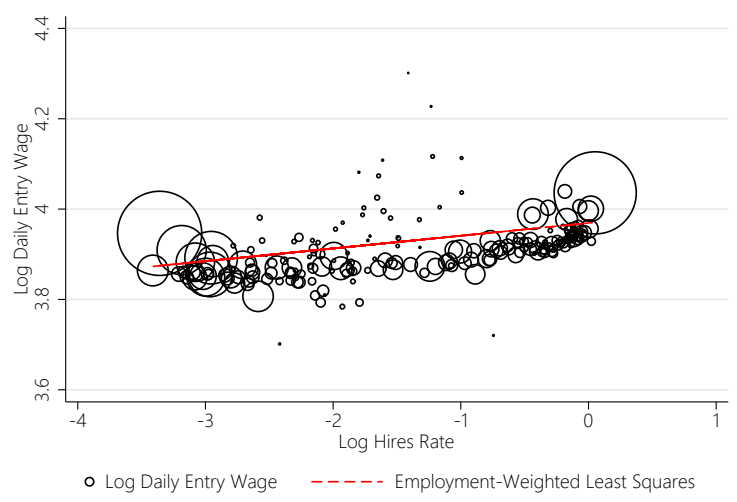
Slope (s.e.) $=0.028(0.000)$, R-squared $=0.364$

Notes: Average log daily entry wages by monthly hires rate in the ASSD 1997-2014. The figure plots average log daily entry wages, controlling for year fixed effects and establishment (size, industry and region) as well as worker characteristics (age, gender, year of labor market entry and AKM worker fixed effects), against employment-weighted averages of the (log) hires rate by DFH employment growth rate bin. While the left-hand side shows employment-weighted averages and least-squares estimates for the overall sample, the right-hand side absorbs establishment fixed effects for the log hires rate. 


\section{Vacancy Duration and Wages on New Jobs}

\section{C.1 AKM Decomposition}

Table C1: Variance Decomposition of AKM Effects

\begin{tabular}{lrr}
\hline & \multicolumn{2}{c}{ ASSD Sample } \\
\cline { 2 - 3 } & $1985-2014$ & 1997-2014 \\
\hline & & \\
Var(Log Wage) & 0.271 & 0.285 \\
Var(Worker FE) & 0.114 & 0.115 \\
Var(Firm FE) & 0.071 & 0.075 \\
Var(Covariates) & 0.017 & 0.017 \\
Var(Residual) & 0.037 & 0.036 \\
Cov(Worker,Firm) & 0.012 & 0.014 \\
Corr(Worker,Firm) & 0.128 & 0.147 \\
Observations & $45,955,080$ & $32,166,392$ \\
Firms & 902,926 & 718,603 \\
Workers & $3,240,176$ & $3,031,343$ \\
\hline Notes: Variance and covariance of different components of \\
AKM regression in the ASSD sample 1985-2014 and 1997-2014.
\end{tabular}


Figure C1: Mean Residuals by Person/Establishment Deciles

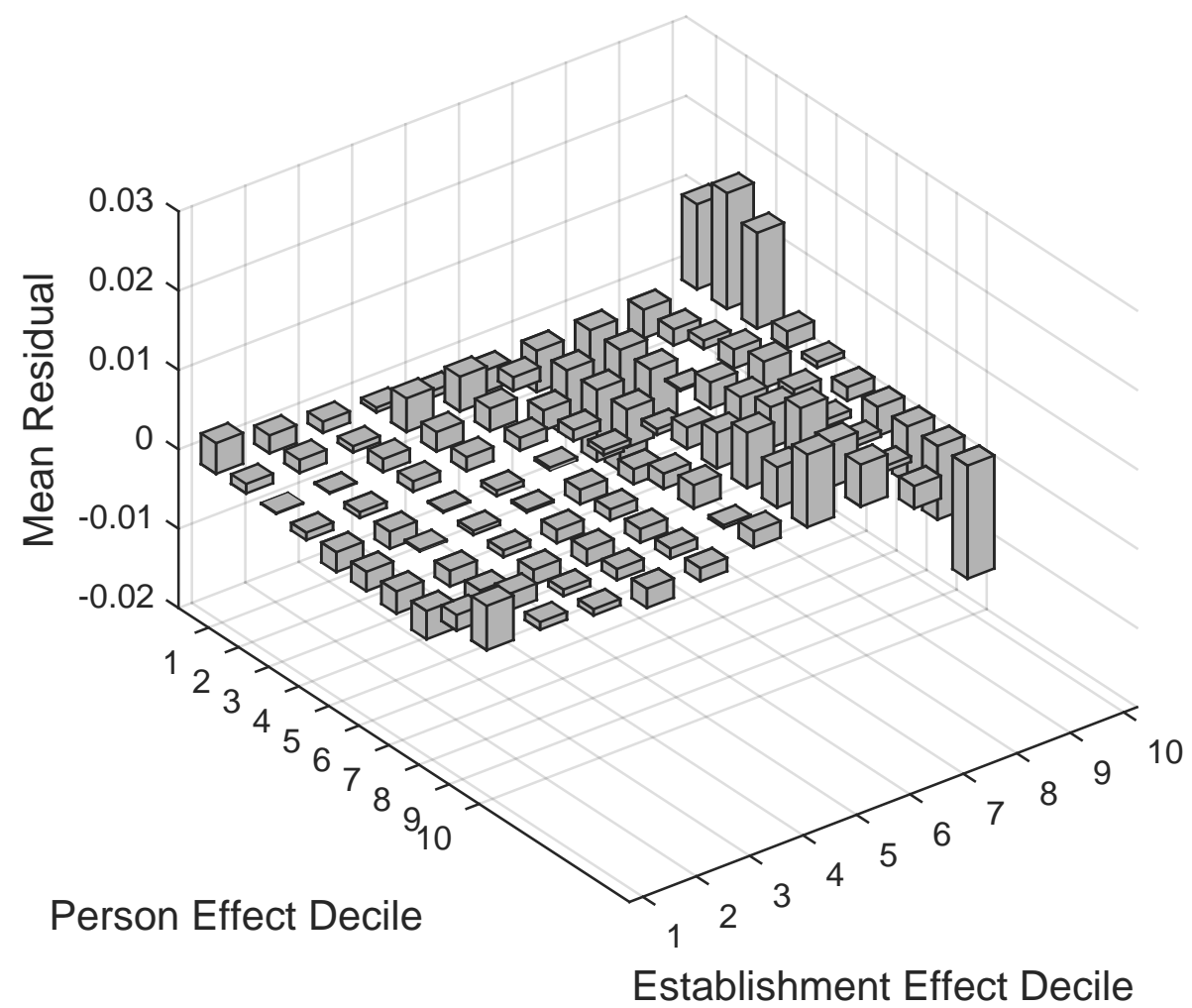

Notes: Mean residuals by person and establishment deciles. 


\section{C.2 Additional Regression Results}

Table C2: Results for Linear Specification (Instead of Log-Linear)

\begin{tabular}{|c|c|c|c|}
\hline & \multicolumn{3}{|c|}{ Vacancy Concept } \\
\hline & $(1)$ & $(2)$ & (3) \\
\hline & AMS & JOLTS & Posting \\
\hline \multicolumn{4}{|l|}{ Panel A. } \\
\hline Log entry wage & $\begin{array}{c}-1.505 \\
(0.264)^{* * *}\end{array}$ & $\begin{array}{c}-1.151 \\
(0.283)^{* * *}\end{array}$ & $\begin{array}{c}-2.617 \\
(0.346)^{* * *}\end{array}$ \\
\hline $\begin{array}{l}\text { Observations } \\
R^{2}\end{array}$ & $\begin{array}{c}803115 \\
0.144\end{array}$ & $\begin{array}{c}803115 \\
0.127\end{array}$ & $\begin{array}{c}803115 \\
0.308\end{array}$ \\
\hline \multicolumn{4}{|l|}{ Panel B. } \\
\hline AKM establishment effect & $\begin{array}{c}-2.130 \\
(0.566)^{* * *}\end{array}$ & $\begin{array}{c}-2.422 \\
(0.555)^{* * *}\end{array}$ & $\begin{array}{c}-4.956 \\
(0.797)^{* * *}\end{array}$ \\
\hline AKM worker fixed effect & $\begin{array}{l}-0.174 \\
(0.372)\end{array}$ & $\begin{array}{c}1.079 \\
(0.374)^{* * *}\end{array}$ & $\begin{array}{c}-1.136 \\
(0.611)^{*}\end{array}$ \\
\hline AKM worker exp. effect & $\begin{array}{c}-1.389 \\
(0.281)^{* * *}\end{array}$ & $\begin{array}{c}-0.863 \\
(0.308)^{* * *}\end{array}$ & $\begin{array}{c}-1.969 \\
(0.371)^{* * *}\end{array}$ \\
\hline AKM residual & $\begin{array}{c}-1.557 \\
(0.272)^{* * *}\end{array}$ & $\begin{array}{c}-1.192 \\
(0.298)^{* * *}\end{array}$ & $\begin{array}{c}-2.081 \\
(0.351)^{* * *}\end{array}$ \\
\hline $\begin{array}{l}\text { Observations } \\
R^{2}\end{array}$ & $\begin{array}{c}724690 \\
0.146\end{array}$ & $\begin{array}{c}724690 \\
0.130\end{array}$ & $\begin{array}{c}724690 \\
0.305\end{array}$ \\
\hline \multicolumn{4}{|l|}{ Panel C. } \\
\hline Avg. establish. log earnings & $\begin{array}{c}-1.919 \\
(0.402)^{* * *}\end{array}$ & $\begin{array}{c}-1.649 \\
(0.401)^{* * *}\end{array}$ & $\begin{array}{c}-3.512 \\
(0.542)^{* * *}\end{array}$ \\
\hline Residual entry wage & $\begin{array}{c}-1.307 \\
(0.264)^{* * *}\end{array}$ & $\begin{array}{c}-0.915 \\
(0.295)^{* * *}\end{array}$ & $\begin{array}{c}-2.195 \\
(0.356)^{* * *}\end{array}$ \\
\hline $\begin{array}{l}\text { Observations } \\
R^{2}\end{array}$ & $\begin{array}{c}802611 \\
0.144\end{array}$ & $\begin{array}{c}802611 \\
0.127\end{array}$ & $\begin{array}{c}802611 \\
0.308\end{array}$ \\
\hline $\begin{array}{l}\text { Baseline Controls } \\
\text { Occ. FE ( } 6 \text { digits) } \\
\text { Individual FE }\end{array}$ & $\begin{array}{l}\text { Yes } \\
\text { Yes } \\
\text { No }\end{array}$ & $\begin{array}{l}\text { Yes } \\
\text { Yes } \\
\text { No }\end{array}$ & $\begin{array}{l}\text { Yes } \\
\text { Yes } \\
\text { No }\end{array}$ \\
\hline
\end{tabular}

Notes: Authors' regressions with the worker sample for the years 1997-2014. Standard errors are clustered at the establishment level. The table reports results using vacancy duration, measured in days, in linear form as dependent variable instead of log vacancy duration as in Table 6. Each columns report results with a different vacancy concept: Column (1) uses AMS duration, Column (2) uses JOLTS duration; Column (3) uses duration since posting as dependent variable. See notes in Table 5 for further details regarding the control variables. 
Table C3: Linear Regressions with Log Vacancy Duration as Dependent Variable

Log Vacancy Duration

(1) (2) (3) (4)

(5)

\begin{tabular}{lccccc}
\hline Panel A. JOLTS Duration & & & & & \\
Log entry wage & 0.165 & 0.041 & -0.021 & 0.015 & -0.045 \\
& $(0.013)^{* * *}$ & $(0.010)^{* * *}$ & $(0.010)^{* *}$ & $(0.016)$ & $(0.011)^{* * *}$ \\
& & & & & \\
Observations & 787623 & 787623 & 787623 & 312576 & 428650 \\
$R^{2}$ & 0.008 & 0.152 & 0.185 & 0.218 & 0.479 \\
& & & & & \\
\hline Panel B. Posting Duration & & & & & \\
Log entry wage & 0.151 & 0.049 & -0.017 & 0.010 & -0.037 \\
& $(0.013)^{* * *}$ & $(0.008)^{* * *}$ & $(0.008)^{* *}$ & $(0.012)$ & $(0.010)^{* * *}$ \\
Observations & 796457 & 796457 & 796457 & 316710 & 432600 \\
$R^{2}$ & 0.008 & 0.310 & 0.341 & 0.396 & 0.568 \\
\hline Panel C. AMS Duration (Weighted) & & & & \\
Log entry wage & 0.220 & 0.041 & -0.051 & -0.069 & -0.049 \\
& $(0.014)^{* * *}$ & $(0.011)^{* * *}$ & $(0.011)^{* * *}$ & $(0.020)^{* * *}$ & $(0.016)^{* * *}$ \\
Observations & 535357 & 535357 & 535357 & 205783 & 294208 \\
$R^{2}$ & 0.012 & 0.152 & 0.192 & 0.226 & 0.607 \\
& & & & & \\
\hline Baseline Controls & No & Yes & Yes & Yes & Yes \\
Additional Controls & No & No & No & Yes & No \\
Occ. FE (6 digits) & No & No & Yes & Yes & No \\
Individual FE & No & No & No & No & Yes \\
\hline
\end{tabular}

Notes: Authors' regressions with the worker sample for the years 1997-2014. Standard errors are clustered at the establishment level. Weights are constructed by running a probit regression for each year in the AMS universe of a dummy for being in the worker sample on dummies for educational requirement of job, region and industry and then taking the inverse of the predicted value of the probit regression. Values above 1000 are windsorized (affecting 0.01 percent of observations in the worker sample). All regressions include a quarter fixed effect. Baseline controls include gender, age, age squared, dummies for the minimum educational requirement of the job and the year of labor market entry, as well as region \& industry and an early posting fixed effect, where early posting fixed effects are dummies for posting the vacancy 0-7 days, 8-30 days, 31-60 days, and more than 60 days prior to the desired start date. Additional controls include on-job wage growth, log(job duration), lagged firm employment growth, firm age and $\log$ (firm size). 
Table C4: Linear Regressions with Log JOLTS Duration as Dependent Variable

Log JOLTS Duration
(1)
(2)
(3)
(4)
(5)

Panel A.

Log entry wage

0.051

$(0.009)^{* * *}$

AKM establishment effect

$\begin{array}{cccc}-0.080 & -0.074 & -0.040 & -0.154 \\ (0.016)^{* * *} & (0.015)^{* * *} & (0.020)^{* *} & (0.019)^{* * *}\end{array}$

AKM worker fixed effect

$\begin{array}{ccc}0.215 & 0.046 & 0.064 \\ (0.011)^{* * *} & (0.011)^{* * *} & (0.015)^{* * *}\end{array}$

AKM worker exp. effect

$\begin{array}{llll}0.070 & -0.000 & 0.021 & 0.031\end{array}$

$\begin{array}{llll}(0.011)^{* * *} \quad(0.011) & (0.019) \quad(0.020)\end{array}$

AKM residual

$\begin{array}{cccc}0.050 & -0.012 & 0.021 & -0.009 \\ (0.010)^{* * *} & (0.010) & (0.019) & (0.012)\end{array}$

$\begin{array}{lccccc}\text { Observations } & 711293 & 711293 & 711293 & 283102 & 400126 \\ R^{2} & 0.158 & 0.159 & 0.190 & 0.224 & 0.482\end{array}$

\section{Panel B.}

Log entry wage $\quad 0.041$

$(0.010)^{* * *}$

Avg. establish. log earnings

$\begin{array}{cccc}-0.011 & -0.047 & 0.001 & -0.106 \\ (0.012) & (0.012)^{* * *} & (0.016) & (0.014)^{* * *}\end{array}$

Residual entry wage

$\begin{array}{llll}0.071 & -0.008 & 0.024 & -0.015\end{array}$

$(0.011)^{* * *} \quad(0.011) \quad(0.018)$

\begin{tabular}{lccccc} 
Observations & 787123 & 787123 & 787123 & 312575 & 428379 \\
$R^{2}$ & 0.152 & 0.153 & 0.185 & 0.218 & 0.479 \\
& & & & & Yes \\
\hline Baseline Controls & Yes & Yes & Yes & Yes \\
Additional Controls & No & No & No & Yes & No \\
Occ. FE (6 digits) & No & No & Yes & Yes & No \\
Individual FE & No & No & No & No & Yes \\
\hline
\end{tabular}

Notes: Authors' regressions with the worker sample for the years 1997-2014. Standard errors are clustered at the establishment level. All regressions include a quarter fixed effect. Baseline controls include gender, age, age squared, dummies for the minimum educational requirement of the job and the year of labor market entry, as well as region \& industry and an early posting fixed effect, where early posting fixed effects are dummies for posting the vacancy 0-7 days, 8-30 days, 31-60 days, and more than 60 days prior to the desired start date. Additional controls include on-job wage growth, $\log$ (job duration), lagged firm employment growth, firm age and $\log$ (firm size). 
Table C5: Linear Regressions with Log Posting Duration as Dependent Variable

Log Posting Duration

$\begin{array}{llll}(1) & (2) & (3) & (4)\end{array}$

\section{Panel A.}

Log entry wage

0.059

$(0.008)^{* * *}$

AKM establishment effect

AKM worker fixed effect

AKM worker exp. effect

$\begin{array}{ccccc} & -0.072 & -0.074 & -0.046 & -0.139 \\ & (0.014)^{* * * *} & (0.013)^{* * *} & (0.017)^{* * *} & (0.017)^{* * *} \\ & 0.224 & 0.050 & 0.056 & - \\ & (0.010)^{* * *} & (0.009)^{* * *} & (0.013)^{* * *} & \\ & 0.076 & 0.004 & 0.014 & 0.026 \\ & (0.010)^{* * *} & (0.009) & (0.014) & (0.017) \\ & 0.058 & -0.007 & 0.019 & -0.002 \\ & (0.009)^{* * *} & (0.008) & (0.014) & (0.011) \\ 718968 & 718968 & 718968 & 286667 & 403772 \\ 0.310 & 0.311 & 0.342 & 0.395 & 0.567\end{array}$

\section{Panel B.}

Log entry wage

0.049

$(0.008)^{* * *}$

Avg. establish. log earnings

Residual entry wage

$\begin{array}{cccc}-0.002 & -0.044 & -0.007 & -0.096 \\ (0.010) & (0.010)^{* * *} & (0.014) & (0.013)^{* * *}\end{array}$

Residualentry wage

0.080

$-0.004$

0.020

$-0.009$

$(0.009)^{* * *}$

(0.008)

(0.012)

(0.011)

\begin{tabular}{lccccc} 
Observations & 795954 & 795954 & 795954 & 316709 & 432327 \\
$R^{2}$ & 0.310 & 0.310 & 0.341 & 0.396 & 0.568 \\
\hline Baseline Controls & Yes & Yes & Yes & Yes & Yes \\
Additional Controls & No & No & No & Yes & No \\
Occ. FE (6 digits) & No & No & Yes & Yes & No \\
Individual FE & No & No & No & No & Yes \\
\hline
\end{tabular}

Notes: Authors' regressions with the worker sample for the years 1997-2014. Standard errors are clustered at the establishment level. All regressions include a quarter fixed effect. Baseline controls include gender, age, age squared, dummies for the minimum educational requirement of the job and the year of labor market entry, as well as region \& industry and an early posting fixed effect, where early posting fixed effects are dummies for posting the vacancy 0-7 days, 8-30 days, 31-60 days, and more than 60 days prior to the desired start date. Additional controls include on-job wage growth, $\log$ (job duration), lagged firm employment growth, firm age and $\log$ (firm size). 
Table C6: Weighted Regressions with Log AMS Duration as Dependent Variable

Log AMS Duration

$\begin{array}{llll}(1) & (2) & (3) & (4)\end{array}$

(5)

\section{Panel A.}

Log entry wage

0.058

$(0.012)^{* * *}$

AKM establishment effect

$\begin{array}{cccc}-0.078 & -0.105 & -0.168 & -0.178 \\ (0.024)^{* * *} & (0.022)^{* * *} & (0.033)^{* * *} & (0.030)^{* * *}\end{array}$

AKM worker fixed effect

$$
\begin{array}{ccc}
0.261 & 0.042 & 0.024 \\
(0.018)^{* * *} & (0.018)^{* *} & (0.026)
\end{array}
$$

AKM worker exp. effect

$$
\begin{array}{cccc}
0.062 & -0.033 & -0.049 & -0.016 \\
(0.016)^{* * *} & (0.014)^{* *} & (0.025)^{* *} & (0.031)
\end{array}
$$

$\begin{array}{lccccc}\text { AKM residual } & & 0.044 & -0.037 & -0.046 & -0.016 \\ & & (0.013)^{* * *} & (0.012)^{* * *} & (0.023)^{* *} & (0.017) \\ & & & & \\ \text { Observations } & 486997 & 486997 & 486997 & 188290 & 275967 \\ R^{2} & 0.157 & 0.158 & 0.198 & 0.231 & 0.608\end{array}$

\section{Panel B.}

Log entry wage

0.041

$(0.011)^{* * *}$

Avg. establish. log earnings

Residual entry wage

$\begin{array}{cccc}-0.012 & -0.074 & -0.103 & -0.111 \\ (0.016) & (0.016)^{* * *} & (0.026)^{* * *} & (0.021)^{* * *} \\ 0.072 & -0.040 & -0.049 & -0.021 \\ (0.012)^{* * *} & (0.011)^{* * *} & (0.021)^{* *} & (0.016)\end{array}$

\begin{tabular}{lccccc} 
Observations & 535087 & 535087 & 535087 & 205783 & 294043 \\
$R^{2}$ & 0.152 & 0.152 & 0.192 & 0.226 & 0.607 \\
\hline Baseline Controls & Yes & Yes & Yes & Yes & Yes \\
Additional Controls & No & No & No & Yes & No \\
Occ. FE (6 digits) & No & No & Yes & Yes & No \\
Individual FE & No & No & No & No & Yes \\
\hline
\end{tabular}

Notes: Authors' regressions with the worker sample for the years 1997-2014. Standard errors are clustered at the establishment level. Weights are constructed by running a probit regression for each year in the AMS universe of a dummy for being in the worker sample on dummies for educational requirement of job, region and industry and then taking the inverse of the predicted value of the probit regression. Values above 1000 are windsorized (affecting 0.01 percent of observations in the worker sample). See notes in Table 5 for details regarding the control variables. 
Table C7: Additional Robustness Checks

\begin{tabular}{lccccccc}
\hline & \multicolumn{7}{c}{ Sample } \\
\cline { 2 - 8 } & $(1)$ & $(2)$ & $(3)$ & $(4)$ & $(5)$ & $(6)$ & $(7)$ \\
\hline Log entry wage & -0.037 & -0.033 & -0.021 & -0.028 & -0.036 & -0.037 & -0.040 \\
& $(0.009)^{* * *}$ & $(0.011)^{* * *}$ & $(0.014)$ & $(0.011)^{* * *}$ & $(0.009)^{* * *}$ & $(0.009)^{* * *}$ & $(0.010)^{* * *}$ \\
Observations & 535357 & 525046 & 483588 & 365654 & 535357 & 518570 & 458536 \\
$R^{2}$ & 0.211 & 0.211 & 0.213 & 0.214 & 0.213 & 0.213 & 0.204 \\
& & & & & & & \\
\hline
\end{tabular}

Notes: Column (1) reports the baseline results from Column 4 in Table 4; Column (2) reports results where the sample is trimmed below the 1st and above 99th percentile of the distribution of starting wages; Column (3) reports results where the sample is trimmed below the 5th and above 95th percentile of the distribution of starting wages; Column (4) reports results where the sample is restricted to men; Column (5) reports results where we additionally control for quintiles of average establishment turnover in the sample period; Column (6) reports results where we exclude recalls; Column (7) reports results where the sample is restricted to E-U-E transitions. 


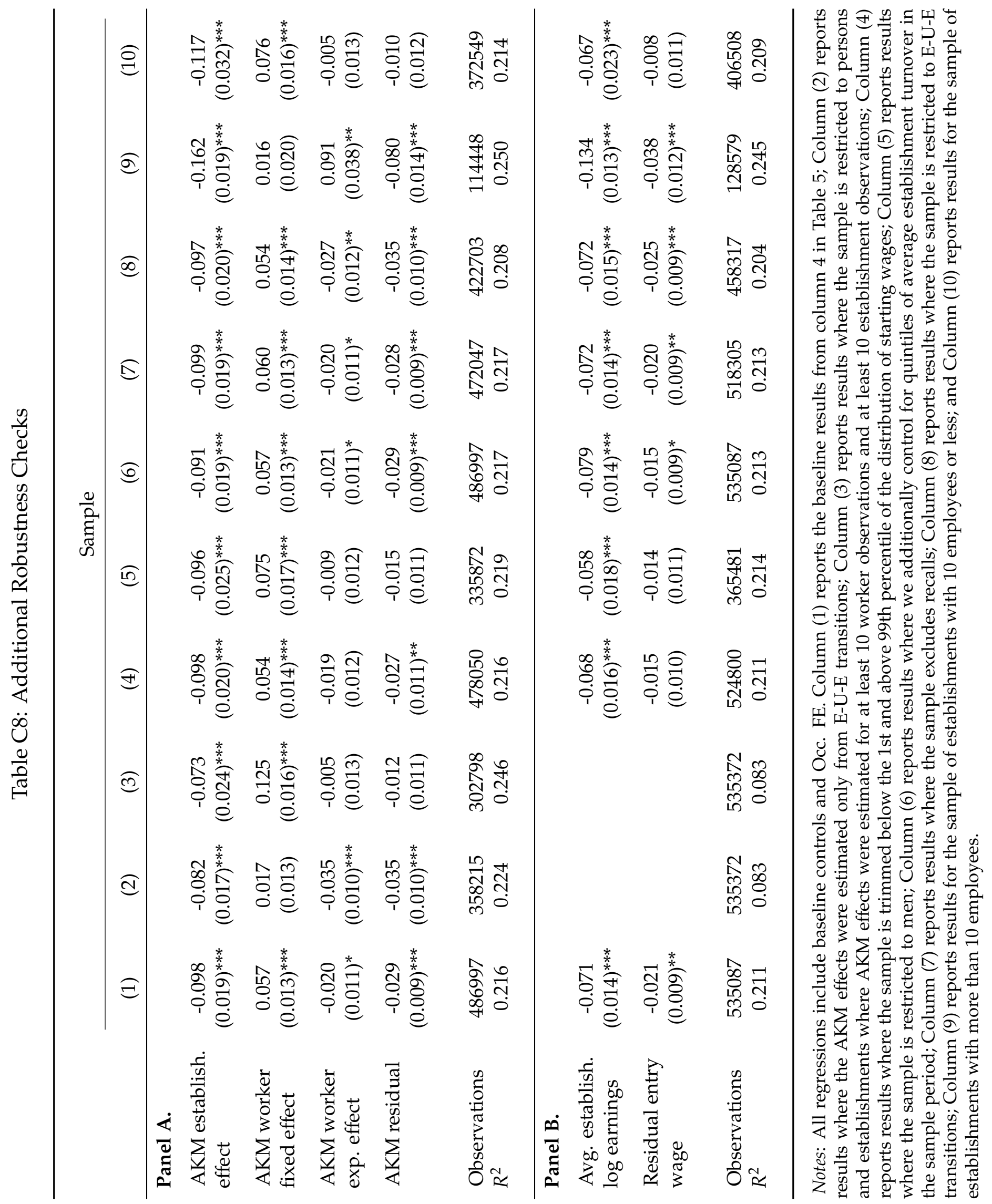


Log AMS Duration

$\begin{array}{lllll}(1) & (2) & (3) & (4) & \text { (5) }\end{array}$

Panel A. Establishments with at least 50 wage observations

$\begin{array}{lccccc}\text { Log entry wage } & 0.063 & & & & \\ & (0.011)^{* * *} & & & & \\ \log (\mathrm{PDV}) & & -0.010 & -0.018 & -0.063 & -0.055 \\ & & (0.017) & (0.017) & (0.019)^{* * *} & (0.024)^{* *} \\ \text { Observations } & & & & & \\ R^{2} & 506487 & 506487 & 506487 & 197874 & 278096 \\ & 0.173 & 0.173 & 0.211 & 0.236 & 0.601\end{array}$

Panel B. Establishments with at least 200 wage observations

\begin{tabular}{lccccc} 
Log entry wage & 0.082 & & & & \\
& $(0.012)^{* * *}$ & & & & \\
Log(PDV) & & -0.002 & -0.023 & -0.058 & -0.058 \\
& & $(0.022)$ & $(0.022)$ & $(0.023)^{* *}$ & $(0.031)^{*}$ \\
& & & & & \\
Observations & & & & & \\
$R^{2}$ & 436279 & 436279 & 436279 & 173720 & 238541 \\
& 0.173 & 0.173 & 0.211 & 0.237 & 0.633 \\
\hline Baseline Controls & & & & & \\
Additional Controls & Yes & Yes & Yes & Yes & Yes \\
Occ. FE (6 digits) & No & No & No & Yes & No \\
Individual FE & No & No & Yes & Yes & No \\
\hline
\end{tabular}

Notes: Authors' regressions with the worker sample for the years 1997-2014. Standard errors are clustered at the establishment level. All regressions include a quarter fixed effect. Baseline controls include gender, age, age squared, dummies for the minimum educational requirement of the job and the year of labor market entry, as well as region \& industry and an early posting fixed effect, where early posting fixed effects are dummies for posting the vacancy 0-7 days, 8-30 days, 31-60 days, and more than 60 days prior to the desired start date. Additional controls include on-job wage growth, log(job duration), lagged firm employment growth, firm age and $\log$ (firm size). The samples in Panel A and B are restricted to establishments with at least 50 and 200 wage observations in the ASSD data, respectively, to limit attenuation bias due to measurement error in the estimated PDV of wages. See Section C.3 for details of how we compute the PDV of wages of a job. 


\section{C.3 Estimating the Expected Present Discounted Value of Wages of a Job}

In this section, we describe how we compute the expected presented discounted value (PDV) of wage payments of a job. Let us denote years of tenure as $t$, the yearly wage payment as $w$ and the yearly interest rate as $r$. We can express the expected PDV of wages of a given job as

$$
V(t)=w(t)+\frac{1-\delta(t)}{1+r(t)} V(t+1)
$$

Solving this forward and assuming that $r(t)=r$, we get

$$
\begin{aligned}
V(t) & =\sum_{m=0}^{T}\left[\prod_{k=0}^{m} \frac{1-\delta(t+m)}{1+r}\right] w(t+m) \\
& =\sum_{m=0}^{T}\left(\frac{1}{1+r}\right)^{m} S(t+m) w(t+m),
\end{aligned}
$$

where $T$ is a fixed end date of a job (e.g., retirement) and $S(t)$ is the probability of survival to tenure $t$.

While we observe the realizations of wages and separations over the entire duration of a job, the difficulty lies in measuring the expected PDV because (1) separation probabilities are not observed but only the random realization thereof and (2) wages are not observed post separation. We deal with these issues by

1. estimating industry-specific separation rates by tenure. We implement this by estimating a proportional hazard model with industry-specific shifters. Figure C2 shows the estimated baseline survival function and separation rates by years of tenure.

2. estimating wage-tenure profiles at the firm level. We implement this by estimating the regression model of the form

$$
\log w_{j}(t, y)=\alpha_{j}+\beta_{j \tilde{t}(t)}+\gamma_{y}
$$

where $\alpha_{j}$ is a firm fixed effect that reflects the firm's average entry wage (i.e. at tenure 0) and $\beta_{j \tilde{j}(t)}$ is a tenure fixed effect with $\tilde{t}(t)$ a tenure-year $\operatorname{bin}$. We bin tenure years because of considerations of sample size and choose the following bins: less than 1 year, 1 year, 2-3 years, 4-5 years, 6-9 years, 10-19 years, 20 years and higher. We also control for aggregate time trends by controlling for $y$ (ear) fixed effects, $\gamma_{y}$.

We further assume that all jobs end deterministically after 30 years, $T=30$, which reflects the average years worked prior to retirement. We also assume a value of $r$ of 0.02 , which corresponds to the average interest rate in Austria over the sample period. 
Figure C2: Survival Function and Separation Rate Based on Proportional Hazard Model
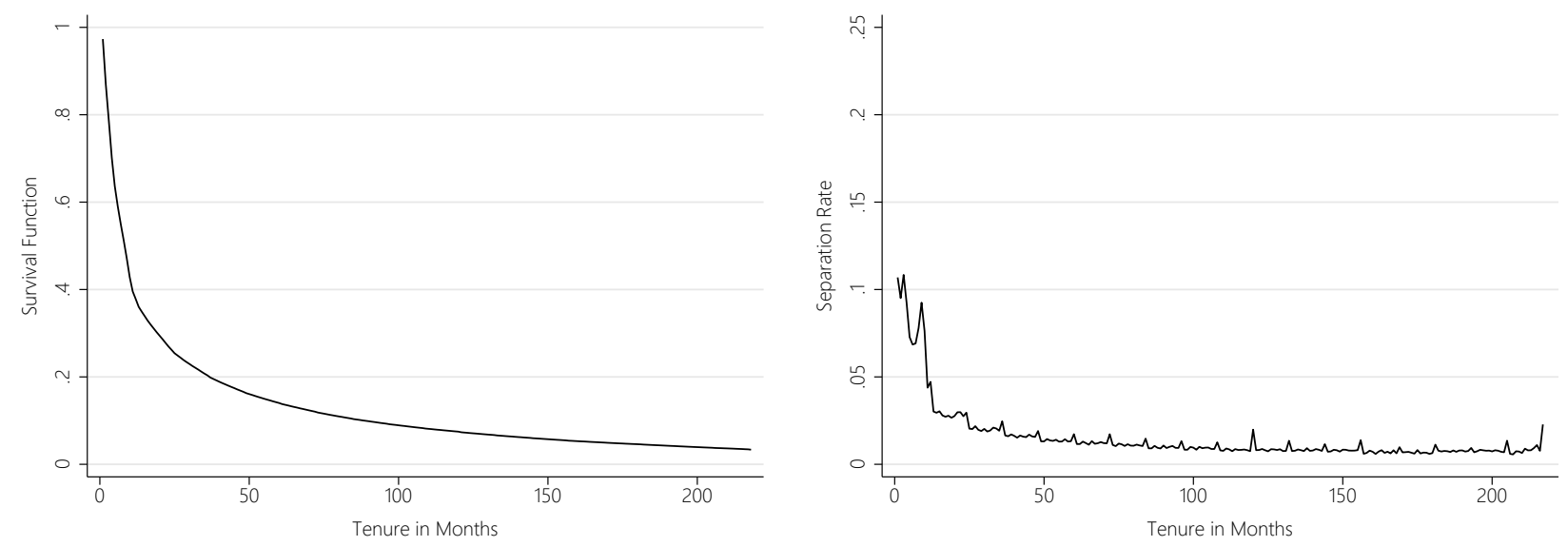

Notes: Survival function and separation rate by monthly tenure based on a proportional hazard rate model for all employment spells starting between 1997-2014.

Given all these assumptions, our estimate of the PDV at tenure 0 in firm $j$ in industry $k$ is

$$
\hat{V}_{j}=\sum_{m=0}^{30}\left(\frac{1}{1+r}\right)^{m} \hat{S}_{j(k)}(m) e^{\hat{\alpha}_{j}+\hat{\beta}_{\tilde{f}(m)},}
$$

where $\hat{S}_{j(k)}(t)$ is the estimated survival rate to tenure $t$ at firm $j$ in industry $k, \hat{\alpha}_{j}$ is the estimated average starting wage at firm $j$ and $\hat{\beta}_{j \tilde{f}(t)}$ is the estimated average wage paid in firm $j$ in tenure-year $\operatorname{bin} \tilde{t}(t)$. 


\section{Implications for Search Theoretic Models}

\section{D.1 Kaas and Kircher (2015) with Ex-Ante Worker Heterogeneity}

In this section, we evaluate our evidence through the lens of directed search theory. The model of Kaas and Kircher (2015) is a natural starting point, as it characterizes directed search in the context of firm heterogeneity in productivity and was calibrated explicitly to match the facts documented in DFH. In the Kaas and Kircher model, posted wages act as a recruitment device: firms that want to grow fast post higher wages to reduce the time it takes to fill a vacancy. As demonstrated in Kaas and Kircher (2015), the model has important implications for the evolution aggregate matching efficiency over the business cycle. ${ }^{2}$

The goal of the exercise here is to re-calibrate the model to match the features of the Austrian labor market, including the DFH-type evidence documented in Section 5. We extend the model to the case of ex-ante worker heterogeneity and then use it to evaluate whether the model can match three key observations of the previous section: (1) the positive association of vacancy durations with raw (unconditional) starting wages, (2) the positive association of vacancy durations with AKM worker effects, and most importantly, (3) the negative association of vacancy durations with AKM establishment effects.

Model Setup We extend the model of Kaas and Kircher to the case of ex-ante worker heterogeneity. ${ }^{3}$ We follow Kaas and Kircher as closely as possible and concentrate here on the features that are specific to the model with ex-ante worker heterogeneity.

In the model, there is a continuum of firms, which produce $F\left(y, x, L_{1}, L_{2}, \ldots, L_{N}, y, x\right)$ units of output with $L_{1} \geq 0, L_{2} \geq 0, \ldots, L_{N} \geq 0$ labor inputs. $x$ is fixed firm-level productivity and $y$ is a firmlevel productivity shock. New firms pay a setup $\operatorname{cost} K$, draw a fixed firm type $x$ with probability $\pi(x)$ and die at exogenous rate $\delta_{0}(x)$, which potentially differs across firm types. ${ }^{4}$ Firms are hit with a firm-level productivity shock $y$ with probability $\pi_{y}$ and which is drawn uniformly at random from the interval $[1-\bar{y}, 1+\bar{y}]$. Firms search for new employees by posting $V_{i}$ vacancies for workers of type $i$, paying a fixed wage $w_{i}$, and paying recruitment costs $C\left(V_{1}, V_{2}, \ldots, V_{N}, L_{1}, L_{2}, \ldots, L_{N}, y, x\right)$. The posted wage determines the number of workers applying to the opening, $\lambda_{i}$, and thus determines the vacancy-filling rate $m_{i}$. There are $N$ different types of workers and there is a continuum of workers for each worker type. Workers direct their search to a particular firm-vacancy sub-market $j$ and quit their job at exogenous rate $s_{0}$, which we assume to be the same across worker types. The

\footnotetext{
${ }^{2}$ In principle, one could also consider a version of the model of Burdett and Mortensen (1998), but we are not aware of any version of this model that was set up and calibrated towards the facts in DFH. In addition, the Burdett and Mortensen model generates a negative relationship of vacancy durations and wages only due to the presence of on-the-job search, where employed workers on different rungs of the job ladder have different acceptance probabilities of outside offers, whereas in our data we only observe the matching process of unemployed workers.

${ }^{3}$ The model of Kaas and Kircher also features aggregate shocks, which we abstract from here.

${ }^{4}$ Kaas and Kircher assume this mainly to match the establishment dynamics in the data.
} 
quit rate is the lower bound on the total separation rate $s_{i} \in\left[s_{0}, 1\right]$ for a given worker type, as firms hit by negative productivity shocks may decide to layoff some or all of their workers of a given type. In equilibrium, workers are indifferent between the different sub-markets. Workers supply a unit of labor when employed, and receive $b_{i}$ when unemployed. There is no on-the-job search.

As Kaas and Kircher, we solve in our numerical simulations the social planner version of the problem with flat-wage contracts. ${ }^{5}$ In equilibrium, wages vary both across worker and firm types. Even though there is no bargaining, wages vary across worker types because workers don't search in submarkets that deliver less than the value of unemployment and thus, the unemployment benefit $b_{i}$ is a critical determinant of the posted wage. Posted wages also depend on fixed and transitory firm productivity, $x$ and $y$, and the size of its labor force for each type of worker, $L_{1}, L_{2}, \ldots, L_{N}$. Newly-born firms tend to post more vacancies and at higher wages because they want to grow quickly toward their optimal size. The relationship between firm productivity and posted wages is less clear and depends on assumptions about the shape of the vacancy-posting cost function. All else equal, firms that face a higher cost of posting a vacancy, post a higher wage in order to fill their vacancies more quickly.

Recursive Representation To gain some intuition, let's consider first the model without any shocks and assume that $\delta_{0}(x)=\delta_{0}$, i.e. the exogenous firm death rate does not depend on firm productivity. In a model without shocks, firms never want to shrink and thus firm death and separations are purely exogenous, i.e. $\delta(x)=\delta_{0}$ and $s_{i}=s_{0}$. Let $J^{x}(\boldsymbol{L}, \boldsymbol{W})$ be the value function of the firm with productivity $x$, and $W_{i}$ the wage bill to which the firm is committed for each type of worker $i$. As in Kaas and Kircher, one can write $J^{x}(\boldsymbol{L}, \boldsymbol{W})=J^{x}(\boldsymbol{L}, \mathbf{0})-\frac{\sum_{i=1}^{N} W_{i}}{1-\beta\left(1-\delta_{0}\right)\left(1-s_{0}\right)}$ where $\frac{\sum_{i=1}^{N} W_{i}}{1-\beta\left(1-\delta_{0}\right)\left(1-s_{0}\right)}$ is the net present value of existing wage commitments, which is independent of future hiring decisions. The firms recursive maximization problem can thus be written as

$$
\begin{gathered}
J^{x}(\boldsymbol{L}, 0)=\max _{(m, V)} x F(\boldsymbol{L}, x)-C(\boldsymbol{V}, \boldsymbol{L}, x)-\sum_{i=1}^{N} D_{i}\left(m_{i}\right) V_{i}+\beta\left(1-\delta_{0}\right) J^{x}\left(\mathbf{L}^{+}, 0\right), \\
\text { s.t. } L_{i}^{+}=L_{i}\left(1-s_{0}\right)+m_{i} V_{i}, \forall i=1, \ldots, N,
\end{gathered}
$$

where $D_{i}\left(m_{i}\right) V_{i}=w_{i}\left(m_{i}\right) \frac{1-\delta_{0}}{1-\beta\left(1-\delta_{0}\right)\left(1-s_{0}\right)} m_{i} V_{i}$ is the net present value of wage commitments paid for the $m_{i} V_{i}$ new hires of type $i$ and $w_{i}\left(m_{i}\right)$ is the wage for worker type $i$ with vacancy-filling rate $m_{i}$. We refer to the text of Kaas and Kircher for the first order conditions and other details, which follow in exact analogy for each worker type. Free entry of firms implies that $\sum_{x \in X} \pi(x) J^{x}(\mathbf{0}, 1) \leq K$.

Now, let's turn to the model with firm-level shocks and where exogenous firm death rates depend on firm-level productivity, i.e. $\delta_{0}(x){ }^{6}$ In analogy to Kaas and Kircher, we solve the social

\footnotetext{
${ }^{5}$ See their paper for further details.

${ }^{6}$ Unlike Kaas and Kircher, we abstract from aggregate shocks, as this is not the focus of our analysis.
} 
planner version of the problem. ${ }^{7}$ The social value of the firm of type $x$ satisfies the Bellman equation

$$
\begin{aligned}
G^{x}(\boldsymbol{L}, y ; \boldsymbol{M})= & \max _{(\boldsymbol{m}, \boldsymbol{V}, \boldsymbol{s}, \delta)}\left\{F(\boldsymbol{L}, y, x)-\sum_{i=1}^{N} b_{i} L_{i}-\sum_{i=1}^{N} \mu_{i}\left[L_{i}+\lambda\left(m_{i}\right) V_{i}\right]-f\right. \\
& \left.-C(\boldsymbol{V}, \boldsymbol{L}, \boldsymbol{y}, x)+\beta(1-\delta) E_{y} G^{x}\left(\boldsymbol{L}^{+}, \boldsymbol{y}^{+} ; \boldsymbol{M}\right)\right\} \\
\text { s.t. } \quad & L_{i}^{+}=L_{i}\left(1-s_{i}\right)+m_{i} V_{i}, \forall i=1, \ldots, N,
\end{aligned}
$$

and subject to $\delta \in\left[\delta_{0}(x), 1\right], s_{i} \in\left[s_{0}, 1\right], m_{i} \in[0,1]$, and $V_{i} \geq 0, \forall i=1, \ldots, N$, and where $\boldsymbol{M}=$ $\left(\mu_{1}, \mu_{2}, \ldots, \mu_{N}\right)$ are the social values of each type of worker tied to the firm in a given period. In our calibration, we set $f=0$ and thus all firm exit is exogenous, i.e. $\delta=\delta_{0}(x)$. As discussed in detail in Kaas and Kircher, the firm's social flow value consists of the output of the firm minus the opportunity cost of employment $\left(b_{i} L_{i}\right)$, the social cost of workers tied to the firm, including the unemployed applying to the firm $\left(\mu_{i}\left[L_{i}+\lambda\left(m_{i}\right) V_{i}\right]\right)$, fixed operating costs $(f)$ and vacancy-posting costs $(C(\boldsymbol{V}, \boldsymbol{L}, y, x))$. Positive entry requires that $\sum_{x \in X} \pi(x) G^{x}(\mathbf{0}, 1 ; \boldsymbol{M})=K$, which is satisfied in all calibrations that we explore. We solve the model, by first forming an initial guess of $\boldsymbol{M}$, then solving the Bellman equation above, and then iterating on $\boldsymbol{M}$ until the resource constraints of the economy are satisfied with equality (i.e., workers of all types are either employed or unemployed searching for a job).

Calibration We start by parameterizing the model of Kaas and Kircher (i.e., without worker heterogeneity). We follow them as closely as possible, allowing for 5 different firm types $x$ and 5 different shocks $y$ on the interval $[1-0.312,1+0.312]$, but re-calibrate certain parameters to match certain features of the Austrian labor market and vacancy data (see Table D1 for all the parameter values): First, we set the vacancy cost scale parameter $c$ to 0.11 to match a weekly vacancy-filling rate of 0.10 . Second, we set the parameters $k$ and $r$ of the matching function $m(\lambda)=\left(1+k \lambda^{-r}\right)^{-\frac{1}{r}}$ to target a weekly job-finding rate of 0.033 and an elasticity of job finding to labor market tightness of 0.72. Finally, we set the entry cost $K$ to 2.4. As discussed in the Appendix of Kaas and Kircher, this is a pure normalization since all firms' value functions are linearly homogeneous in the vector $(x, b, c, K)$.

\footnotetext{
${ }^{7}$ For the type of production function and vacancy cost functions considered in the calibration below, it is easy to show that the proof of Kaas and Kircher that the decentralized economy is efficient carries over the case with ex-ante heterogeneous workers.
} 
Table D1: Calibrated Parameter Values

\begin{tabular}{|c|c|c|c|}
\hline Parameter & Value & Description & Target/Source \\
\hline$c$ & 0.11 & Vacancy cost scale parameter & Weekly vacancy-filling rate of 0.102 \\
\hline$\gamma$ & 0.5 & Vacancy cost elastiticity & $\begin{array}{l}\text { Vacancy-filling rates by employment growth } \\
\text { \& Elasticity of vacancy filling to hiring of } 0.18\end{array}$ \\
\hline$k$ & 4.8 & Matching function scale parameter & Weekly job-finding rate of 3.3 percent \\
\hline$r$ & 0.56 & Matching function elasticity & Elasticity of job finding to tightness of 0.72 \\
\hline K & 2.4 & Entry cost & Normalization \\
\hline$\beta$ & 0.999 & Discount factor & Kaas and Kircher \\
\hline$b$ & 0.1 & Unemployment income & Kaas and Kircher \\
\hline$s_{0}$ & $0.48 \%$ & Quite rate & Kaas and Kircher \\
\hline$x_{1}$ & 0.37 & Firm productivity of firm type 1 & Kaas and Kircher \\
\hline$x_{2}$ & 0.74 & Firm productivity of firm type 2 & Kaas and Kircher \\
\hline$x_{3}$ & 1.17 & Firm productivity of firm type 3 & Kaas and Kircher \\
\hline$x_{4}$ & 2.03 & Firm productivity of firm type 4 & Kaas and Kircher \\
\hline$x_{5}$ & 4.14 & Firm productivity of firm type 5 & Kaas and Kircher \\
\hline$\sigma_{1}$ & $98.820 \%$ & Firm share at birth of firm type 1 & Kaas and Kircher \\
\hline$\sigma_{2}$ & $1.000 \%$ & Firm share at birth of firm type 2 & Kaas and Kircher \\
\hline$\sigma_{3}$ & $0.153 \%$ & Firm share at birth of firm type 3 & Kaas and Kircher \\
\hline$\sigma_{4}$ & $0.025 \%$ & Firm share at birth of firm type 4 & Kaas and Kircher \\
\hline$\sigma_{5}$ & $0.002 \%$ & Firm share at birth of firm type 5 & Kaas and Kircher \\
\hline$\delta_{0,1}$ & $1.710 \%$ & Exogenous exit rate of firm type 1 & Kaas and Kircher \\
\hline$\delta_{0,2}$ & $0.270 \%$ & Exogenous exit rate of firm type 2 & Kaas and Kircher \\
\hline$\delta_{0,3}$ & $0.160 \%$ & Exogenous exit rate of firm type 3 & Kaas and Kircher \\
\hline$\delta_{0,4}$ & $0.088 \%$ & Exogenous exit rate of firm type 4 & Kaas and Kircher \\
\hline$\delta_{0,5}$ & $0.016 \%$ & Exogenous exit rate of firm type 5 & Kaas and Kircher \\
\hline $\bar{y}$ & 0.312 & Transitory productivity range & Kaas and Kircher \\
\hline$\pi_{y}$ & 0.027 & Adjustment probability & Kaas and Kircher \\
\hline
\end{tabular}

In the model extension with ex-ante heterogeneous workers, we assume the following functional forms for the production function and vacancy-posting costs 8

$$
\begin{gathered}
F(\boldsymbol{L}, y, x)=y x \sum_{i=1}^{N}\left(a_{i}(x) L_{i}^{\alpha}\right) \\
C(\boldsymbol{V}, \boldsymbol{L}, y, x)=\sum_{i=1}^{N}\left(\frac{c_{i}}{1+\gamma}\left(\frac{V_{i}}{L_{i}}\right)^{\gamma} V_{i}\right),
\end{gathered}
$$

which are the same as in Kaas and Kircher (2015), except that we sum over $N$ types of workers and $a_{i}(x)$ denotes worker-type-specific productivity, which potentially interacts with firm type $x$. Note that our assumption of additivity of worker types in production and vacancy costs implies that there are no complementarities in production or vacancy posting between worker types, as the marginal product and the marginal vacancy-posting cost for each worker type $i$ is independent of the number of other types of workers employed at the same firm. In the model without worker heterogeneity, the firm productivity levels for each type of firm are directly taken from Kaas and

\footnotetext{
${ }^{8}$ See also Eeckhout and Kircher (2018) who provide an extension of the model of Kaas and Kircher (2015) with more general production functions, but linear vacancy-posting costs.
} 
Table D2: Calibration of Key Parameters in Model with Ex-Ante Heterogeneous Workers

\begin{tabular}{lcccc}
\hline & & & \multicolumn{2}{c}{$\begin{array}{c}\text { Model Extension w/ } \\
\text { Worker Heterogeneity }\end{array}$} \\
\cline { 3 - 5 } & Parameters & Kaas \& Kircher & $(1)$ & $(2)$ \\
\hline Worker & $a_{1}\left(x_{1}\right) / a_{2}\left(x_{1}\right)$ & $1 / 1$ & $0.7 / 1.3$ & $0.9 / 1.1$ \\
Productivities: & $a_{1}\left(x_{2}\right) / a_{2}\left(x_{2}\right)$ & $1 / 1$ & $0.7 / 1.3$ & $0.8 / 1.2$ \\
& $a_{1}\left(x_{3}\right) / a_{2}\left(x_{3}\right)$ & $1 / 1$ & $0.7 / 1.3$ & $0.7 / 1.3$ \\
& $a_{1}\left(x_{4}\right) / a_{2}\left(x_{4}\right)$ & $1 / 1$ & $0.7 / 1.3$ & $0.6 / 1.4$ \\
& $a_{1}\left(x_{5}\right) / a_{2}\left(x_{5}\right)$ & $1 / 1$ & $0.7 / 1.3$ & $0.5 / 1.5$ \\
Vacancy & $c_{1}$ & 0.11 & 0.07 & 0.10 \\
Posting Costs: & $c_{2}$ & 0.11 & 0.08 & 0.08 \\
\hline
\end{tabular}

Kircher, but then scaled down by a factor of 0.815 in the case of the model with multiple worker types to target that the average firm size in the economy remains unchanged.

In what follows, we present three calibrations: (i) the baseline model of Kaas and Kircher without ex-ante worker heterogeneity, but calibrated to Austrian data, (ii) a model with worker heterogeneity, where relative worker productivities are independent of firm productivities, and (iii) a model with worker heterogeneity with complementarities between worker skills and firm productivities (generating positive assortative matching as high-skilled workers are relatively more productive at high-productivity firms). Table D2 presents the assumed parameter values on worker productivities and vacancy-posting costs in the three calibrations. The two calibrations with ex-ante worker heterogeneity assume (for simplicity) two types of workers and set relative worker productivities to match the dispersion of AKM worker fixed effects in the data with a standard deviation of 0.3. As shown in Table D3 below, the correlation of worker and firm types in calibration (iii) (assortative matching) is 0.51 , which is in the range of estimates provided by Borovickova and Shimer (2019) using Austrian data. All our calibrations with ex-ante worker heterogeneity assume that type-2 workers are preferred by all firms and thus we refer to them as the high-skilled type. There is nothing, however, that restricts us to do so; in principle, we could allow for type- 2 workers to be less productive than type-1 worker at low productivity firms, which would generate even stronger positive assortative matching.

Note that we assume that $b_{i}=b E\left(a_{i}(x)\right)$, where $b=0.1$, i.e. the unemployment benefit is proportional to average worker productivity across firms. We calibrate the model such that the replacement rate ( $b$ over average wage) is 0.7 , as in Kaas and Kircher. In the versions with heterogeneous workers, we calibrate vacancy-posting costs $c$ to match a job-filling rate of 0.11 for the worker of type 1 and 0.094 for the worker of type 2, to generate the positive association of AKM-worker fixed effects and vacancy duration. This calibration strategy generates vacancyposting costs that are nearly identical across worker types. In fact, if we were to impose identical 
costs, the results would be very similar. ${ }^{9}$ The key point here is that vacancy-posting costs are less than proportional to worker-ability and thus, for workers of type 1, firms post fewer vacancies but at a higher filling rate (by increasing posted wages).

Results We start by reporting a few results of the model without ex-ante worker heterogeneity, calibrated to Austrian data. Panel A in Table D3 shows selected model results in the model where the vacancy cost elasticity, $\gamma$, varies between 0.1 and $1 .{ }^{10}$ As can be seen in the table, the elasticity of vacancy duration to the starting wage is negative and very large. In other words, the posted wage appears to be a very strong instrument to affect vacancy duration by affecting the length of the queue in a given labor market. The elasticity declines substantially with the parameter $\gamma$ but remains below -1. At the same time the model with a low value of $\gamma$, is inconsistent with the DFH-type of evidence, which shows that the vacancy-filling rate is strongly positively correlated with employment growth and hiring at the firm level. This is also illustrated in Figure D1, where among the three calibrations shown in the figure the one with $\gamma=0.5$ yields the best fit to the relationship of the firm growth and the weekly vacancy-filling rate. ${ }^{11}$

Panels B and C of Table D3 show the results for the model with ex-ante heterogeneous workers. The table includes the AKM regression coefficients, which were estimated on data simulated from the model with 20,000 firms and 400,000 workers over a period of 10 years. ${ }^{12}$ The results show that now the relationship between the entry wage and vacancy duration is positive, with a similar coefficient as in the data. Just like in our empirical results, however, this masks the differential effects of the AKM worker and AKM firm effects on vacancy duration: The coefficient on the AKM worker effect is positive and similar to the one in the data. This is not surprising, given that we calibrated the vacancy cost scale parameter $c$ to generate a vacancy-filling rate of 0.11 for the low-skilled worker and 0.094 for the high-skilled worker. Qualitatively, the model matches the sign of the coefficient on the AKM firm effect. However, just like in the baseline model, the magnitude of the coefficient is more than an order of magnitude higher than in the data. Similarly, the coefficient on the AKM residual of the starting wage is very negative in the model but close to zero in the data. The model version with a lower value for the vacancy cost elasticity parameter $\gamma$ lowers the elasticity of vacancy duration to the AKM firm effect and the AKM residual, but at $\gamma=0.1$ the model no longer matches the elasticity of the hires rate to the vacancy-filling rate

\footnotetext{
${ }^{9}$ See Engbom and Moser (2018) for a similar finding in the context of an extension of the model of Burdett and Mortensen (1998) to ex-ante worker heterogeneity.

${ }^{10}$ Table D4 contains the results for various alternative calibrations, including the original calibration in the paper of Kaas and Kircher (2015).

${ }^{11}$ While the calibration with $\gamma=0.5$ slightly over-predicts the vacancy-filling rates for growing firms, it slightly under-predicts the elasticity of vacancy filling to hires rates. If we changed $\gamma$ to a lower value, we would do better on the former, but worse on the latter. We believe, therefore, that a calibration with $\gamma=0.5$ provides a reasonable fit to the data on vacancy-filling rates by both employment growth and hires rates.

${ }^{12}$ To be precise, we estimated the model for 520 weeks and then used the data from the last week of each year to estimate the AKM worker and firm fixed effects. In analogy to the empirical results, in a second step, we then estimated the linear regressions of log vacancy duration on the starting wage and the AKM effects.
} 
Table D3: Simulation Results of Model of Kaas and Kircher and Model Extension with Ex-Ante Worker Heterogeneity

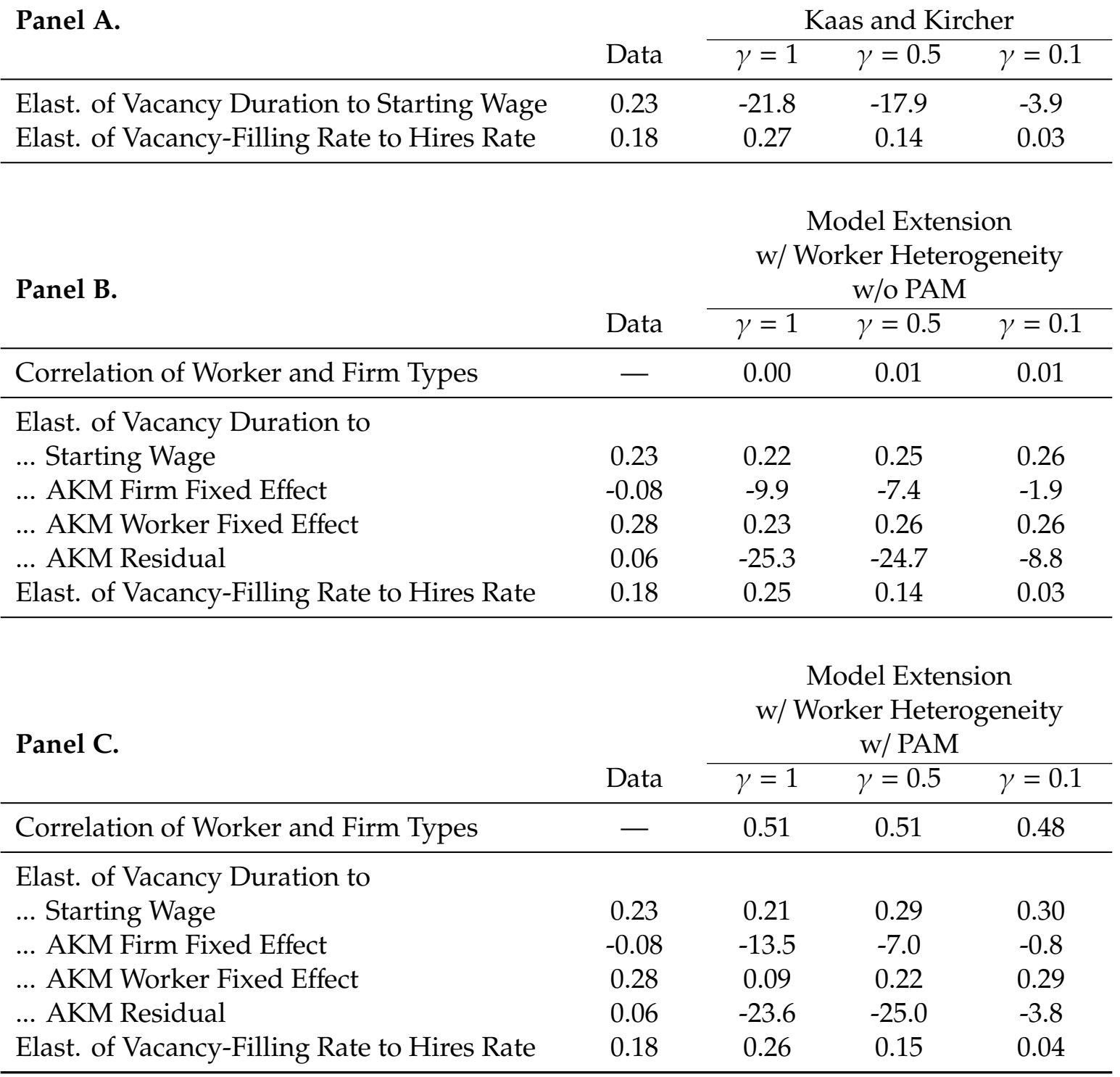

Notes: Panel A shows the results of the model without worker heterogeneity, i.e. the model of Kaas and Kircher calibrated to the Austrian data. Panel B shows results for the calibration (1) and Panel C shows results for the calibration (2) of the model with worker heterogeneity in Table D2. The model calibration in Panel C features substantial Positive Assortative Matching (PAM), as can be seen in the correlation of worker and firm types in the table. The statistics from the data refer to the coefficients reported in Column 1 of Table 4 (elasticity of vacancy duration to starting wage), Figure B1 (elasticity of vacancy-filling rate to hires rate) and Column 2 of Table 5 (elasticity of vacancy duration to AKM effects). The statistics from the model are based on simulated data with 20,000 firms and 400,000 workers over a period of 10 years. 
Figure D1: Weekly Vacancy-Filling Rates by Employment Growth in Data and Model

Panel A. Kaas and Kircher

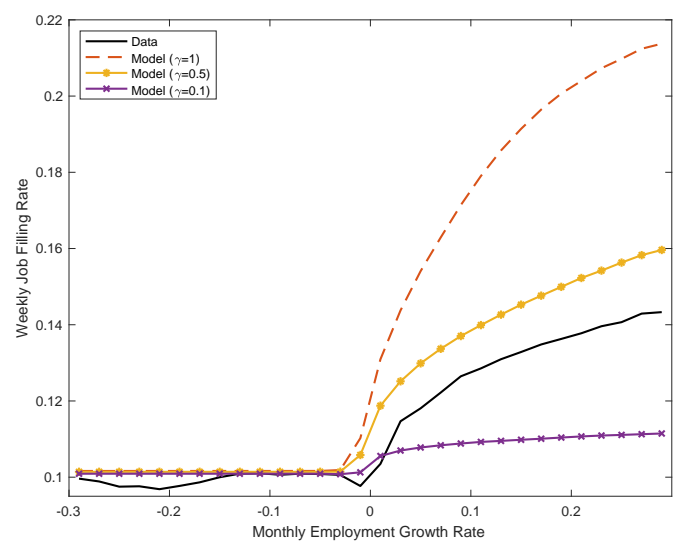

Panel B. Model Extension w/ Worker Heterogeneity (w/o PAM)

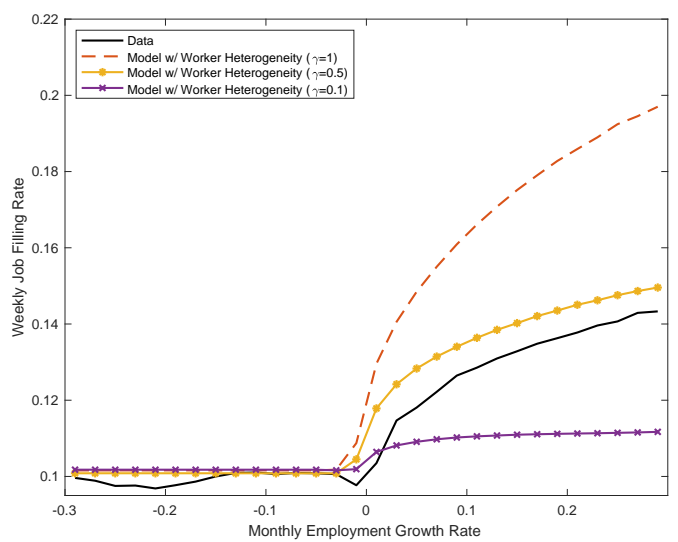

Panel C. Model Extension w/ Worker Heterogeneity (w/ PAM)

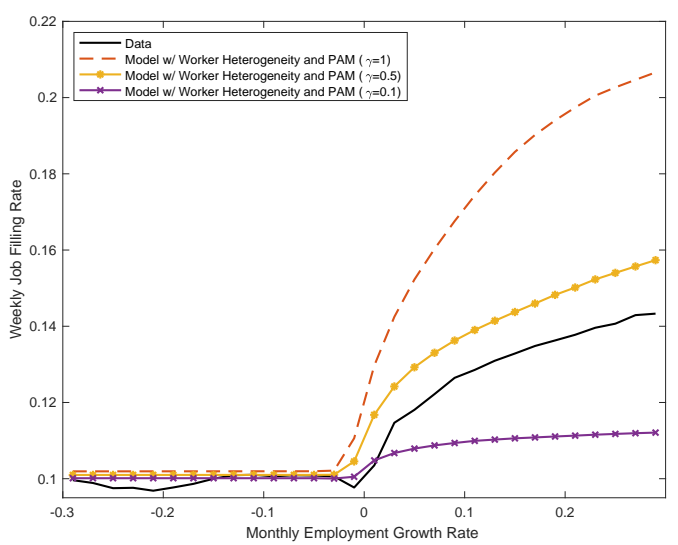

Notes: The figure shows weekly vacancy-filling rates by employment growth in data and model. Panel A shows the results for the model in Kaas and Kircher (2015), but calibrated to match the patterns of vacancy filling and job finding in the Austrian data. Panel B shows the results for the model extension with worker heterogeneity and no positive assortative matching. Panel $\mathrm{C}$ shows the results for the model extension with worker heterogeneity and positive assortative matching. 
Table D4: Additional Simulation Results of Model of Kaas and Kircher with $\gamma=0.5$

\begin{tabular}{lcccccccc}
\hline & Data & Baseline & $\mathrm{KK}$ & $\mathrm{RR}=0.98$ & $\bar{y}=0.5$ & $\pi_{y}=0.5$ & $s 0=0.01$ & $\epsilon=0.5$ \\
\hline Key Model Elasticities: & & & & & & & & \\
Vac. dur. to starting wage & 0.23 & -17.9 & -43.8 & -239.5 & -12.6 & -19.3 & -14.6 & -11.3 \\
Vacancy filling to hires rate & 0.18 & 0.15 & 0.33 & 0.14 & 0.13 & 0.16 & 0.15 & 0.15 \\
& & & & & & & & \\
Calibration Targets: & & & & & & & & \\
Replacement Rate (RR) & & 0.72 & 0.70 & 0.98 & 0.70 & 0.72 & 0.70 & 0.72 \\
Vacancy-Filling Rate & 0.10 & 0.10 & 0.30 & 0.10 & 0.10 & 0.10 & 0.10 & 0.10 \\
Job-Finding Rate & 0.03 & 0.03 & 0.11 & 0.03 & 0.03 & 0.03 & 0.03 & 0.03 \\
\hline
\end{tabular}

Notes: All simulations use a value of $\gamma=0.5$. KK refers to the parameters in the baseline calibration of Kaas and Kircher (2015), which targets the weekly vacancy-filling and job-finding rate for U.S. data.

(see Table D3) and the relationship of the vacancy-filling rate to the growth rate of the firm (see Figure D1). The similarity of the results in the model without and with complementarities between high-skilled workers and high- $x$ firms, suggests that our regressions results are not affected by the issues related to AKM that impede the identification of assortative matching.

Overall, we conclude from this exercise, that - while qualitatively consistent with models of wage posting - the measured elasticity of vacancy duration to wage posting is too small to explain meaningful variation in hires rates across firms. Firms' wage policies are unlikely to serve as an important recruiting instrument, as in Kaas and Kircher (2015), at least not in a manner that is quantitatively important and that could account for the patterns in vacancy filling by establishment growth. 


\section{D.2 Non-Wage Amenities and Attenuation Bias}

In this section, we assess to what extent the OLS regression coefficients are attenuated in the presence of non-wage amenities based on the estimated in Hall and Mueller (2018). Hall and Mueller (2018) posit that the (log of the) flow value of a job $(v)$ is composed of a wage value $(y)$ and a non-wage value $(n)$, where the two are imperfectly correlated, with

$$
n=\eta-\kappa(y-\bar{y}),
$$

where $\bar{y}$ is the mean of the distribution of $y, \eta$ is the part of the non-wage value that is uncorrelated with the wage value $y$ and $\kappa$ captures the (negative) correlation between wage and non-wage values.

If we want to run a regression of the log of vacancy duration on the log of the flow value of the job $(v)$, but instead use the wage flow value $(y)$ as a proxy for $v$, this may bias the estimated coefficient. To see this more clearly, assume a population relationship of the following linear form

$$
\log (d)=\alpha+\beta v+\varepsilon,
$$

which we estimate by using the log wage value $(y)$ instead of the log of the total value $(v)$. One can therefore write

$$
\begin{aligned}
y & =v-n \\
& =v-\eta+\kappa(y-\bar{y}),
\end{aligned}
$$

where $-n=-\eta+\kappa(y-\bar{y})$ is akin to non-classical measurement error.

Without loss of generality, we assume in what follows that all variables have mean zero (or represent demeaned values). Using $v=y+n=(1-\kappa) y+\eta$, we can write the estimated OLS coefficient as

$$
\begin{aligned}
\beta^{O L S} & =\frac{\operatorname{Cov}(\log (d), y)}{\operatorname{Var}(y)} \\
& =\frac{\operatorname{Cov}(\alpha+\beta v+\varepsilon, y)}{\operatorname{Var}(y)} \\
& =\beta \frac{\operatorname{Cov}(v, y)}{\operatorname{Var}(y)} \\
& =\beta \frac{\operatorname{Cov}((1-\kappa) y, y)}{\operatorname{Var}(y)} \\
& =\beta(1-\kappa),
\end{aligned}
$$

which implies that the relationship is attenuated by a factor $1-\kappa$. Hall and Mueller (2018) estimate a value of $\kappa=0.25$, which implies that our empirical elasticities should be scaled up by a factor 
$\frac{1}{1-\kappa}=1.33$ to get to the elasticity w.r.t. job values $(v)$ instead of wages. Note also that Hall and Mueller (2018) cannot empirically distinguish non-wage amenities from the value attributed to rising future wage payments. In other words, in their approach, future wage payments are just another amenity that is not reflected in the current wage and thus, the estimate here of the bias in the OLS coefficient should account for both bias arising due to non-wage amenities and bias arising due to wage-tenure contracts. 